\title{
Negotiating the transition: Parents' experience of their oldest child's transition to school
}

\author{
By
}

Maureen Catherine Stockman Woodhams

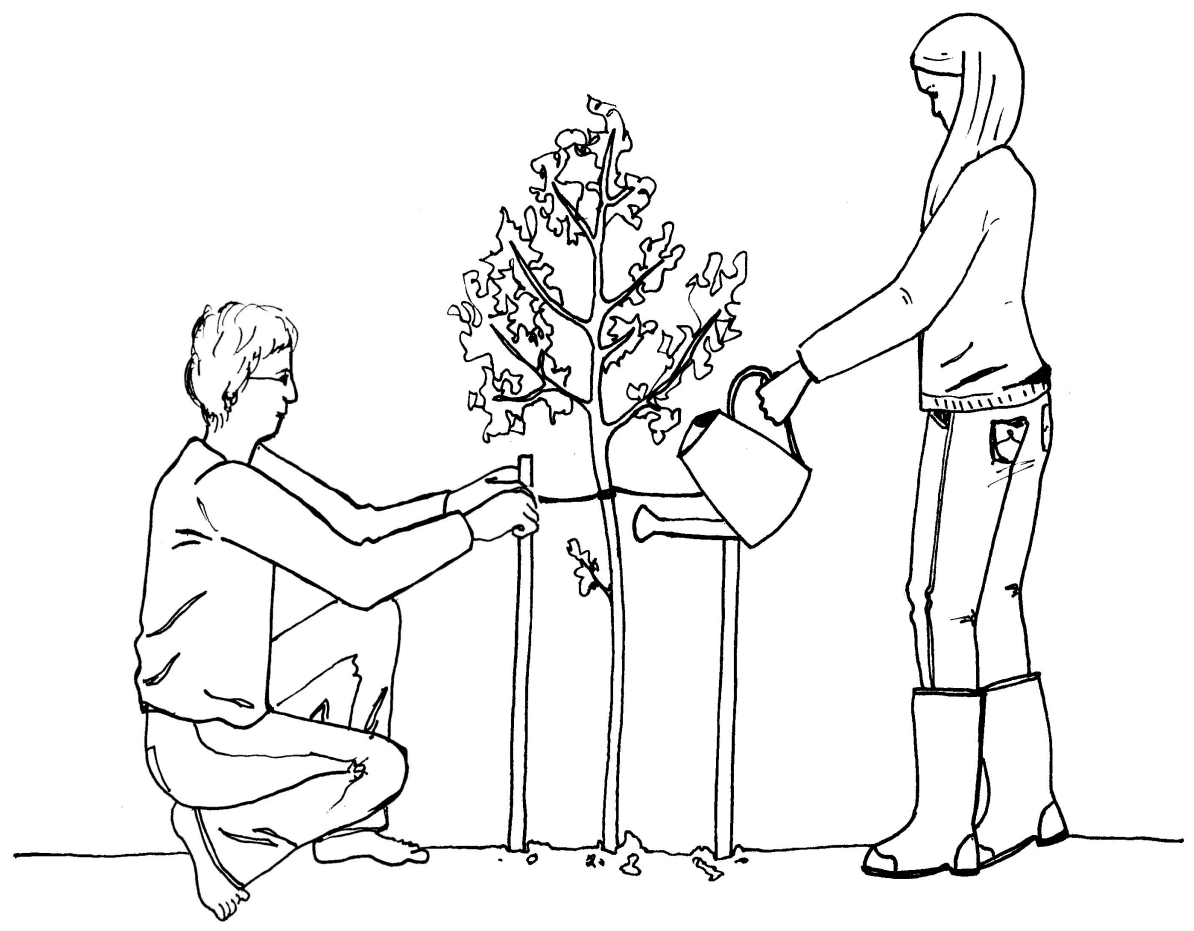

A thesis

submitted to Victoria University of Wellington in part fulfilment of the requirements for the degree of Master of Education 


\begin{abstract}
This study follows the lived experience of parents within six families during their oldest child's transition from early childhood centre to school. The aim was to understand the transition to school from a parent perspective in order that early childhood and school staff can better support families through their child's transition. A successful transition to school is frequently associated with later success in schooling. Research into children's transition has often focused on the child as an individual, with adults acting as informants about children's experiences. Parents have the unique position as the adults who are part of each of the three microsystems of home, early childhood centre and school, and therefore have an essential role in communicating between the microsystems and supporting their child's transition. This qualitative constructionist study interviewed parents one month before and one month after their oldest child started school, followed by a parent focus group. Each of the families in the study had existing theories of development and transitions which they combined with the information they obtained about school to plan and enact strategies to support their child's transition to school. The parents viewed school as a community to which they wanted their child and themselves to belong. They had some expectations of their role as a school parent; this identity was affected by the discourses of parents and teachers which they held and encountered, and by their interactions with people at school. The essence of these parents' experience was of negotiating the transition to school. There were two aspects to this: fitting in to an existing school culture; and attempting to adapt some aspects of the transition experience for their child by discussion with the teacher. Good communication, including feeling their point of view had been heard and also understanding the teacher's point of view, helped these parents to feel effective and valued in their role as school parents.
\end{abstract}




\section{Acknowledgements}

There are many people who I would like to thank for their assistance, encouragement and support throughout this research project.

Firstly, to the parents who participated in interviews and focus group. Thank you for sharing your transition journeys with me and reflecting patiently and openly on your experiences. I'd also like to thank the key informant staff members at the ECE centres and schools, for welcoming me into their teaching spaces.

Secondly, thanks to my research supervisors, Sarah Te One, who got me started on this project, and Kate Thornton, who got me to the finish line. You were continually encouraging and provided wisdom and insight when that was needed. Thanks also to Victoria University of Wellington, for a study scholarship which enabled the project to progress.

A special thank you goes to my daughter Katie, who brought to life with her cover illustration my metaphor for the way parents and teachers work in partnership to settle a child into school. The illustration shows two gardeners working together to transplant a young sapling into its new environment.

Finally, thanks to my family and friends. To Suzanne and Bernard, for reading drafts for meaning and finding the holes in my logic, and to Kate for her meticulous proof reading. Thanks also to my daughters, Katie, Rowena, Sophie and Elanor, for inspiring my interest in education and for their patience during the (sometimes stressful) writing process. And thanks to my husband Bernard, who is my number one supporter, and always believes in me. 


\section{List of Figures}

Figure 4.1 Summary of contacts with school prior to entry

Figure 6.1 Summary of relationships which impacted on transition to school

Figure 8.1 Summary of main themes in the research

Figure 8.2 Two gardeners working in partnership to nurture a young sapling

\section{List of Tables}

Table 6.1 Changes in subjective experience of time

Table 7.1 Summary of factors in choosing a school 


\section{Table of Contents}

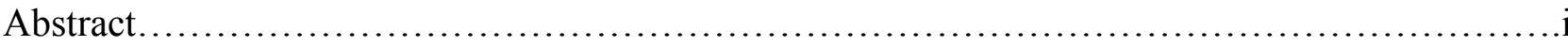

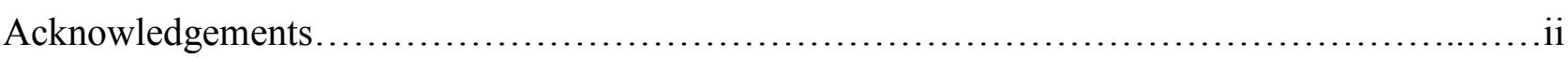

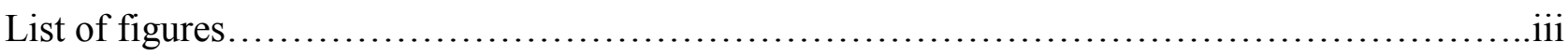

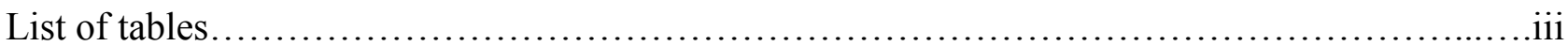

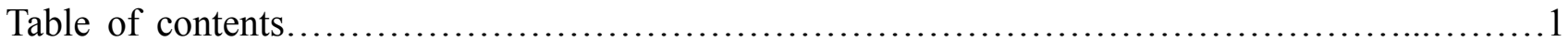

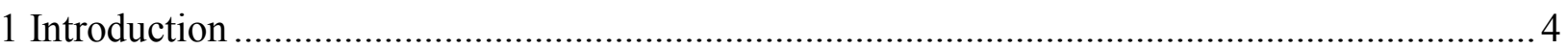

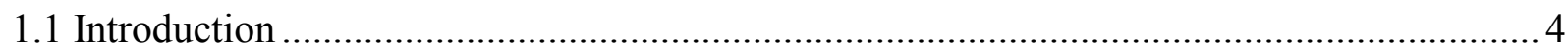

1.2 Early childhood education and schooling in New Zealand ......................................... 4

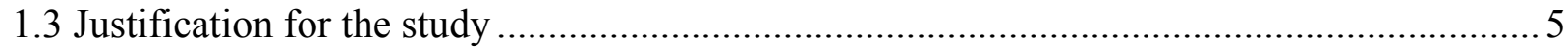

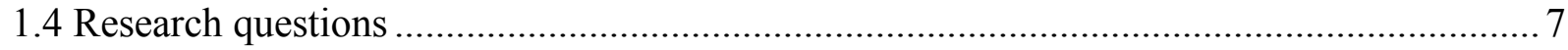

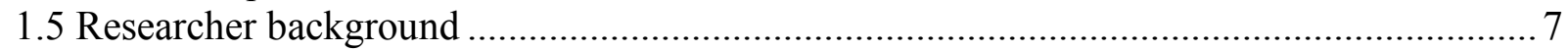

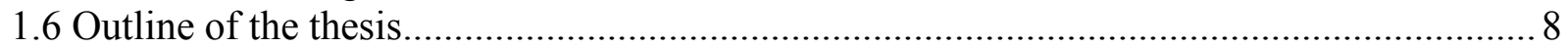

2 Review of literature

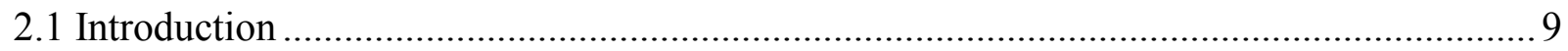

2.2 Theoretical understanding of transition to school .................................................... 9

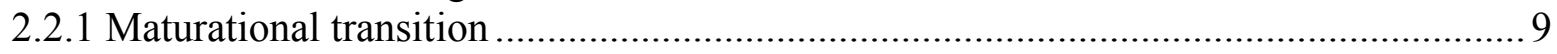

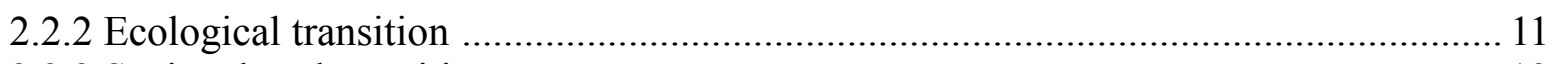

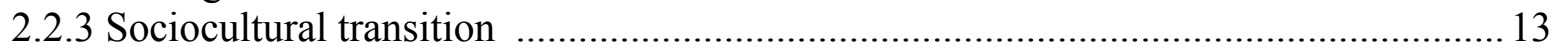

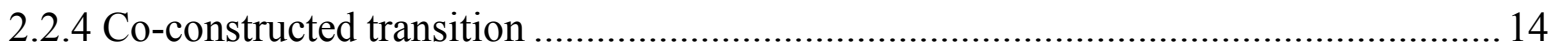

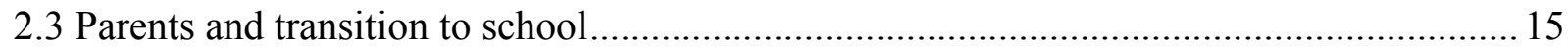

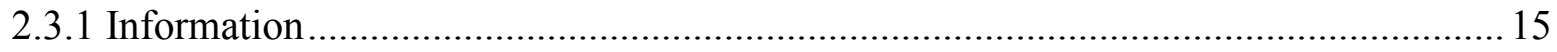

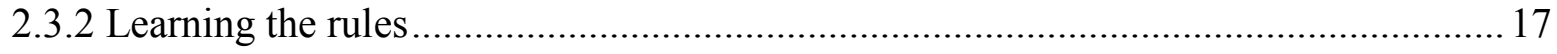

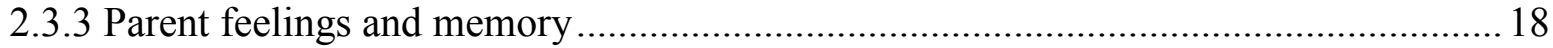

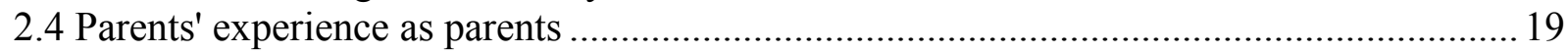

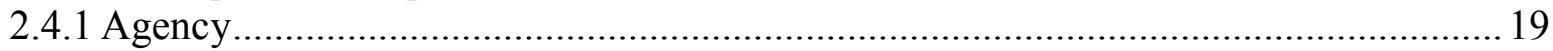

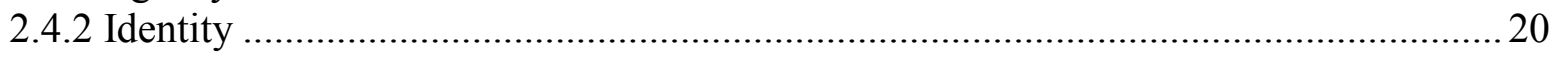

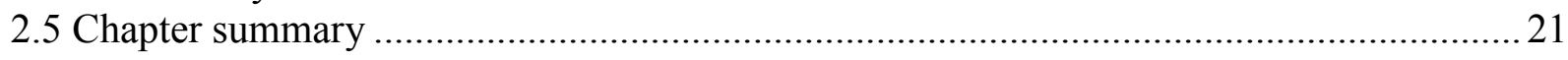

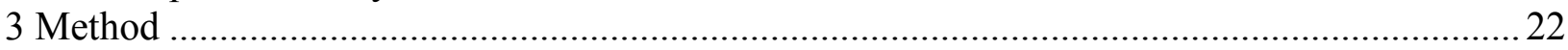

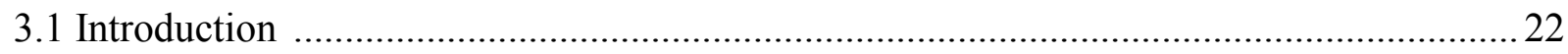

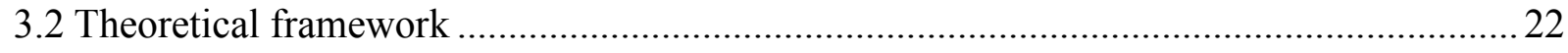

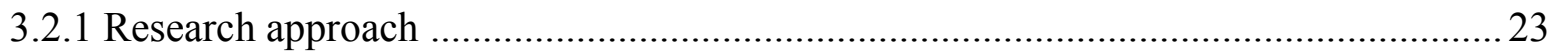

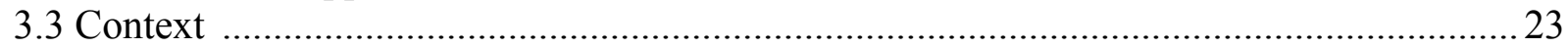

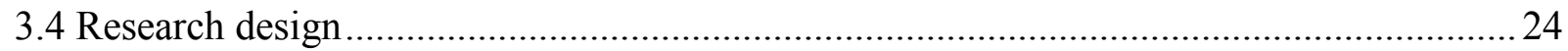

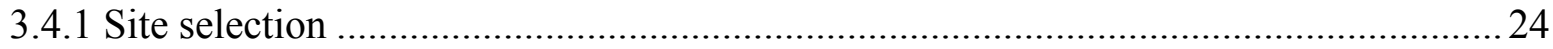

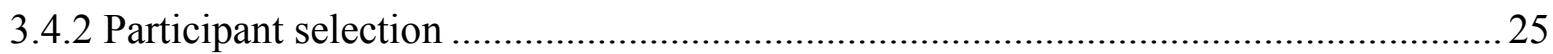

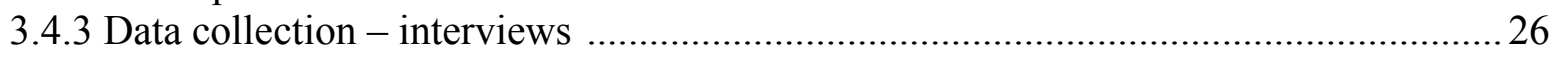

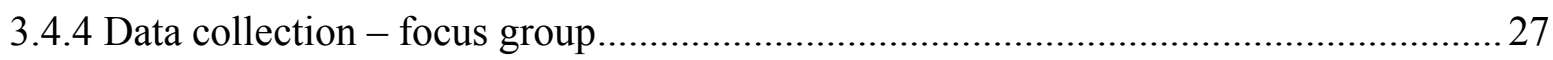

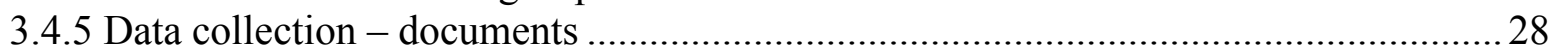

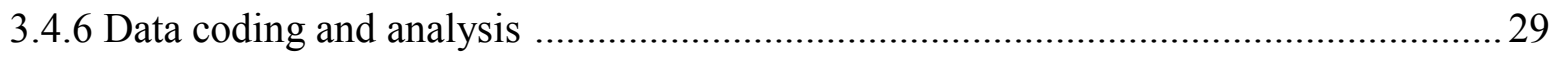

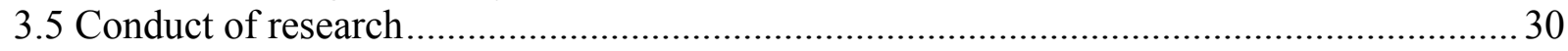

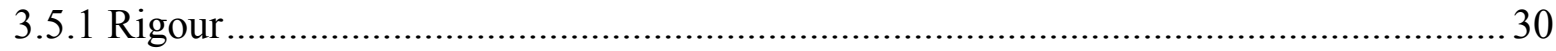

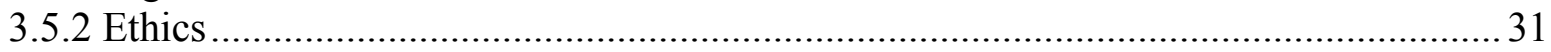

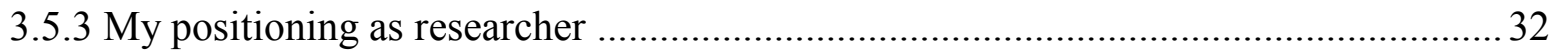

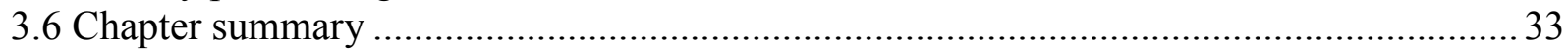

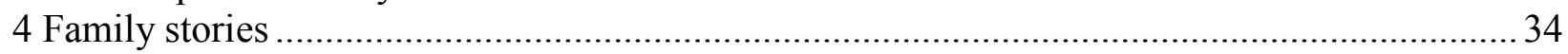

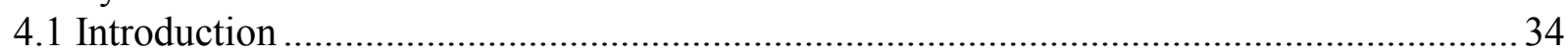

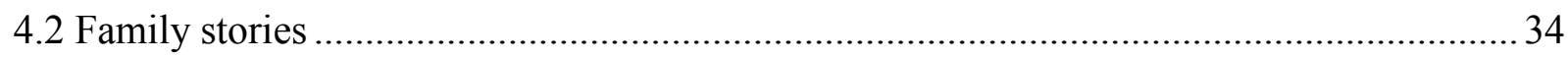

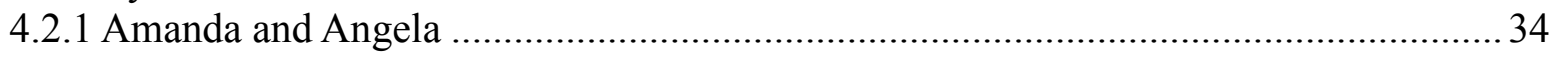




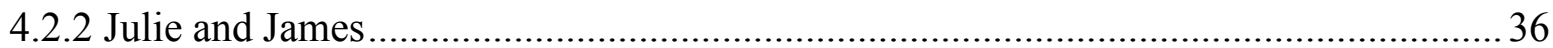

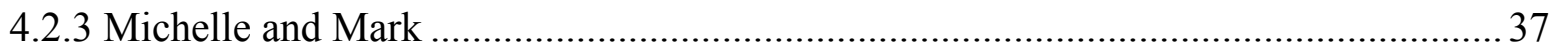

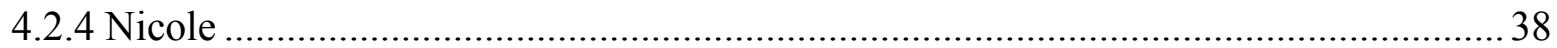

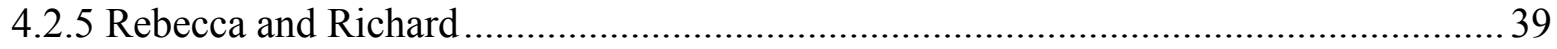

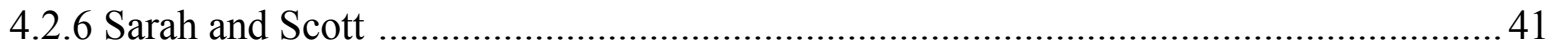

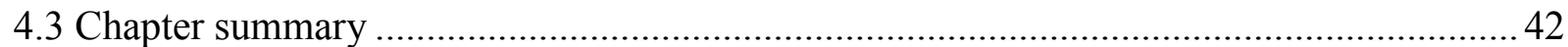

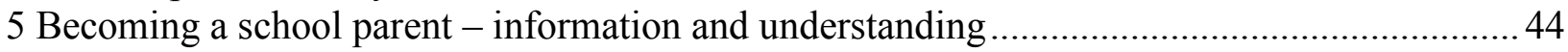

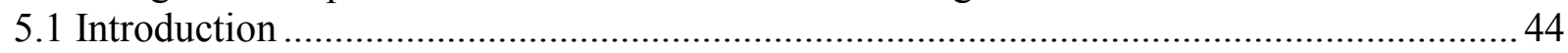

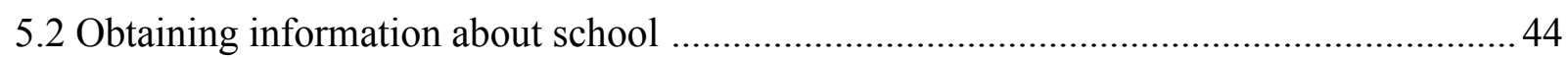

5.2.1 Information from prior to school settings ........................................................ 44

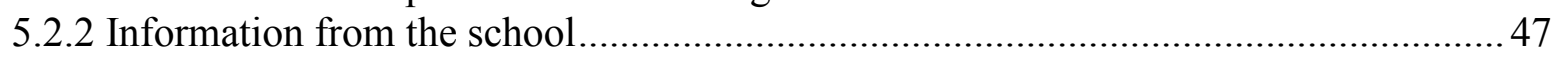

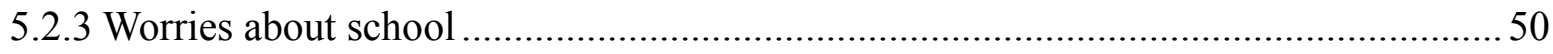

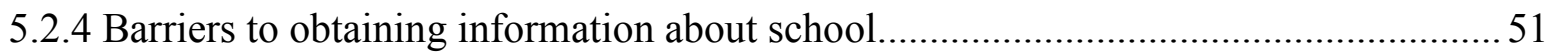

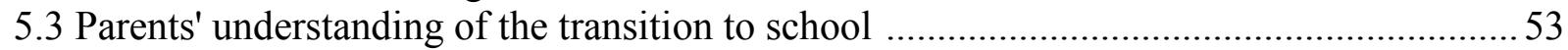

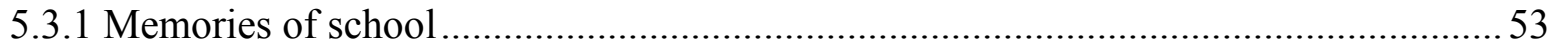

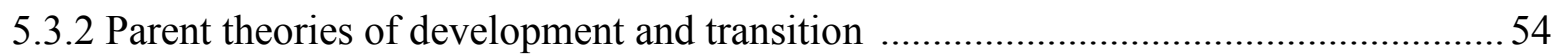

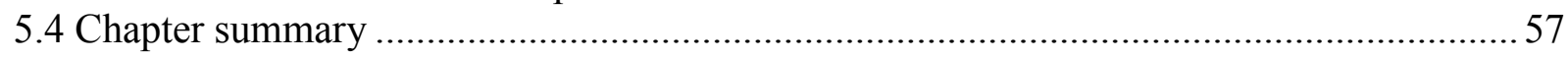

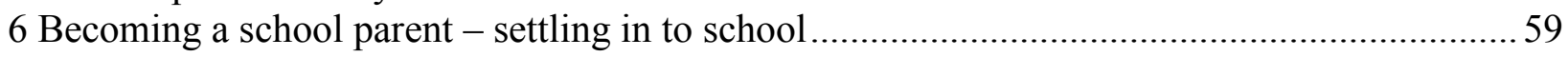

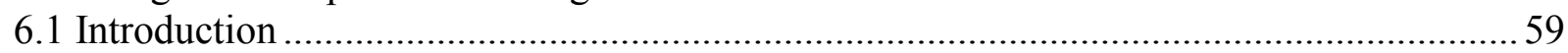

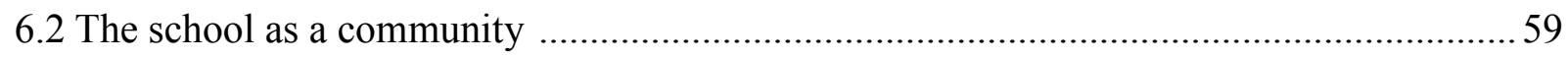

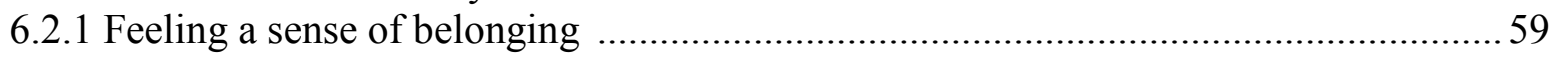

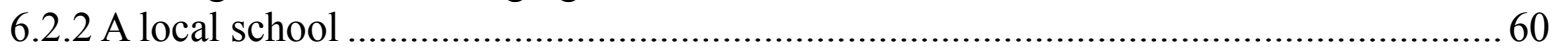

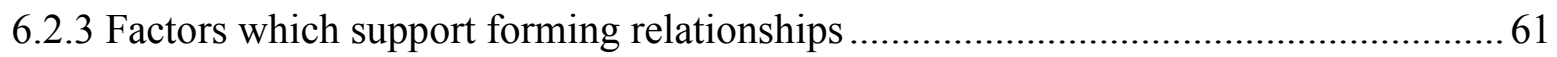

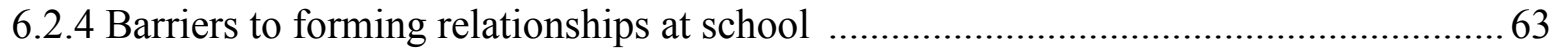

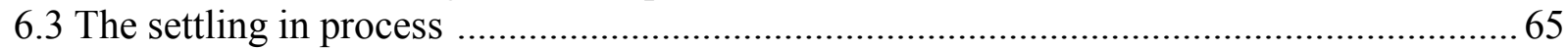

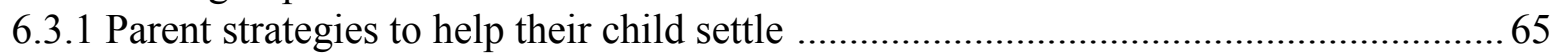

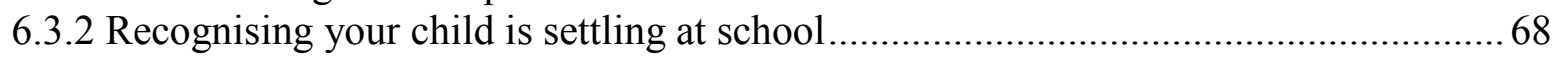

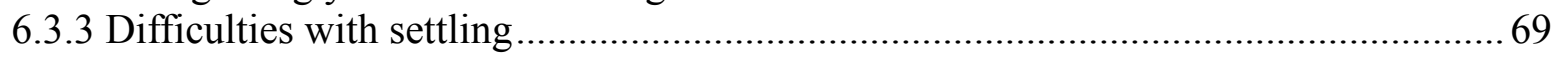

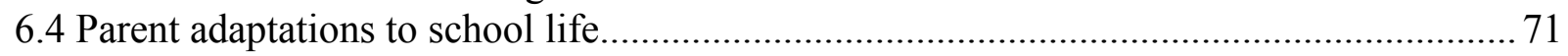

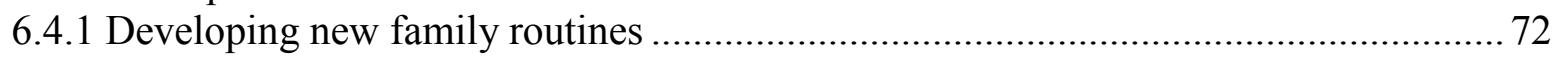

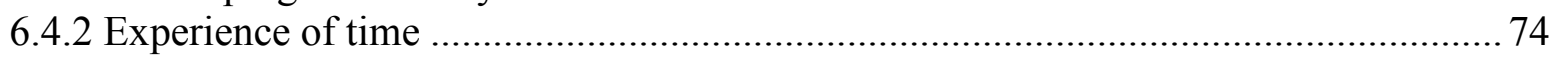

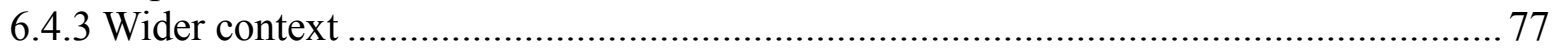

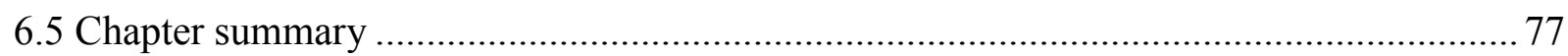

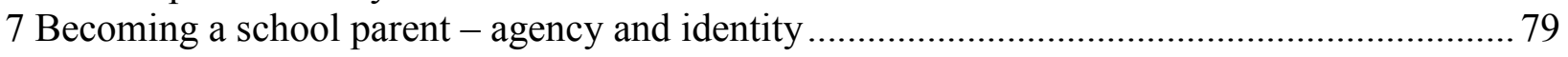

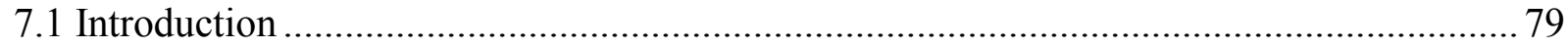

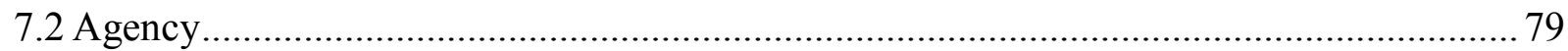

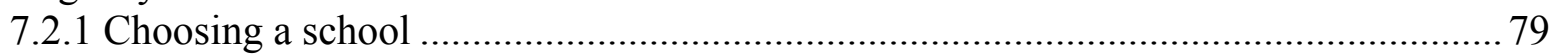

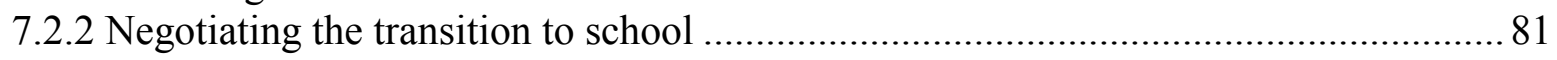

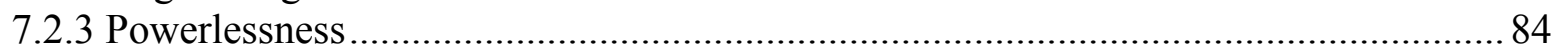

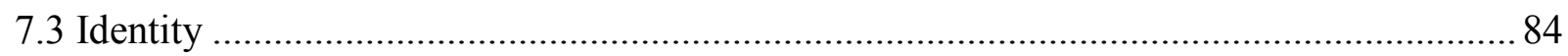

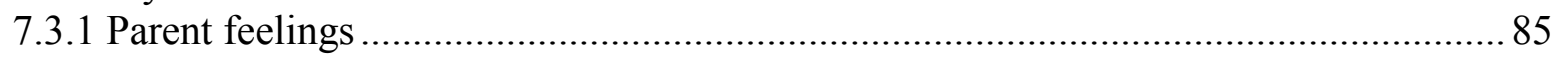

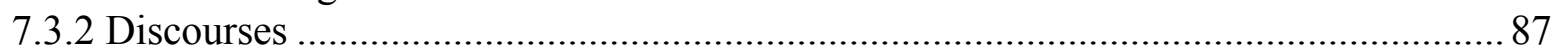

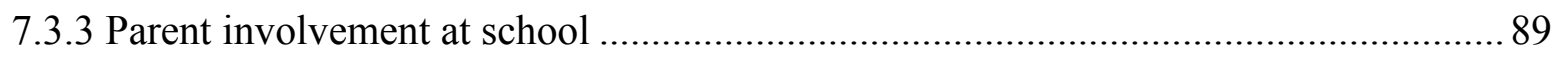

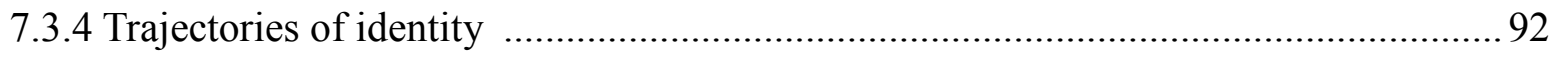

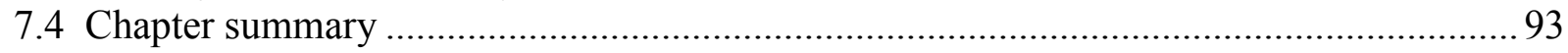

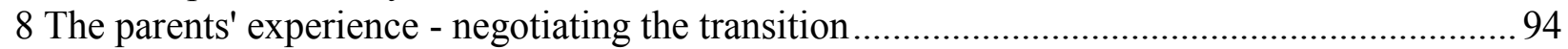

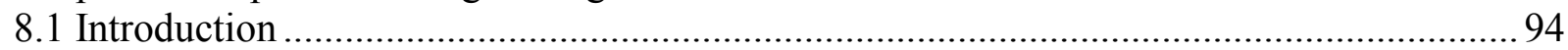

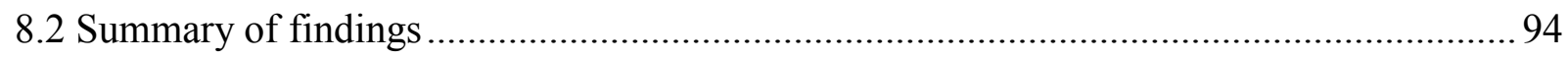

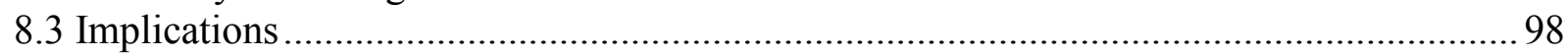

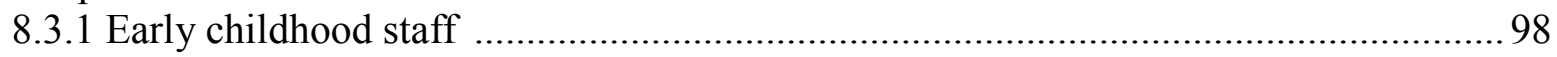

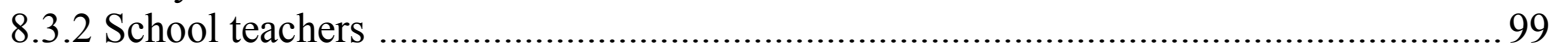

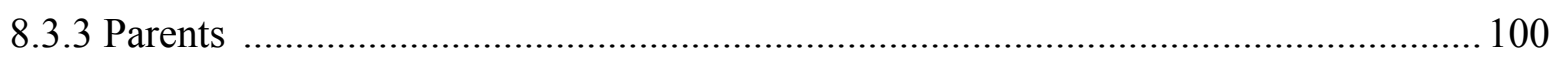


8.3.4 Liaison between ECE and school staff. 101

8.4 Limitations

101

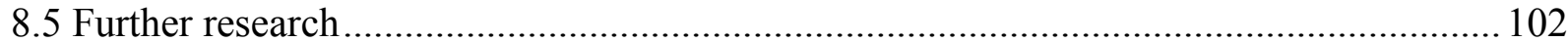

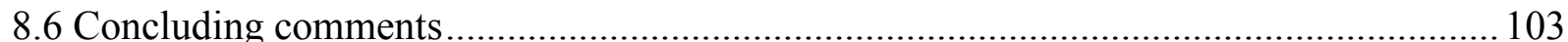

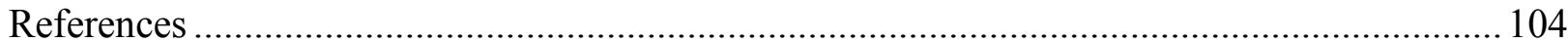

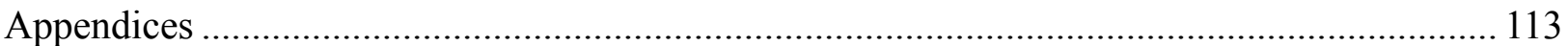




\section{Introduction}

\subsection{Introduction}

The transition from early childhood centre to school is a process which occurs in the life of almost every New Zealand child. It is much anticipated by children and their parents, and wider family members are also very interested in what is seen as an important milestone in the child's lives. It is also a common view in the literature that the transition to school creates a pattern for future success in schooling (Dockett \& Perry, 2007; Everiss, 2010; Fabian, 2007; Fthenakis, 1998; Giallo, Treyvaud, Matthews \& Kienhuis, 2010; Pianta \& Kraft-Sayre, 2003). In New Zealand children typically start school on or just after their fifth birthday; this 'continuous entry' throughout the year contributes to the focused attention which each child receives around that time. Both child and parents are likely to experience a range of emotions including "excitement, trepidation, happiness or sadness" (Dockett \& Perry, 1999, p. 1), and may have either a great deal, or very little, information about what a modern school is like.

The focus of this study is the lived experience of parents during the period when their oldest child is moving from an early childhood education (ECE) setting to start compulsory schooling. While their child is making the transition to school, parents are also making a transition (Dockett \& Perry, 2007) as they negotiate the roles and expectations of being a school parent for the first time. This chapter introduces the topic of the study including research questions, provides a rationale for the study, and outlines the structure of the thesis.

\subsection{Early childhood education and schooling in New Zealand}

This section introduces the ECE and compulsory schooling sectors in Aotearoa New Zealand. It also gives a brief overview of the ECE and school curricula.

Enrolment in formal ECE services is voluntary in New Zealand; some participation in high quality ECE programmes is widely seen as beneficial to child outcomes, parent support and workforce participation outcomes (Ministry of Education, 2002; Mitchell, Wylie \& Carr, 2008). The proportion of children attending formal ECE increases with age, with the large majority of four year olds participating in an ECE service prior to starting compulsory schooling (Ministry of Education, 2010). Parents can choose from a wide variety of services, including part and fullday, those operating from designated centres or based in the family or a carer's home, staffed by volunteer parents or paid teachers, and operated as non-profit community organisations or profit making businesses (Robertson, Gunn, Lanumata \& Pryor, 2007). Each different service type has 
a suite of structural and process factors, including group size, adult qualifications, parental involvement and adult:child ratios, which combine to influence high quality care and education (Mitchell et al., 2008).

New Zealand has a national ECE curriculum framework, Te Whāriki (Ministry of Education, 1996), which is used by all licensed early childhood services (Education (Early Childhood Education) Regulations 2008). This curriculum is a bi-cultural document, being based on both Māori and Pākehā worldviews, and was the first Ministry of Education document to be published in both English and Maori (Te One, 2003). Te Whāriki has the aspirational statement that children will grow up "as competent and confident learners and communicators, healthy in mind, body and spirit" (Ministry of Education, 1996, p. 9), and is based on four principles, and the five strands of well-being, belonging, contribution, communication, exploration, with broad goals and individual learning outcomes under each strand.

Children in New Zealand most commonly begin school on or soon after their fifth birthday, although enrolment is not compulsory until age six. There is a comprehensive network of state schools, which are fully funded by the government, plus a range of private and special character schools which receive a combination of government funding and parent contributions (Education Review Office, 2009). A typical school day runs from 9am to 3pm, and many schools provide an after-school childcare service outside these hours. All school teachers must hold an approved teaching qualification and be registered with the New Zealand Teachers Council. Schools follow the New Zealand Curriculum (Ministry of Education, 2007), and learning is based on the development of five key competencies: thinking; using language, symbols and texts; managing self; relating to others; and, participating and contributing.

The first decade of the twenty-first century saw a particular emphasis on promoting smooth transitions between ECE settings and compulsory school. This emphasis was visible in the goal within the strategic plan for ECE, Ngā Huarahi Arataki (Ministry of Education, 2002) to promote collaborative relationships between ECE services and schools, and the goal of improving the transition to school for children and their whānau within the Māori education strategy, Ka Hikitea (Ministry of Education, 2008). It was further evidenced in Ministry of Education research funding into the transition to school (Peters, 2010), and in the adoption and adaptation of the strands of Te Whāriki to the key competencies of the revised school curriculum (Ministry of Education, 2011).

\subsection{Justification for the study}

Research into children's transition from ECE settings to school has traditionally focused on the 
child, and more specifically the child as an individual, with adults acting as informants about children's experiences. More recently some researchers have involved children in studies of their own perspectives on starting school (Einarsdottir, Docket \& Perry, 2009; Gallagher, 2006; MacDonald, 2009; Mirkhil, 2010; Peters, 2004). When viewed through the lens of sociocultural and ecological theory, all the people in the settings of home, early childhood centre and school contribute to a successful transition (Niesel \& Griebel, 2007). Hence, an individual child focus does not give an adequate view of the transition. A parent typically has the unique position of being the adult who is part of each of these three microsystems. Literature recognises the importance of parents in supporting their child's transition to school in a number of different ways, for example through obtaining and supplying information and by helping their child understand what happens at school (Dockett \& Perry, 2007; Giallo et al., 2010; Pianta \& KraftSayre, 2003; Renwick, 1997).

Dockett and Perry (2007) note that the experience of parents during their children's transition to school has been under researched to date. Where the parents' experience has been considered it has largely been in terms of the feelings they may have about their child starting school, and practical suggestions of ways parents can scaffold their child's transition. This study seeks to take a wider view of what it is like to be a parent whose child is starting school, and how parents make meaning of their experiences.

An important task for parents is learning about the new education setting, and providing information to school staff about their child. Parents may already know some people at the school, and they begin to build relationships with others, including the teacher, staff members, other children, and in some cases their parents. Parents also have hopes and expectations for their child's education and development. Through these developing relationships and understandings about school, parents develop an identity as a member, along with their child, of the wider school community. This identity can be thought of as a trajectory (Wenger, 1998), as it continues to develop as a function of time and as a result of the experiences parents and children have.

The parent's ability to access information, communicate with the school, make decisions about education, and support their child, all appear to be contingent on the relationships they have with other adults, and with their understanding of and access to school culture (Brooker, 2002; Dockett \& Perry, 2007; Peters, 2010; Sauvao, Mapa \& Podmore, 2000). Equally, the ability of the school teacher to adapt the classroom environment to the child depends on their relationships with parents (Dickie, 2005; Gallagher, 2006). Thus, the development of mesosystems or interrelations (Bronfenbrenner, 1979) between home, the ECE service, and school are crucial to the flow of information and the support which parents and teachers can give children starting school. 
Through understanding the parent's experiences the study aimed to make visible factors which affect parents in order to investigate potential improvements to transition practices of early childhood centres and schools.

\subsection{Research questions}

This study seeks to explore how the transition to school is experienced by parents, in particular parents who have had little to do with schools since having a child. It fills a gap in understanding the experiences of parents and how they interact with their children and teachers over an important time in the educational pathway.

The main research question is: What is it like for parents during the transition to school of their oldest child?

The parent's experience of the transition to school is examined through three inter-related subquestions:

- How do parents learn about school and the transition to school?

- What affects the development of relationships between parents and other people at their child's school?

- What affects how parents develop their identity as a 'school parent'?

\subsection{Researcher background}

My interest in the parent's experience of their child's transition to school began from remembering my own experience as a mother of four children who have started school. In the months leading up to my oldest child turning five I remember initially knowing little about schools and searching out information, both from the schools themselves and from parents with older children. I also remember how interested my peers with slightly younger children were in hearing about any contacts I had with schools, including visits and the events of my daughter's first weeks.

My experience within ECE has included work as a volunteer parent-educator within playcentre and as a teacher in several other ECE services. I completed the Supervisor certificate of the Playcentre Education Diploma, and acted as session team leader within my centre, and volunteered in various management roles. I later completed a Graduate Diploma of Teaching (ECE) and worked within the childcare sector. My interactions with parents with children approaching school age continued my interest in the transition to school, and how teachers in particular could support parents with this. 


\subsection{Outline of the thesis}

This chapter has outlined the social context in which the transition from ECE centre to compulsory school is set in Aotearoa New Zealand, and provided a justification for undertaking this study. It has also introduced the research questions and myself as researcher.

Chapter Two presents a survey of the literature on the theoretical understandings of the transition to school and parents' experience both of their child's transition and of parenting. Chapter Three describes the methodology behind this study and the data collection and analysis methods used. Chapter Four then presents the transition experience story of each of the six families in the study.

Chapters Five, Six and Seven amalgamate the findings from the six families under the three research sub-questions, related to learning about school, forming relationships, and the parent's developing identity as a school parent. The final chapter discusses some implications of the findings for practice in supporting children in their transition from ECE to school. It also looks at limitations of this study, and makes some suggestions for possible future research. 


\section{Review of literature}

\subsection{Introduction}

Starting school is an experience shared by most New Zealand children, therefore having a child start school is also experienced by most New Zealand parents. In reviewing the literature on children's transition to school it was noted that the voices of researchers and teachers were prominent, and the experience of parents appeared to be less evident. The voice of children involved in the transition was also not prominent, but children's own experience has been the subject of a number of studies in the last decade.

This chapter begins with a review of the literature around children's transition to school and the theoretical ways these have been understood. Theoretical views of transition are based on theories of the nature of childhood and of society, and there is noticeable overlap between different understandings. The following section looks at how parents' involvement in their child's transition to school has been reported, and themes relating to this. Finally, the chapter explores some themes around how people become involved in social groups.

\subsection{Theoretical understanding of transition to school}

A number of different theoretical positions are apparent in literature which discusses children's transition to school. These have arisen from differing views of the nature of children and childhood (Jenks, 2004), their role in the wider world (Freeman \& Mathison, 2009), and the nature of education. The following sections review transition to school literature and discuss how writers suggest this affects adults' support of children's transition to school.

\subsubsection{Maturational transition}

Theories of maturational 'readiness' assume that children develop in a predictable way as a result of "a natural unfolding of innate biological programming" (Fosnot \& Perry, 2004, p. 9), and that characteristics of the child are sufficient to indicate their likelihood to make a successful transition to school. Rimm-Kaufman and Pianta (2000) describe this as the 'child effects model', where the importance of characteristics such as socio-economic status, cognitive readiness, gender, ethnicity and temperament are highlighted. Hair, Halle, Terry-Humen, Lavelle and Calkins (2006) group child characteristics into five dimensions: physical characteristics; social/emotional development; having appropriate approaches to learning; language skills; and cognitive skills. The concept of measurable 'readiness' has led to a variety of formal or informal 
'readiness tests' or checklists to determine a child's progress against a 'normal' expectation for their age, and sometimes to decide progress through the education system (Graue, 1992; Peters, 2003).

Different groups do not always agree on the relative importance of different child characteristics in predicting a successful transition to school. Parents, early childhood teachers, and school teachers may differ in their expectation for children's social/emotional and academic skills prior to school entry (Griebel \& Niesel, 2002; Neuman, 2002; Scott-Little, Kagan \& Frelow, 2006). In particular, teachers of low-income groups, and parents of racial minority groups are more likely to emphasise the importance of academic preparation than teachers and parents of higher income or white children (Snow, 2007). It is also not always clear what children are to be 'ready' for and different communities can have quite different constructs of 'readiness' (Graue, 1992; Hair et al., 2006). Enz, Rhodes and LaCount (2008) specify that the construct is about children's "readiness to be successful" in school (p. 61). But Doucet and Tudge (2007) contend that 'school readiness' really means the child is 'ready for school culture', possibly at the expense of family or community culture, although this is seldom acknowledged.

One of the notable features of the 'child readiness' view is that the school and classroom culture to which the child transitions is assumed to be relatively fixed. It is the child who is expected to adapt to this culture (Margetts, 2007), possibly with little instruction in the required new ways of operating (Fabian, 2007). If they are slow to learn to adapt, it is likely to be the child who is viewed as a 'problem' child (Kienig, 2002). Dockett and Perry (2007b) question this assumption of the 'child readiness' view, challenging the reasonableness of expecting the person who has the least life experience to be the one who is expected to change the most during any transition. Niesel and Griebel (2007) further question the assumptions behind child-focused readiness assessments, They state that, as a child learns to operate within a new setting by the experience of being involved in that setting, there is no logical selection criteria to point to a child being 'ready' to start school.

Other writers extend the idea of school readiness to include a number of interrelated factors as well as child characteristics. Brostrom (2002) describes the goal of a successful transition as the child coming to feel a sense of well being and belonging in their school. The child's individual 'readiness' is one aspect which supports this; other aspects include a supportive family and community, a high quality ECE environment, and the school being 'ready' to guide the child. Blair et al. (2007) propose that school readiness be understood as a "multidimensional matrix" (p. 150), including a range of characteristics of the child (for example, behavioural skills, language ability, social skills, general cognition), and of the school system (for example, teacher 
practice, administration policy, quality ECE experiences). Hair et al. (2006) add community services and family supports as a third strand of school readiness alongside child and school system characteristics. They also explain that the quality of the first year of formal schooling makes a huge difference to the child's academic achievement even after controlling for their readiness profile on school entry.

\section{'Ready' schools}

One of the factors identified as critical in a smooth transition to school is the school's approach to helping children make the transition; the concept of a 'ready school' (Brostrom, 2002; Dockett \& Perry, 2009; Hair et al., 2006; Lam \& Pollard, 2006; Niesel \& Griebel, 2007). In their research into parent, teacher and child concerns about starting school, Dockett and Perry (1999) found that while teachers wanted the child to fit in well at school, the parents also wanted to know whether the school would adapt for their child. LoCassale-Crouch, Mashburn, Downer and Pianta (2008) suggest that a 'ready school' should assist with transition by "reaching out proactively to families and other teachers, and doing so with a high level of intensity, prior to the actual physical move into a new classroom" (p. 126). In their research they noted that most teachers focused on low-intensity approaches, such as brochures and open evenings, which occurred after the child had started school. Brostrom (2007) develops the idea of ready schools by suggesting that a 'school ready preschool' and a 'child ready school' work together to assist with the child's transition to school. This approach appears to put the responsibility for transition on the institutions rather than devolving them to the child or family.

\subsubsection{Ecological transition}

Ecological theory foregrounds the interconnected environments and processes in which humans develop (Bronfenbrenner, 1979). Each local setting where a person interacts with others, such as home, an ECE setting or the school classroom, is termed a microsystem, and contains a characteristic pattern of activities, roles and interpersonal relationships. Ecological theory sees transition as occurring when a person undergoes a change in role and/or setting within the ecological environment.

In the transition to school, the education setting changes from home and/or ECE centre to include school classroom and playground, and a child takes on the role of a 'school pupil' (Bronfenbrenner, 1979). The child adapts to their class by 'learning the rules' which apply in that new microsystem (Dockett \& Perry, 2007; Ledger, 2000; Peters, 2004). Priming events are regular and routine activities which help children adapt in this way, especially when all children have repeat opportunities to observe, participate, and take responsibility for them (Corsaro \& 
Molinari, 2000). Learning the rules in relation to transition is described by Fabian (2007) as leaving one's comfort zone and "encountering the unknown: a new culture, place, people, roles, rules and identity" (p. 7). This involves children acquiring specific language and social skills, and might also involve unlearning ways of behaving which were appropriate to other places (Rosewarne, White \& Wright, 2010).

Within the transition to school the mesosystem includes the connections and communication between home, ECE service and school, and is affected by the attitudes that people in each setting have for the practices and values of the other settings. The wider cultural, economic and political macrosystem influences each microsystem and the relations and communication between them. For example, government education policy may affect when a child may start school (Dockett \& Perry, 2007) or which school a child may attend (Education Act, 1989; Renwick, 1997). Fabian and Dunlop (2005) relate priming events to the situated learning which occurs within communities of practice (Wenger, 1998) due to their emphasis on participation and increasing responsibility. If priming events encouraged in the ECE setting are to have long-term benefit for the child's school experience, staff in pre- and compulsory school sectors need to share an understanding of the skills and attitudes which will be useful for children to develop (Dickie, 2005; Firlik, 2003; Salter \& Redman, 2006; Timperley, McNaughton, Howie \& Robinson, 2003). Hence, communication between those microsystems will contribute to effective priming events. Further examples of priming events might occur in the home or community, for example, interactions with older siblings, parents or neighbours.

\section{Continuity and discontinuities}

Continuity between settings is an important construct of the ecological view of transition because of the belief that similar practices, people, curriculum or learning styles will help children settle in to school sooner. In discussing continuity, Dockett and Perry (2007b) take a broad view of curriculum, including all the activities and events of the school day, such as arrival at and departure from school, playtime, and formal classroom learning time. The child having a friend from outside school settings in the class is often regarded as an important aspect of continuity (Norris, 2000; Peters, 2004). However, in practice it is the discontinuities between settings which have created attention in the transition to school.

Literature identifies many areas in which the school environment differs from the environment in prior settings. These include teacher warmth and interactions, a greater focus on an academic curriculum, increased social independence required, group size and composition, decreased parent choices, the way communication between parents and teachers occurred, increased teacher 
direction of students, and the amount of one-on-one time a child has with an adult (RimmKaufman \& Pianta, 2000; White \& Sharp, 2007). Ledger (2000) noted a marked difference in the activity choices which children have in the three settings of home, centre and school, including the type of activities, the range of choices and the time available to complete an activity.

While lack of continuity is often regarded as leading to difficulties in transition, Niesel and Griebel (2007) note that experiencing discontinuity provides a context which can promote development, as long as the child has competencies to cope with the discontinuity. A better focus might be to help children develop these competencies. Timperley et al. (2003) noted that, despite a high level of commitment from teachers in ECE and school settings to collaborate over children's transition, there was a low level of agreement about which early childhood practices best helped prepare children for the school environment. Without agreement on the value of each part of the education sector it was difficult to create priming events which helped children develop agreed competencies.

\subsubsection{Sociocultural transition}

The transition to school has also been understood through a sociocultural lens, which emphasises children learning through social interaction with more experienced others (Vygotsky, 1978). Learners do this by working collaboratively at tasks which are valued by their culture and which they cannot yet perform alone. From this socio historical perspective, "the basic unit of analysis is no longer the (properties of the) individual, but the (processes of the) sociocultural activity, involving active participation of people in socially constituted practices" (Rogoff, 1990, p. 14). When studying the transition to school, therefore, a sociocultural perspective includes a wider group of people and the reciprocal processes among them, and avoids an individualistic view of the child (Cosaro \& Molinari, 2000; Griebel \& Niesel, 2002; Mirkhil, 2010b; Rimm-Kaufman \& Pianta, 2000).

A sociocultural perspective suggests that involvement in novel situations promotes development as long as the appropriate support, or 'scaffolding', is available in the form of adults or more experienced peers (Bulkeley \& Fabian, 2006; Dockett \& Perry, 2007; Rogoff, 2003; Smith, 2002). Scaffolding refers to the way that more experienced people provide a framework to support the learner's involvement in novel situations or problems, and then slowly removes that support as the learner grows in ability (Bruner, 1978).

Doucet and Tudge (2007) argue that the transition to school is a cultural process, with the experience, expectations and goals around the transition being different for different cultural groups. They define culture as any group with a shared set of values, beliefs and practices, which 
transmits these to the next generation. The transition to school has often been framed as where children learn to 'fit in' to the culture of school (Fabian, 2007; Fabian \& Dunlop, 2005), but Dockett and Perry (2007) note that, because schools reproduce existing social values, they are more likely to serve families with similar cultural background to the school. This perspective was reflected in, for example, difficulties for parents in accessing information about school (Brooker, 2002), or in misunderstandings about school routines (Timperley et al., 2003).

\subsubsection{Co-constructed transition}

In recent years several authors have begun to use the concept of co-construction to understand the processes of sociocultural transition. Co-construction describes a process where different parties work together to build an understanding or develop systems which support children and families' transitions, creating new knowledge which is greater than the contribution of any one party (Jordan, 2004). Griebel and Niesel (2002) explain that parents and children co-construct the transition to school through verbal and non-verbal communication of their expectations, hopes and fears. The parents' well-being during the transition period depended on how well they thought their child was doing, and they contributed to the transition by their efforts to support their child.

Other writers include ECE staff and school teachers, along with the child and parents, in the group who co-constructs the transition, although noting that the teachers do not experience a transition themselves (Fabian, 2007; Giallo et al., 2010; Hartley, Rogers, Smith, Peters \& Carr, 2010; Johansson, 2007; Niesel \& Griebel, 2007). Regular visits by centre staff and school teachers to each others' services help them understand each others' curriculum and assessment practices, and how each can support a smoother transition for children (Feltham, 2004; Firlik, 2003). In a Centre of Innovation study ${ }^{1}$, Mangere Bridge Kindergarten took this relationship building a step further by collaborating with the schools in their local area and with centre parents to develop transition resources, such as books, pamphlets and displays (Hartley et al., 2010). These projects took time and commitment from all parties, and created a shared respect for the work done within other services. They concluded that open communication is crucial to developing wider communities of learning which enable all participants to co-construct the transition to school.

Ecological and sociocultural theory both contribute to the understanding of the experience of transitions and some writers have found it useful to use both lenses (Dockett \& Perry, 2007).

1 The Centre of Innovation programme was Ministry of Education-funded research which aimed to improve the quality of ECE by promoting a deeper understanding of teaching and learning processes within selected ECE services. 
Ecological theory focuses on the different settings, the interrelationships between them, and the effects of wider contexts - the macrosystem - on more local settings. Sociocultural theory emphasises the processes of relationships of people within and between those settings.

Parents are the adults who share, at least to some extent, each of the microsystems of home, centre and school with their child, and who have the primary nurturing and socialising role in their child's development. The following section explores the literature on children's transition to school through the perspective of their parents.

\subsection{Parents and transition to school}

The transition to school also involves a transition for parents as they learn the roles and expectations which apply in this new setting, form relationships with people at school, and develop a new identity as a school parent (Brooker, 2002; Niesel \& Griebel, 2005; 2007). Parents have a unique position as the adults most likely to be part of each of the three microsystems of home, centre and school. Parents have the opportunity to observe their child in these different settings and to act as a communication channel between other people in each setting. However, there is concern that to date there has been little written about parent factors in the transition to school, how parents manage the transition and the ways in which parent support helps their child's transition (Dockett \& Perry, 2007; Giallo, Kienhuis, Treyvaud \& Matthews, 2008). This section looks at literature around how parents receive information about school, learn to be a school parent, and their feelings about the transition to school.

\subsubsection{Information}

Parenting is widely understood as a normal process which is learned from one's own parents and other role models with young children (Shulruf, 2005). This learning occurs through remembering childhood experience, getting advice and practical support from family members once a new child arrives, and watching how other people interact with their own children, as well as through access to books and other written material (Davis, 1999). Examples thus gained can provide a model to follow - or to reject or modify (Biddulph \& Biddulph, 2000). Family members, along with friends and organisations such as churches, ECE services and neighbourhoods, form 'naturally occurring support networks' which enable parents to access a wide range of information and support (Munford \& Sanders, 1999).

The access parents have to good information appears to be crucial to their adjustment to school processes and culture, their ability to help settle their child into school (Education Review Office, 2009; Sanagavarapu, 2010), and in alleviating their worries about the transition (Giallo et 
al., 2010; Peters 1998). During the transition period scaffolding is provided by parents, teachers or older children to support the new school child in becoming familiar with the school environment, school practices and the expectations of being a pupil. Literature lists many things parents can do to assist children, for example, by taking the child to visit school before the first day, talking with the child about what they might do in school, engaging in literacy practices with the child, and encouraging siblings to look out for the new child in the playground (Peters, 2004; Pianta \& Kraft-Sayre, 2003; Renwick, 1997; Taylor, Clayton \& Rowley, 2004; Turoa, Wolfgramm, Tanielu \& McNaughton, 2002).

In order to scaffold their child's transition parents need information on what activities will help and information about the school. Some writers focus on the need for parents to provide a stimulating home as one way to assist with the transition for their child (Lara-Cinisomo, Fuligni, Ritchie, Howes \& Karoly, 2008; Taylor et al., 2004), and suggest home visiting or parent support programmes to aid this. Other writers have noted that it can be challenging for parents to access information, for example, if they struggled to find an appropriate time to talk to the teacher (Cosaro \& Molinari, 2000; Renwick, 1997) or if they had English as a second language (Brooker, 2002; Sanagavarapu, 2010; Sauvao et al, 2000).

In their study of the communication between families and ECE setting or school, RimmKaufman and Pianta (2005) found that the action of individual teachers was likely to be an important factor in the number of communication opportunities which occurred. This is because they noted no correlation between the number of communication events between a particular parent and their child's ECE teacher, and the number of communication events between that parent and their child's school teacher. Peters (1998) also noted that parents wanted to share information about their child with the school, although they might prefer to do this after the child had been in the classroom for several weeks. These parents reported frustration if this opportunity was not then made available. Gallagher (2006) also discusses the benefits of meaningful parent-teacher communication in planning for children's programmes, and that some parents experience difficulties with this.

In many cases it was easier for parents to both access information about the school and give information about their child once trustful relationships with teachers had been formed (Peters, 2004; Rimm-Kaufman \& Pianta, 2005). Parents involvement as a helper in the classroom has been noted as a strategy which can lead to increased opportunities for information sharing (Peters, 2004), although there can sometimes be a mis-match in expectations between teachers and parents about the level and type of involvement that parents should have (Brooker, 2002; Renwick, 1997). Rimm-Kaufman and Pianta (2005) list factors which can prevent parents from 
being involved as helpers in the classroom, including less flexible jobs and stress related to financial circumstances. They also reported that if parents viewed the school as supportive of them, parents were more likely to become involved with the school in some way, which could lead to more trustful relationships and better access to information. Home and school are "overlapping spheres of influence" (Epstein, 1995, p. 702) where the effectiveness of each in supporting the child's transition is enhanced by good communication and common messages about how to support the transition.

\subsubsection{Learning the rules}

Just as children learn the rules which apply in the school setting, parents also need to learn the expectations which the school has for their children and themselves. These include expectations around correct attendance and appropriate food (Brooker, 2002; Peters, 2004), and enforcement of homework tasks (Griebel \& Niesel, 2002). Parents can obtain information about the school's expectations from other parents (Hannigan, 1998; Pianta \& Kraft-Sayre, 2003), however, Dockett and Perry (2007b) also noted that in many cases it was the child who was expected to pass on the school's expectations to parents, in the form of notes or verbal messages.

Teachers sometimes take an active role in helping parents learn and adapt to school culture, and this is often appreciated by parents. Doucet and Tudge (2007) commented that the way teachers scaffold parents' understanding of what is required of their children, and, by extension, themselves, on starting school is analogous with the way that teachers scaffold children over the transition. Many writers have noted that planned transition activities affect parent behaviour in ways which improve the outcomes for children's transition (Clarke, 2007; Enz et al., 2008; Margetts, 2007; Schull \& Anderson, 2008). Gallagher (2006) particularly notes the importance of respect and good communication between parents and teachers to support this scaffolding.

In her study of mothers' experience of their toddlers starting childcare, Dalli (2002) found that mothers were aware they needed to learn the rules which applied at the centre, but would have preferred that staff gave them more guidance on this. The staff in this setting were ambiguous about their roles with respect to both parent and child while the parent was at the centre. What may be unacknowledged by writers is a possible discontinuity between home and school values and expectations, which mean that scaffolding of parents can be more an attempt to convert the parents to the cultural values of the school (Doucet \& Tudge, 2007).

\subsubsection{Parent feelings and memory}

Griebel and Niesel (2002) described several stages in the transition to school from a parent 
perspective, including changes in their relationship with their child and with the teachers, integrating the demands of school into the routines of home, and coming to terms with changes in their identity as a parent. One aspect of the literature discussing parents' experiences of the transition to school is consideration of the range of parent feelings. Writers suggest that parents might be both excited and apprehensive as their child's first day of school approaches, experiencing a complex mix of joy, pride, optimism, sadness and loss (Dockett \& Perry, 1999; Griebel \& Niesel; 2002). Rosewarne et al. (2010) comment on the shift between certainty and uncertainty, loss and gain, which they noted from memory work of adults reflecting on personal transitions. Renwick (1997) described two contrasting feelings - either being teary, or feeling 'free at last' - as typical for parents on the first day of school.

Worry about how their child would adapt to school was a particular theme, regardless of the child's academic ability before school entry (Cosaro \& Molinari, 2000; Renwick, 1997). Some writers noted things which could mitigate parents' worries. Giallo et al. (2008) developed a tool to measure parents' sense of self-efficacy in helping their child prepare for school, and their feelings of anxiety, and found that parents who felt more able to help their child with the transition had fewer worries about their child's school experience. Parents interviewed by Peters (1998) identified good access to information before the child started school as essential, and believed this could alleviate their worries and the anticipated risk of 'infecting' their child with their anxiety. It appears, then, that good access to information and a sense of agency may be significant in helping parents to mitigate any anxiety and effectively manage the transition to school for their child.

A further theme in literature about transition is that parents' recollection of their own schooling may affect their feelings about school, and how they approach the school. Docket and Perry (1999) noted that school may not hold positive memories for some parents to the extent that stepping into an education institution could be challenging. Barnett and Taylor (2009) agreed, and also noted that mothers who remembered their own parents' involvement in school more positively reported engaging in more academic transition activities with their own child. Ross and Buehler (2004) discuss how memory works and state that people do not recall every aspect of a situation: memory is selective and goal driven, and can be retrospectively reinterpreted. Rimm-Kaufman and Pianta (2000) suggest, therefore, that positive family-school relationships should be considered a key outcome of a good transition to school as they can help to overcome past negative experiences with the education system which parents may have had. These relationships need to be formed early in the contact between family and school and include many opportunities for formal and informal communication. 


\subsection{Parents' experience as parents}

Parenting involves taking responsibility for the nurture and well being of an initially highly dependent infant, and managing changes as the child matures. This section discusses themes of personal agency and identity formation with groups as they apply to parents.

\subsubsection{Agency}

As noted above, some authors found that parents who felt able to actively support their child's transition to school had fewer worries about the child's school experience (Giallo el at., 2008). The concept of agency refers to the capacity people have to act or cause change (Gunn, 2009). It involves a cycle of initiative where people plan, take action, reflect on the effects of their action, and plan further actions to achieve their goals (Bandura, 2006). In setting goals and planning actions a person imagines what the outcome of their actions might be; that imagined outcome is then a motivator for their action. A parent may use their personal agency to influence the conditions relating to their child's development, for example by acting on information they have obtained or choosing from a set of options the one which they feel would best suit their child. In turn, school staff have their own personal and institutional agency, leading to potential conflicts between the goals and actions of the different parties (Campbell, 2005). Iyengar (2010) notes that having the opportunity to make frequent small choices over even minor aspects of one's life gives a sense of control which in turn greatly increases one's sense of personal satisfaction.

Agency can be exerted directly by an individual, by appealing to others to act on one's behalf, or by the collective action of a group. People set goals for their actions, but because most human activity takes place with other people these goals must take into account the goals of other individuals and groups. Bandura (2006) notes that there is a great deal of difference in the agentic resources which different people have, and their efficacy depends also on the interplay between societal role structures and their own and others' beliefs. This leads to a connection between agency and power (Gunn, 2009), where social structures, like 'teacher' or 'professional' can alter the perceived autonomy of the different players in a social situation. Gallagher (2006) described the experience of parents who struggled to form a meaningful partnership with teachers to provide a suitable programme for their gifted children. The parents' response was to turn to outside groups to provide this programme, such as the 'one day school' organisation.

\section{Belonging}

One model of individual agency highlights four interconnected aspects: belonging, community, sense of place, and spirituality (Reid \& Stover, 2005). These aspects are linked by the 
individual's participation in the setting, including attempts to become involved and knowing that their contribution is accepted and valued. Reid and Stover (2005) note that "a sense of belonging requires involvement, relationships, familiarity with the place, and participation" (p. 38). This model suggests that in order to exercise personal agency, parents would need to have knowledge of the routines and normal practices of the setting, feel that their contributions are accepted and respected, and develop relationships with school staff which are receptive to discussion and negotiation.

\subsubsection{Identity}

As parents undergo the transition of their child to school, a new strand is added to their identity; that of being a 'school parent'. Sarup (1996) defines identity as "the story we tell of ourselves and which is also the story that others tell of us" (p. 3). He suggests that one's identity always has a history and is located in a particular time and place. When people 'tell their stories' to others they can choose to emphasise some elements and exclude others depending on the effect they wish to produce. Wenger (1998) focuses on people's involvement in social groups and agrees that identity is constructed. He notes that this is caused by the interplay between how people see themselves, how they perceive that others see them, and the opportunities which their social institutions offer them. Thus, for Wenger, identity forms a pivot point between the individual and the social.

For parents, their identity is likely to be influenced by their own memories of school and view of themselves as students, and by the tacit and explicit expectations which the school, and their social groups, communicate to them. Identity is not fixed, but develops over time as people continue to interact with others and with the social institutions they are part of (Wenger, 1998). Wenger proposes the concept of identity as a "constant becoming" (p. 154), or a trajectory, whose future path is composed of what we imagine might be our participation with the social institutions, based on expected opportunities and our choices. This trajectory may then change as a result of further interactions with people and knowledge about the possibilities of involvement which are available.

Wenger (1998) notes that people produce their identities through both their participation in a group or its practices, and non-participation in that group - those things which they either choose not to become involved in, or are excluded from. A 'peripheral' trajectory implies a lower level of participation which may either be the precursor to participating more fully in the future once the individual has more knowledge and experience in that setting, or may be a chosen long-term goal. In either case the peripheral trajectory focuses attention on the areas of participation which 
one has within that setting. In contrast, a 'marginalised' position is characterised by one's role being in some way constrained by others; it focuses attention on areas of non-participation, or things one would like to do that one is unable to. Two people may have the same pattern of participation within a setting but experience it as "enabling or problematic" (Wenger, 1998, p. 167) depending on context.

\subsection{Chapter summary}

In this chapter the literature on children's transition from early childhood settings to school has been reviewed. Theoretical understanding of transition has been influenced by understandings of the child, and of communities, with child-focused maturational models sometimes developing to, and sometimes sitting alongside, more community-wide models of transition. The themes directly related to parents of children starting school were then reviewed. Parents are the adults most likely to be in each of the three microsystems of home, centre and school with their child, and therefore have an important role in supporting their child and communicating between others in each setting. However, literature suggests that the experience of parents during their child's transition to school, and their opinions about what would support them, has been explored only in a limited way.

This review of literature suggests that parents need good information about schools and relationships with school staff which are respectful and allow for effective ongoing communications. Issues around parental agency and participation within the school also seem to have some bearing on the efficacy of parent support of their child and their own experience of the transition to school. The study seeks to fill a gap in the literature by reflecting with a group of parents what their experience is like and how their needs are met over the transition of their child.

In Chapter Three I will explain the methodology which this study is based on and the research methods and procedures used. 


\section{Method}

\subsection{Introduction}

This study focused on the lived experience of parents during the period when their oldest child was transitioning from an ECE centre to a compulsory school setting. The main research question for this study was:

What is it like for parents during the transition of their oldest child from early childhood education to school? Three sub questions were:

- How do parents learn about school and the transition to school?

- What affects the development of relationships between parents and other people at their child's school?

- What affects how parents develop their identity as a 'school parent'?

This chapter is divided into four sections. The first section introduces the theoretical framework and research approach taken. This is followed by sections outlining the social context at the time of data collection and elements of the research design. Finally, the conduct of research is outlined, including research quality and ethics.

\subsection{Theoretical framework}

The research question was focused on developing a rich understanding of how parents perceived their experience of having a child start school. Therefore an interpretative, qualitative methodology was deemed appropriate (Mutch, 2005). The study took inspiration from interpretive phenomenology in that it aimed to describe "the meaning of the lived experiences for several individuals about a concept, the phenomenon" (Creswell, 1998, p. 51), where the phenomenon was being a parent whose oldest child is approaching and starting school. Phenomenology is focused on human experience, and how this experience is interpreted by people (Denscombe, 2007; Willig, 2003). It investigates "the ways events appear when theories and constructs are for the moment put aside by the researcher" (Fischer \& Wertz, 2002, p. 276). In interpretive phenomenology, participants are asked to describe their experience of the phenomenon in detail (Fischer \& Wertz, 2002). Therefore it seemed appropriate to use individual or couple interviews of several participant families as the primary data collection method as these provide in depth data. 


\subsubsection{Research approach}

This study takes both a social constructionist and interpretivist approach. Social constructionism acknowledges that there are multiple realities, and knowledge is co-constructed by the interactions of participants within social contexts (Crotty, 1998; Guba \& Lincoln, 2008; Freeman \& Mathison, 2009; Fosnot \& Perry, 2004). The objective of research is to create a description of the phenomenon in question which is rich, is informed by these different perspectives, and is negotiated between the researcher and the participants. Social constructionists believe that language plays a crucial role in the construction of knowledge in daily life (Burr, 2003). Language does not transparently convey thoughts or ideas to others; we are able to think the way we do because we are born into a world in which certain concepts and ways of understanding already exist and are available to be used. In turn, our thoughts communicated through language are interpreted by others to create meaning (Gergen, 2003).

Interpretivists acknowledge that a researcher cannot report findings objectively as scientific 'fact' because the researcher is a part of the system containing the phenomenon under study. The researcher always filters data through their own experience: their social background, language, gender, race, ethnicity (Denzin \& Lincoln, 2008), even when they intend to describe the experience of others. This is in contrast to an objectivist view, which has a goal of "discovering the universal laws of society and human conduct within it" (Walliman, 2005, p. 205). Hence, the researcher must position themselves in relation to the phenomenon in question, and attempt to take into account their personal experience in their interpretation of the data.

This study included interviews with couples, and the meaning of participants' experience was negotiated between them as couples interacted during the interviews (Fontana \& Frey, 2008). Reality and knowledge are socially constructed, and organisations and practices are invented by social groups through their interactions (Walliman, 2005). Individuals and couples within the study also reflected on their interactions with other members of their social group, and the institutional expectations they encountered, and constructed meaning from those reflections.

\subsection{Context}

A study which uses a social constructionist approach must be located within its specific historical time and place (Burr, 2003; Walliman, 2005). The main data collection for this study was conducted from June to October 2009 in an urban area in New Zealand. Some relevant aspects of the social and political context at that time included:

- The economy had been in a recessionary phase for nearly a year. Media commentators 
noted that unemployment was increasing, and people who had jobs were careful to retain them as new employment was likely to be hard to find.

- A National-led government had been elected the previous November after nine years of Labour-led administrations. This government was developing a policy of 'national standards' in primary schooling, and commentators were discussing in the media whether this would lead to increased testing of primary aged pupils.

- Schools in the area had reported increasing rolls in the previous several years and many had introduced a school zoning policy to manage this.

\subsection{Research design}

This section describes how centres to recruit participant families from were chosen, how participant families were selected, and the data collection and analysis methods used.

\subsubsection{Site selection}

Participant parents for this study were recruited through ECE centres located in a medium sized urban area of New Zealand. I wished to include some families from each of a playcentre and a childcare centre as a proxy for achieving some variety in the parents' experience of involvement in the ECE service. I had an expectation this would provide such a variety because of my experience of the two service types. Playcentres run half day sessions staffed by teams of volunteer parents with each parent attending and supervising play for at least one session per week. Parents are also expected to take on some management role within the centre, such as secretary or gardener, and be involved in monthly business meetings for the centre. Childcare centres, on the other hand, are staffed by paid teachers and are typically used by parents while they are engaged in paid work or study (Robertson et al., 2007). Some parents may be involved on a management committee or in settling activities with their children. Seidman (1998) recommends maximising variation in participant characteristics, while keeping the dominant phenomenon constant in order to ensure rich data and avoid drawing easy conclusions. I aimed to recruit three families from each service type.

The selection criteria for centres was that they had several children expected to start school during the winter of 2009 who were the oldest or only child in their family. I wanted to interview parents during what might be their first experience of the compulsory school system as a parent. I initially approached centres by telephone. I then sent each centre which met the criteria an information sheet about the study and gave them an opportunity to ask questions before they agreed to participate (see Appendices A and B). Each centre nominated a staff member as the 
contact person for the research. Once I had recruited one centre I looked for a second centre which was geographically close to it. I hoped this would increase the likelihood of children from the different centres moving on to the same school, thus allowing for the possibility of insights on transition from parents with differing early childhood experience moving to the same school. This situation occurred, with children who attended two different centres being enrolled in the same school.

I was not able to find a single childcare centre with three or more children in the target age range who wished to participate in the study. Therefore a second childcare centre was recruited. It may have been easier to recruit participants with an oldest child of the appropriate age from a state kindergarten given the high proportion of four year olds at that service type. While surveying the literature I noticed that many studies of transition to school in New Zealand had recruited participants from kindergartens. Since I wished to include the voice of parents with different early childhood experiences I chose to avoid that option.

\subsubsection{Participant selection}

Six participant families were recruited through the three ECE centres. The centre contact staff member identified possible participants on the basis of having an oldest or only child due to start school during June, July or August 2009. The centre gave the parents an information sheet which I had prepared and invited them to consider whether they would become involved with the study (see Appendix D). Centres then passed on to me the contact details of those parents who agreed. I used quota sampling (Mutch, 2005) until I had recruited three participant families from each of a playcentre and childcare centre. Of seven families approached, six agreed to become involved. One of the families recruited through the playcentre also concurrently attended another early childhood centre not involved in the study.

Questions about workforce participation and ECE centre involvement occurred during the first interviews. All six families were involved in paid work at least part-time. Of the five two-parent families, three had both parents involved in part- or full-time paid work. Each of the three playcentre families had one parent who had been assigned to a regular weekly session 'on duty' providing the education programme as part of a team, although one family had ceased attending playcentre at the start of the term her child turned five. In each of the three childcare centre families both parents shared drop off and collection responsibilities for their child, and had regular opportunities to speak with a primary caregiver at the centre. I did not collect socioeconomic or ethnic information about the six families. These were not selection criteria and I 
wanted to avoid influencing parent responses by potentially drawing attention to stereotypes (Steele \& Aronson, 1995).

Although child gender was not a selection criteria for this study, it happened that each of the six families had a son due to start school rather than a daughter. It is possible that parents with a daughter starting school may have a different experience of the transition, but this was not considered in this study.

In addition to the main participants, I also interviewed one staff member from each of the centres and from two of the four schools. I was unable to schedule an interview time with a staff member of the other two schools. Each centre and school contact person proposed who they thought was the appropriate staff member to speak with me.

\subsubsection{Data collection - interviews}

A combination of data collection methods were used to obtain a rich insight into the participants' experience. These included interviews with parents; key informant interviews with a staff member from each centre and some schools; a focus group of parents; parent diaries; collection of relevant documents from the centres and schools; and researcher journal. Multiple methods are frequently used in qualitative research in order to give a deep and broad perspective into the subject of interest (Denzin \& Lincoln, 1995). Mutch (2005) also suggests that the use of multiple data collection methods helps to ensure credibility of a study by giving different insights into the data. Each of these data collection methods will now be discussed in turn.

\section{Parent interviews}

The purpose of this study was to gain a rich insight into parents' experiences across the transition to school using an interpretive, qualitative approach. I therefore chose to use interviews with parents as the primary means of data collection. Interviews can be structured, with a set of specific questions, or open-ended, with more general prompts for participants to share their experiences. Semi-structured interviews are recommended when the purpose of the research is to obtain insights into people's emotions and experiences (Denscombe, 2007; Fontana \& Frey, 2008: Silverman, 2006; Willig, 2003).

An advantage of using interviews noted by Mutch (2005) is that they are inclusive of a wider range of people than written surveys as they do not rely on participant literacy ability. Interviews also allow the researcher to "be able to judge the quality of the responses of the subjects, to notice if a question has not been properly understood" (Walliman, 2005, p. 284) and to seek clarification or encourage a more indepth response. 
I carried out two semi-structured, open-ended interviews with the participant parents. The first was conducted approximately four weeks before their child was due to start school, and the second interview took place four to five weeks after the child had started school. Each family chose whether they wished to have one or both parents involved in the interviews. Of the five two-parent families all chose to be interviewed together on the first occasion, and four couples chose to be interviewed together on the second occasion. I offered to conduct the interviews at a time and place that was convenient for the families. In most cases this was in their homes during the evening.

\section{Key informant interviews}

Short semi-structured, open-ended interviews were held with a staff member from each ECE centre. The intention was to get a centre perspective on the practices which staff commonly used to support parents whose children were moving from the centre to school, and their views on the transition for parents.

Information about the project was sent to each of the four schools which children in the study transitioned to including an invitation for a staff member to attend a similar short key informant interview. Interviews eventuated with key informants from two schools. The research design did not allow for schools to be approached about participating in a key informant interview before the parent participants were selected. Centre key informant interviews were held after the child had started school, and school key informant interviews were held after the focus group. This was to ensure the parent's voice was the primary perspective in the research.

\subsubsection{Data collection - focus group}

A focus group of parent participants was conducted to create an opportunity for participants to hear each others stories and engage with the possible meanings of their own experience (Barbour, 2007). The focus group was held after all children in the study had started school and all second participant interviews had been completed. Five families were available for the focus group and each sent one parent; the sixth family withdrew on the day due to illness. The venue was a community-based ECE centre located centrally for all families and which none of the families attended.

Punch (2005) notes that "the hallmark of focus groups is the explicit use of the group interaction to produce data and insights that would be less accessible without the interaction found in a group" (p. 171). The facilitator's role is to introduce the topic areas for discussion and then to ensure the group runs smoothly with each person having a chance to contribute (Waldegrave, 
1999). It is important to ensure that the participants engage with each other rather than merely answering the interviewers questions in turn (Barbour, 2007; Denscombe, 2007). I have had a great deal of experience facilitating small group discussions, so was confident of my ability to manage this process.

I initially invited each parent to share their experience of having a child start school, with the assurance that they would be able to have further turns after each group member had spoken for a first time. In practice I found that the conversation developed with no further input from myself, with participants contributing further aspects of their own experience in response to comments by others. After some time I chose a pause in the flow of conversation to introduce the next focus area. I also used the focus group as an opportunity to verify the initial themes developed from analysing the interview data. I presented the themes to the participants and invited them to reflect on these with respect to their own experience and suggest any changes or additions.

\subsubsection{Data collection - documents}

A number of different documents were used as supplementary data sources. These included centre and school policies and information, my own research journal, and participant journals.

\section{Centre and school documents}

I collected documents relating to the transition to school, including any transition policies, from each of the three centres in the study. Each centre had a transition to school policy; for one centre this was contained within a more general policy on transitions into, within, and from the centre. One centre showed me a parent noticeboard with local school leaflets displayed on it, and another centre described having leaflets from local schools to give parents who were considering those schools. Each of the three centre key informant staff members noted that they intended to update their information held on local schools to be more current.

I received information packs from two of the schools in the study and perused the website of each of the four schools. Information packs were obtained at the time of the school key informant interviews. However, I was only able to schedule these interviews with two schools. Written information provided context on some of the strategies which centres and schools used to support parents during the transition to school.

\section{Research Journal}

I maintained a research journal throughout the research process. This included notes made during the process of the research, my reflections on literature and how it related to data during the 
collection process, reflection on mainstream media items which I noticed during the research period, and reflective memos developed during the period of research. The journal enabled me to be reflectively aware of happenings in the wider world which may influence the participants' experience during the data collection phase (Denzin \& Lincoln, 1995) and provided a site for initial and ongoing analysis of the data.

\section{Participant journals}

The parent participants were invited to keep a diary of their experiences and thoughts from the time of the first interview until the second interview. The journals were designed so that parents and children could complete them together if they wished. I provided a plain paper A5 booklet and included a note suggesting they might like to include photos, comments, descriptions, pictures or writing samples from the children, and/or comments from other family members. I suggested parents might focus on occasions leading up to starting school, such as the last week at the centre, any school meetings, their child's birthday, and the first day or week at school. In introducing the diary I suggested that it could become a keepsake for the family of their child's transition to school.

Of the six families, three made extensive use of the diary and a fourth made one entry in it. Two families included pictures and/or writing samples by their children, and photos. The diaries included descriptions of rituals around leaving the early childhood centre and of the child's first day at school, and comments about relationships the children had at centre and at school. The diaries were used to enable the parents to have some control over what information they wished to note. Providing written information is considered to privilege participants who are most comfortable with written literacies (Willig, 2003) so I intended that this data collection method be supplementary to the individual and group interviews.

\subsubsection{Data coding and analysis}

My approach to analysing the data was informed by interpretive phenomenological analysis (IPA) and more general precepts for qualitative analysis of texts. In a description of IPA, Willig (2003) suggests that interview transcripts for each participant be analysed individually at first, reading and re-reading to become highly familiar with the texts and then identifying themes and concepts. The themes and concepts are then compared with those from other participants, and master themes created to describe the phenomenon. This process is designed to systematically describe the meaning of the participants experience, while setting aside any researcher prejudgements (Creswell, 1998). 
Specifically I used a process suggested by Auerback and Silverstein (2003) of reducing the transcript text, identifying key themes, and representing these with examples. Later, transcripts were compared to look for commonalities and repeating ideas across the experiences of the six families. Where possible, examples of language used by the participants acted as emotive labels to capture the essence of the repeating themes (Auerback \& Silverstein, 2003), and these are indicated in Chapters Five, Six and Seven by sub-headings, italicised and in single quote marks. The first interviews, conducted before each child started school, were analysed and compared separately from the second interviews. This ensured that I had an initial analysis of themes and concepts available to present back to participants at the focus group for their feedback.

The process of analysis began soon after the first interviews were transcribed and was recursive. When the second interviews and focus group data became available, any new themes suggested by this material resulted in me returning to previous transcripts to look for examples which might have been overlooked earlier (Willig, 2003; Auerback \& Silverstein, 2003). Similarly, texts from the parent journals, centre and school documents, and key informant interviews were first read as the separate data type, and then used to inform reflection on the parent interview data.

I used the qualitative analysis programme Nvivo to collate all interview data. This collation drew on the prior analysis work in generating nodes and the relationships between nodes, and allowed me to manage the data and keep examples from different sources together. I also wrote research memos (Strauss, 1987) to clarify themes which arose and link with ideas from literature.

\subsection{Conduct of research}

This section discusses how the quality of the research was maintained, and ethical standards which were applied. It also notes some relevant points related to my position as researcher.

\subsubsection{Rigour}

Appropriate measures of the rigour or quality of research depend on the research design. Toma (2006) notes that qualitative researchers must "at least satisfy themselves that they have not misrepresented data and have not been careless in recording and analysing data" (p. 409). The concepts of trustworthiness and authenticity or credibility are suggested for research in a constructionist paradigm (Toma, 2006; Guba \& Lincoln, 2008). Trustworthiness refers to a sufficiently clear documentation of research and analysis decisions (Mutch, 2005). Authenticity means that the research "relates to some reality" (Toma, 2006, p. 410), through means such as using more than one data source and confirmation that notes and findings resonate with participants' own experience of the phenomenon. 
In this study I used several methods to ensure trustworthiness and authenticity. During interviews paraphrasing was used to check the meaning which participants intended (Anderson, 1998). This helped to avoid simple misunderstandings which might have arisen through my having had a different experience to the participants.

Member checking was used to confirm that the summary family stories were a fair reflection of each family's experience. Participant parents were invited to correct drafts of the family stories. Additionally, the focus group provided an opportunity for participants to check the initial themes which I had developed from analysis of the interview data. It was important that they felt these themes related to the reality which they have experienced and sought to describe for me and to what they thought was occurring in their world.

Finally, Rapley (2007) notes that findings must be reported in such a way that they are credible and plausible to readers by giving access to the method used, and sufficient examples from the data to show that these are the basis of the research argument. Where multiple instances of a point were found in the data I have chosen representative examples to illustrate that point.

\subsubsection{Ethics}

When designing research which involves people, independent consideration of ethical factors and practices helps to ensure that the study will do no harm to participants and is respectful of their time and involvement (Snook, 1999; Walliman, 2005). Mutch (2005) lists principles of ethical practice for researchers to consider, including informed consent and voluntary participation, the right for participants to withdraw from the research and have their privacy respected, and consideration of participant and researcher safety and any methods of dissemination planned for the study. This project followed the Victoria University of Wellington Human Ethics procedure (Victoria University of Wellington, n.d.). It was approved by the University Ethics Committee in May 2009 prior to any contact being made with potential participants.

My research design involved approaching two ECE centres: a playcentre and a childcare centre, and through them approaching individual parents with oldest children starting school in the prescribed period. Thus there were potentially several layers of consent to obtain (Walliman, 2005). The New Zealand Playcentre Federation (NZPF) has an ethics approval process for research projects with national significance. On enquiring with the NZPF I was advised that my small project was appropriate to be approved at the regional playcentre association level. I applied to the executive of the regional association and was advised that I had permission to approach the president of any playcentre in their association to inform them of my project and ask if their centre wished to take part. 
I expected that some childcare centres would have ethics approval processes for research, especially if they were part of an umbrella organisation. As I had no way of knowing for a particular centre whether this would be the case, I made a point of asking the centre manager on my first phone contact whether there was some process I should go through first. As it happened, each centre I contacted was able to make that decision for themselves.

The management contact for each centre received a verbal and a written explanation of my project before they agreed to participate. The centre's role was to identify families who were potential participants - with an oldest child due to start school between June and August 2009 pass on a participant information sheet and invite them to contact me.

An important principle relating to ethical research is that participants be sufficiently informed to know what they are agreeing to (Mutch, 2005; Snook, 1999; Walliman, 2005). For this study I provided information sheets for centre staff, potential participant parents, and school staff detailing the purpose of the study and the participation that was being requested of them (see Appendices A, B, D, F and G). Maintaining confidentiality of participants and institutions was also a priority. In the publications of findings from research the researcher has a responsibility to protect the identity of participants (Snook, 1999). This study used pseudonyms for individual participants and their children, and I avoided details that would identity the centres and schools involved.

\subsubsection{My positioning as researcher}

In the introduction phase of an interview it is important to first establish trust and rapport with the participant, for example, by saying something about the origins of the researcher's interest in the topic (Denscombe, 2007). When I introduced myself to the participants I noted that, as well as a research student, I was also a mother of children who had started school and an ECE teacher. This identity led to my interest in this transition. This helped establish rapport with the participant parents by providing several ways to create connections with them, including having had some similar life experiences.

While my own experience is of being a mother, my experience has been that both parents will take an interest and be involved in decisions about their children. Therefore my preference in research design was to talk with both parents during the main interviews. I also identify culturally as a Pākehā New Zealander, and from a family background where my generation was the first that was likely to engage in tertiary education. I am therefore of a similar social class and ethnicity to a majority of the education workforce. I take for granted that I will be able to ask school personnel about education matters until I am satisfied with the answers, and am able to 
affect educational conditions for the benefit of my child. This is an important tendency to be aware of as I seek to understand the participants' possibly divergent experiences.

Interpretive phenomenology acknowledges that results are always the researcher's interpretation of the participants description of the phenomenon (Willig, 2003). It was important to bracket off my own experience in order to not make assumptions about the participants experience. One way to do this was by assuming the role of a 'stranger' and asking obvious questions, even when I suspected I might already have some idea of the answer. Further, social constructionism regards objectivity as "an impossibility" (Burr, 2003, p. 152). The choice of research subject and the way questions are asked are factors in constructing how meaning is placed on them by participants. Exploring the participants perspectives is necessarily a co-production between the perspective of the researcher and the participant's reported experience. Therefore my 'bracketed off' experiences sometimes needed to be brought forward to explain how a certain conclusion was reached.

\subsection{Chapter summary}

This chapter has explained the design of the research project and the data collection and analysis methods used. The purpose of the study was to explore and describe parents' experience of the transition to school of their oldest child. To do this I used an interpretive, qualitative methodology, and recruited six participant families from two ECE service types. The main data collection methods were interviews with parents from each family one month before their child was due to start school, and again one month after their child had started school, followed by a parent focus group. I drew on interpretive phenomenological analysis (Willig, 2003) and generic qualitative methods (Auerback \& Silverstein, 2003) in my analysis of the data.

In Chapter Four I will present an overview of the transition experience for each of the six families in the study, including key events as identified by them. Chapters Five, Six and Seven will then present amalgamated findings of the study related to each of the research sub-questions. 


\section{Family stories}

\subsection{Introduction}

This chapter provides an introduction to the six families who participated in this research project. It gives an overview of each family's story and outlines the course of the transition and key events for that family. It also notes the parents' assessment of the impact of the transition on them and their children. The format of the six stories is not identical. This variation was used in order to represent what seemed to be important to each family.

Pseudonyms have been chosen to protect the identity of participant family members. During the focus group, participants were asked if they wished to use their own names, or choose their own pseudonyms. The use of real names, or choosing to alter them, is a statement of power (Guenther, 2009) and I wished to involve participants in this decision. After discussion it was agreed that pseudonyms would be used, and that I would choose them using some consistent and non-intrusive method. My method was to find lists of the most popular baby names from 1975 for the adults, and 2000 for the children, and use these lists to assign names with a consistent initial letter for each family.

\subsection{Family stories}

This chapter presents each family's story in turn, including the decision process around choosing a school and the family's context before and after the transition to school.

\subsubsection{Amanda and Angela}

Amanda and Angela had one child, Alex. They lived in rental accommodation, having recently moved from their house in a nearby suburb. Amanda had been full time caregiver to Alex while Angela worked, and they were members of the playcentre community.

Amanda and Angela had a wide network of friends, including friends who were new entrant teachers, and a couple who had researched how the many schools in the region cater for diverse families, including families with same sex parents. As a lesbian headed family it was important to them that their child not be singled out for undue attention over his family composition. Their experience of community at the centre was also important to them. Amanda reflected that she had moved house a lot as a child, with resultant disruption to friendships, and she would like more continuity of relationships than this for her son 
Amanda and Angela lived within zone for two schools. Through talking with friends and neighbours, and from their professional contacts, they decided that neither school was a good match with what they wished for their family. They knew that most of Alex's friends would attend the school near to the playcentre which they had been members of for nearly four years. They also heard that there would be other children from lesbian headed families at that school. They decided to move house so they would be in zone for this school.

Amanda and Angela received an information pack from the school, and arranged to begin school visits. This school recommended up to four visits, and arranged them on days when other children would be visiting. On their first visit the teacher introduced them to a child who lived on their street and was due to start school on the same day as Alex, and to his parents. Amanda and Angela appreciated the teacher's thoughtfulness in helping the families to connect with each other.

In the several weeks leading up to Alex's first day of school the family had a lot of disruption: moving house; leaving playcentre; illness; and a family holiday. Moving house in particular added to the stress around starting school. They discovered from talking with the teacher that the Education Review Office would be visiting the school during Alex's first week, including a large welcome ceremony on his first morning at school. They decided it would be better for him to start school during a more normal week, so delayed his first day for one week.

Alex had a very happy first day of school. After the first day he became more and more distressed at being left, crying and begging to stay at home or to be collected at lunchtime. After three weeks Amanda and Angela discovered that he had been targeted in a series of manipulative bullying incidents by older boys at playtime and lunch time which the school was unaware of. The school dealt with the situation swiftly once it was discovered by a teacher, and Alex was much happier afterwards. During this time Amanda commented that she knew something was wrong but had no way of knowing what as Alex did not communicate and there were few adults supervising the playground.

Amanda was very grateful for the kind way the teacher supported Alex during his difficult transition, and for the support she received from other parents. She said that other parents, knowing she was upset by leaving her son crying, would wait outside school in the morning to reassure her, or linger in the classroom to observe him and ring her at home to report that he had calmed down.

Amanda and Angela believed that education depends on the involvement of the wider community and were keen to be involved at school. They knew that the school welcomed parent 
involvement in many ways, but not with the regular programme in the classroom. While planning to be involved in the ways she could, this exclusion grieved Amanda. She reported that, while the school was generally good about keeping parents informed, she still felt unsatisfied with the information she had about what happened during the school day.

\subsubsection{Julie and James}

Julie and James had two children, Jacob, who had recently started school, and Jessica aged about three. Jacob and Jessica attended a fullday childcare centre for four days per week while Julie and James worked.

Four months before Jacob was due to start school James attended an evening for parents on the transition to school which was hosted by their centre. Teachers from both the centre and a local school presented information, and the parents used this opportunity to ask many questions about schools, what children need to be well prepared for school, and what to consider over the transition.

Julie and James wanted their child to go to a local school, and to eventually be able to walk to school with his sister and neighbourhood children as James remembered doing as a child. They considered two possible schools, one close to their home and the other a little further away. James and Jacob attended the school fair of each school on consecutive weekends some months prior to choosing a school. James reported that this was a turning point, giving him a strong sense of what each school would be like and helping him to form opinions on what he was looking for in a school for his children.

In the months prior to Jacob starting school both schools introduced enrolment zones which limited the family's choice to the closer school. This was the school they had preferred, and they had also heard from neighbours and friends with children that this school had a good reputation. So the introduction of zoning did not unduly concern them. Julie and James received an information pack from their chosen school and arranged to start school visits.

This school recommended up to four visits prior to starting school, arranged on days when other families were likely to also be visiting. On their first visit the teacher introduced them to a child who was due to start school the same day as Jacob, and to his parents. Julie and James appreciated this effort on the teacher's part to build connections between the families.

Several weeks before Jacob started school Julie's mother died. As a result the family spent some weeks away from home in another town. This was a very emotional time for the family and Julie was concerned at how Jacob might be affected by seeing her and other relatives upset. They 
knew that the new entrant teacher at school was scheduled to be away during the week Jacob was due to start school, and the funeral arrangements meant that Jacob missed the school visit when he would otherwise have met the reliever. Julie and James knew that unexpected change was unsettling for Jacob so decided that he should not start school with a relieving teacher who he did not know. They delayed his school entry by one week until the regular teacher returned.

Julie and James commented that Jacob settled in well to school. They gauged this through observing his increasing confidence in social settings and comfortable interactions with peers. Jacob was interested in engaging with reading and talking about what he did at school right from the first day, and appeared confident in the school setting after four weeks. They reported that Jacob was quite tired at times during these weeks.

Julie and James initially knew only a few people associated with the school, but once they started quickly found they recognised neighbours who had children attending the school. They saw their role as school parents as supporting Jacob's learning, following his lead, helping him to unwind after school, and building his confidence. They tried to include Jessica in home activities associated with school, such as the daily reading.

\subsubsection{Michelle and Mark}

Michelle and Mark had two children, Matthew, who had recently started school, and his younger brother Michael. Matthew and Michael attended a fullday childcare centre three days a week, and Michelle and Mark each had one day per week caring for the children and four days at work.

Michelle and Mark placed a high value on the idea of their children attending a school in the local community which included a wide cross section of people. When they moved to their new house they heard the local school had a good reputation, so they felt no need to look further.

Some months before Matthew's birthday Michelle contacted the school office for information on the process of enrolling him. The office administrator checked their address to ensure they were in zone, and then advised them to phone back closer to the day. Two months before Matthew's birthday Michelle collected an information pack, and enquired about pre-entry visits. She was advised visits would not be held until quite close to when Matthew was due to start due to staffing issues. Michelle and Mark read the Education Review Office website and talked to friends with children at other schools, but otherwise knew little more about the school until Matthew's birthday. They had few connections with the school, staff or families before their child's first day. 
The school phoned Michelle on Matthew's fifth birthday and arranged a pre-entry visit for the next day. Michelle found the visit to be very useful. It gave her an opportunity to have all her questions answered and she discovered that they would know one child in the class. She reported that it was reassuring to meet the teacher and finally get a sense of what school would be like. Matthew's starting day was delayed by several days at the school's request, but a proposed second delay of several days was not agreed to by Michelle and Mark.

Matthew was very settled in his first weeks at school, fitting in socially and not experiencing the tiredness his parents had anticipated. After school care arrangements for him were complex, with a different carer each day, including the one day per week with each of Michelle and Mark, and one day at group after school care. Matthew seemed to cope with these arrangements well, although he did not much like the group care.

During the first four weeks of school Michelle reported a desire to be more involved in the school community than her work schedule allowed. She was surprised by this, as it was a change from her wish for involvement at crèche. She attributed it to her theory about the importance of compulsory schooling. Michelle started helping in Matthew's classroom for half a morning on her at-home day each week, bringing her toddler along also, to satisfy this desire for involvement. This was welcomed by the teacher and Michelle found it interesting to observe classroom practice in action.

Towards the end of term, after about seven weeks of school, Matthew had a sudden change of behaviour, becoming violent at home. Michelle attributed this to tiredness: that he had 'held it in' all term and was no longer able to control his emotions. She also noted that the behaviour coincided with increased stress in her workplace. This behaviour did not last long. Michelle and Mark were puzzling about how to manage holiday care for Matthew throughout the year, and especially in the long summer holidays, given their limited annual leave entitlements.

\subsubsection{Nicole}

Nicole was a sole parent with one child, Noah. Noah attended playcentre, a childcare centre and a state kindergarten concurrently while Nicole worked part-time and studied part-time.

Nicole considered three schools. The first was a school that she and her son had strong connections with through friends at playcentre but which was out of zone for their home. Nicole briefly considered moving house into the school zone, but decided this was not practical. The second school Nicole considered and visited was very close to their home. However, it was a contributing primary school, only going up to year 6 , and she had some concern over whether 
Noah's needs would be catered for, especially as it appeared the school already had many children with various increased needs.

Thirdly, Nicole considered a school which was slightly further away but which was a full primary school. She received a comprehensive information pack from that school which she appreciated, and staff at the school seemed very receptive to learning strategies which would help Noah with his moderate learning needs. After discussing with friends the choice between the second and third schools, Nicole decided on the third school. She also thought it would be beneficial for Noah to have the option of having his intermediate years in the same school where he would be known.

The school recommended up to six pre-entry visits, and suggested these cover different times of the school day to give Noah and Nicole experience across the school day. Nicole found these visits very valuable, although she was a little worried about how her son would conform to a more sedentary classroom environment than playcentre had been.

Nicole had planned that she would delay Noah's first day of school for a week as they had family visiting from overseas. Noah was very proud of turning five, and he insisted that five year olds should be at school. In the end a compromise was reached where he spent part of that week at school, and he enjoyed telling his visiting relatives all about his experience there, and 'reading' to them.

Nicole had been studying part-time at university prior to Noah starting school. She decided to not enrol for papers during Noah's first two terms at school so that she would be able to collect him after school and give him rest days if this was needed. She also arranged her part-time work hours to fit within the school day. Noah continued to be very happy in his first weeks at school. He did not have undue tiredness and Nicole reported that he appeared to adapt smoothly to the classroom and playground. Nicole said that it was very pleasant to have the afternoons with her son. She was considering how to manage their routines when she continued her studies in the future.

\subsubsection{Rebecca and Richard}

Rebecca and Richard had one child, Ryan. Ryan attended a fullday childcare centre five days per week while Rebecca and Richard worked full time.

There were two schools close to Rebecca and Richard's home, a state school and a Catholic integrated school, and they had always intended Ryan to attend the Catholic school. Several months before Ryan was due to start school Rebecca contacted both schools and arranged a 
meeting with each principal including a short tour of the schools. As a result of these visits Rebecca decided that the state school was a better fit with her ideas about the educational setting that would suit their child. Ryan was enrolled at the state school.

The family knew a few people who attended this school before their child's first day and it was one of the two schools which most children from their centre transitioned to. Rebecca considered it an advantage to have some good friends who she could count on at the school. For example, she thought they might be able to provide backup by collecting Ryan for her if she was delayed at work.

In the weeks prior to Ryan starting school Rebecca felt that she had many unanswered questions about the school. She said that she would have liked to be able to talk to Ryan about his school with more authority for at least a few weeks before he started. The school was not able to accommodate any pre-entry visits until the week before Ryan turned five because of staffing issues.

Two pre-entry visits were arranged in the week prior to Ryan starting. Rebecca reported that these were very useful, and gave her the opportunity to follow up on her questions about school. They also enabled Rebecca and Ryan to meet several families who would be in his class.

Ryan enjoyed his first week of school. He was very tired, but generally positive. From the second week he became tearful and clingy in the mornings, not wanting to be left, and still very tired. Rebecca started ensuring they arrived at school early so that Ryan could settle into the classroom without rushing before she had to leave, and that seemed to help him. During this period his parents reported that he displayed an unusually cheeky attitude at home. By his fifth week Ryan was much more settled and less affected by tiredness. His attitude at home was positive and helpful, and he was happy about going to his carer's house after school.

After Ryan had started the school ran a parent information evening to explain how they teach writing and how parents can help their child at home. Rebecca attended this and found it very valuable, and implemented at home some of the ideas suggested. She found that it was not always easy to find time to talk with the teacher before or after school as many parents wanted the teacher's attention. Otherwise the school was very good at keeping them informed. Both Rebecca and Richard commented on how helpful it was to have friends at school who were involved and 'knew everything' as a supplementary source of information.

Ryan's transition to school period coincided with changes at Rebecca's work which contributed to her sense of stress. At the time of the second interview Rebecca and Richard were trying to work out how they would manage care for Ryan during the school holidays given that they had 
limited annual leave entitlements. They indicated they would prefer to avoid placing him in group holiday care programmes at the age of five.

\subsubsection{Sarah and Scott}

Sarah and Scott had two children, Sean, who recently started school, and Sophia, aged two and a half. Sarah was the full time caregiver for the children while Scott worked. They were members of the playcentre community.

Sarah and Scott placed a high value on attending the school in their local community in order to build relationships with local families. They had heard from friends with children that the school had a bad reputation, both in terms of student behaviour and academic achievement, but they catagorised this as 'gossip', and resolved to visit the school and form their own opinion. Sarah and Scott arranged for a meeting with the principal which they were very satisfied with. He confirmed that the school had had a poor reputation for behaviour but this had been turned around some years before. They had a brief tour of the school. They were impressed with the warm relationship apparent between the principal and children at the school.

Sarah and Scott were initially offered two pre-entry visits with Sean in the week he was due to start school, but Sarah negotiated to have three visits a week apart. Due to staffing issues these visits each involved a different teacher or reliever, and no opportunity was found for informal discussion with Sean's class teacher on the visits. The visits were somewhat useful, but as the class teacher did not greet Sean or Sarah, or interact much with Sean during the visits, they were also a cause of concern for how the transition to school would go. Sarah and Scott did not receive an information pack and any written information was only received after asking repeatedly. Sarah reported her extreme personal stress and sleepless nights during this period, and concern that she was not able to answer Sean's questions about school. She reported that Sean was worried about not knowing the rules at school, but otherwise calm about starting school.

The family had no connections with the school prior to starting. Sarah planned to make herself known to another new family who she heard was visiting during the same period, but the teacher would only allow one family to visit the class at a time. Sarah then planned to meet parents after Sean had started school, but found that few parents collected their children from school, and those that did were shy about responding to her greetings. The centre arranged a leaving ceremony for Sean, which the new entrant class and their teacher attended. This was appreciated by the family and provided a welcome connection and point of discussion between Sean's family and the children in the class. 
Sean enjoyed his first weeks of school and was not overly tired. Once he was in the classroom every day he quickly learned the myriad routines which the class operated within by observing the other children. His knowledge of school rules and processes was a source of pride to Sean. One brief incident of teasing was handled swiftly by the class teacher. Sarah reported that the process of starting school was much less stressful once they had daily contact with the school.

Sarah was keen to be involved with the running of the school in some way, perhaps by helping in the classroom once her toddler was attending playcentre by herself. She and Scott believed that involvement by the community was important for any school.

Sarah and Scott reflected that their transition to school would have been much smoother if better communication opportunities had been available. Sarah reported that she was thinking about giving the principal constructive feedback about their experience, and offering to help upgrade the information which the school makes available to new families, including the website.

Figure 4.1 (page 43) summarises the contacts which each family had with the chosen school prior to school entry.

\subsection{Chapter summary}

This chapter presented an overview of each story of the transition to school of the six families in this study. The families reported a variety of experiences during the transition to school, but on the whole they found the experience positive and that their children enjoyed the new opportunities which school presented.

The following chapters analyse the parents' experience of the transition to school of their child in greater detail. Chapter Five discusses how parents gained information about schools and about the transition to school. It then looks at how parents understood the transition to school in light of their theories of child development and of transitions and their knowledge of their own child. 


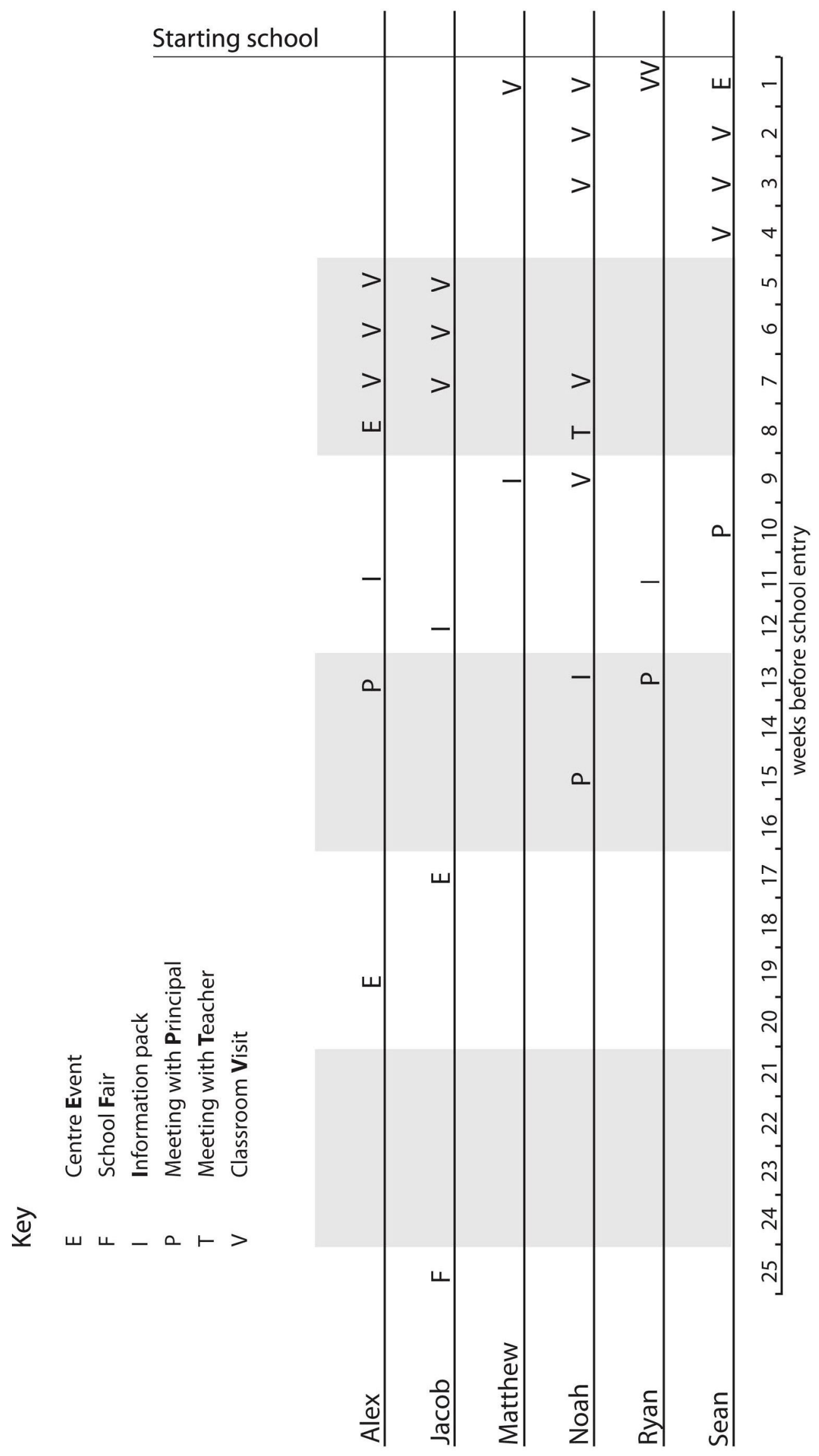

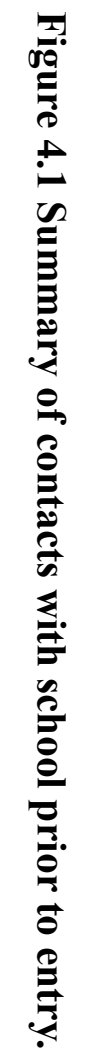




\section{Becoming a school parent - information and understanding}

\subsection{Introduction}

This chapter presents findings focusing on the first research sub-question: how do parents learn about schools and the transition to school? This is part of the overarching question: what is it like for parents during the transition of their oldest child from early childhood setting to school.

The chapter is divided into two main sections: how parents obtained information about school, and how parents understood the transition to school, including the theories of development and transition they held. In the interviews parents were directly asked how they obtained information about schools and the transition to school. Their responses are reported in the first section. The way people construct knowledge also depends on their own experience and understanding (Burr, 2003). While reflecting on finding out about schools the parents also referred to their own experience and theories which affected how they used this information. These responses are considered in the second section.

\subsection{Obtaining information about school}

For the parents in my study finding out about the schools in their area, and then the school they chose for their child, was an important task in the months before their child's fifth birthday. Clarke (2007) notes that children do better when their parents have good information about school prior to school entry. Parents used both informal and formal strategies to find out about schools and the transition to school, both before and after making contact with their chosen school. Strategies included talking to friends with children already at school, reading information packs and websites, and visiting the school. In the following sections I will look at what the parents reported about the effectiveness of the different methods used.

\subsubsection{Information from prior to school settings}

Places where parents obtained information prior to establishing contact with the school included the ECE centre, family members, friends and neighbours, and work colleagues. This information was acquired over many years, with the intensity of interest in finding out about school increasing as their child neared age five. 


\section{Informal strategies - 'word of mouth'}

For most families 'word of mouth' was an important way to get information about schools. Friends, neighbours and other parents at the centre were all sources of information and shared general knowledge about starting school, specific information about what happens at the chosen school, and reassurance that their child would adapt to the school setting.

I have several friends whose children already go there who had told me good things about it and I did also, you know, check up the ERO information on it and things like that.... so basically, it's a good school, he'll know kids there, so it works for us (Michelle/Mark, interview 1).

Several parents commented that they relied on word of mouth because they did not yet know school staff well enough to have a trusting relationship.

And I have to say after my meeting with the principal I would have run in the opposite direction. However, I knew so many people who'd been to the school who, you know, were really really happy with it. And um, and that's how we had to trust the process (Amanda, focus group).

One of the families did not know anyone with children at the school they were planning on sending their child to. This school had a reputation for being rough, and parents at the centre advised against sending a child there. In this case the parents discounted this advice as hearsay and gossip. They went to meet the principal and were reassured that he had addressed the school's reputation satisfactorily.

Lots of people have said to us, "oh you can't send your kids there, it's really violent." ... But we thought, just being aware that reputations can just stick, and they can be so out of date. We thought well we're not just going on that (Sarah/Scott, interview 1).

All the parents reported they had trusting and comfortable relationships with ECE centre staff and could regularly chat with them and ask questions. Staff members at each centre also said they used regular informal opportunities to talk with parents about aspects of the transition to school.

We make time for regular chats with parents. As primary caregivers we take personal interest in that. But also, you know, just having relationships with the parents and children whether or not you're their primary caregiver (centre 2 teacher).

Most parents also mentioned the value of information gleaned from chatting with other parents they knew from the centre.

Being such a small, close-knit community, a lot of children have gone to either [of two local schools]. And so we speak a lot with parents really, and how they've felt about it. That was probably the main [way to get information] (Rebecca/Richard, interview 1). 
ECE centres are commonly regarded as important sites for parenting support (Duncan, Bowden \& Smith, 2006; Ministry of Education, 1996; Woodhams \& Woodhams, 2008). This support occurs both through the community of parents attending the centre sharing practical information and empathy with each other, and the regular availability parents have to staff with specialist knowledge and experience of childhood development.

'Word of mouth' seemed to be important because along with the information parents got a sense of its reliability and authenticity, and its applicability to their own situation from their prior relationship with the informant (Thesing, 2008). As noted in the next section, some centre teachers believed there were parents who would benefit from formal transition activities which systematically involved every family.

\section{Formal strategies - transition activities}

Two of the three centres in the study provided some written information for parents on local schools, such as a leaflet displayed on a noticeboard. The key informant in each of these centres also commented on their intention to update this information. Formal opportunities for parents to find out about the transition to school mainly related to transition activities planned by the centres.

Two centres had developed formal activities to support parents with the transition to school. The playcentre had a close relationship with the school it was next to. This centre regularly took a group of children to visit the new entrant class and they were occasionally invited to attend performances by the school children. These visits familiarised children with what school might be like even if they went on to attend a different school, and parents rostered on duty at the playcentre also were able to observe school practice.

Because the school is so close to the playcentre, sometimes when they're doing a performance they'll invite that particular session that happens to coincide to come down. I think the kids probably do have some idea of school even if it's not the particular school they'll go to (Nicole, interview 1).

The playcentre had a formal poroporoaki, or leaving ceremony, for children transitioning to school to which representatives of the school were invited. This was seen as a celebration of the child's time at the centre and a formal 'handing over' of the child to his new education community. The new entrants class and teacher were able to attend Sean's poroporoaki. Sarah commented that this created a connection between him and his new classmates, none of whom they knew beforehand. 
And it was nice the next day. Like the kids were running in, saying 'oh it was cool seeing Sean's play centre' (Sarah/Scott, interview 2).

One of the childcare centres in the study held an information evening for parents on transition to school. This event was in response to an unusually large number of four year olds at the centre and was facilitated by the centre teachers, with a local school teacher invited to speak and answer questions.

When reflecting on this information evening the centre teacher believed that the parents attending found the centre-organised event an easier place to ask questions than asking at school. Also, some parents seemed to benefit from being present and listening while transition topics were raised and discussed by others.

Well I brought [the school teacher] in so the parents could talk to her and she got picked to bits. The parents just wanted to know. And one thing that came out of it was parents don't feel they can talk to their new entrants teachers. They don't feel like they can ask basic questions. It's the teacher and they know best (centre 1 teacher).

The early childhood centre environment is already familiar, and parents often have comfortable relationships with staff there. This sense of comfort seemed to help parents ask questions, and suggests a role for early childhood staff in supporting the transition to school for parents. The effect on parents of some discourses about teachers and parents' roles will be further discussed in Section 7.3.2.

\subsubsection{Information from the school}

The school itself is an important source of information about transitions and its own practices. All the parents in my study contacted the school several months before their child's fifth birthday, and arranged pre-entry classroom visits, a meeting with the principal, and/or visited the school site outside school hours. Most parents obtained written information packs from schools they were considering and some accessed information from school websites and the Education Review Office website.

\section{Informal strategies - 'seeing for yourself'}

All the parents interviewed commented on the value they found in spending time in the school environment and meeting school staff prior to their child starting school. Seeing the environment and the people there gave parents a sense of what the school was really like and how their family might fit into it.

We take him up every now and then, for a play (Michelle/Mark, interview 1). 
School fairs provide an opportunity for community members to gradually build an impression of a school without committing to a formal visit. James commented on the effect that taking his son to the fairs of the two schools they were considering had on him. He thought it was reasonable to assume that the public face that the school showed during their fair gave a broad estimate of what the school would be like.

The thing that sealed it for me was we went to the school fairs on two consecutive weekends. And Jacob and I went down to this one first, and there was heaps of stuff going on out on the fields, a few stalls, a few games. ... I guess it just kind of reminded me of those laid back school fairs that we had at school. The headmaster was standing there and greeting people and talking to them and handing out flyers, and I thought that was a really nice touch as well.... And then the next weekend we went down to [the other school]. And the first thing you notice is it's all asphalt. There's not grass or anything like that. And you're paying five bucks for a barbecued sausage (Julie/James, interview 1).

One school gave the impression of being welcoming, and triggered pleasant memories from the father's own school days. The other school suffered in comparison. Parents mentioned receiving a 'first impression' of the school, and expected this would be more representative than an arranged visit. For these parents, informal experiences seemed an important complement to more formal ways of getting information from the schools. The opportunity to 'see for yourself' what school was like was also an important component of the arranged pre-entry classroom visits.

\section{Formal strategies - written information}

Three of the four schools provided a comprehensive information pack for parents which was available some weeks or months before their child was due to start school. These packs typically had background material on the school and its culture, the weekly programme for junior classes and practical tips on helping children adapt to school life.

Parents welcomed this information, but noted that it did not always cover the particular things they wanted to know. Michelle commented that she felt she had had little guidance on the appropriate role for herself as the parent of a soon-to-be school child.

The information pack was useful in one sense. It had general information about the school which I did want, so that was good. But it had really nothing on the enrolment process, and what to expect in the weeks before the transition. ... Like, what's the expectation on me as a parent on my child's first day? (Michelle/Mark, interview 1).

The specific areas which each family wanted more information on differed between families. Other parents mentioned they wanted specific information on: 
- $\quad$ how the school communicated with parents;

- how the school handled issues such as bullying;

- how the school welcomed diverse family types;

- what their child would be taught;

- what was meant by jargon words in the daily programme; and

- what the school would do if their child was upset.

\section{Formal strategies - meeting the principal and classroom pre-entry visits}

Four of the families in my study arranged a meeting with the principal of at least one school. This gave them the opportunity to ask questions, and to reflect on how their child might fit in with the school environment.

I knew what I wanted for me personally, and for Ryan's first experience. And visiting the two schools, they both offered totally different things. ... and I think [the school we chose], what they appear to offer seems to cater well for him as an individual (Rebecca/Richard, interview 1).

Pre-entry visits where the parent and child could observe and participate in part of a school day in the classroom, were reported by parents as a highly valuable way to obtain information.

After that visit, I felt - it was funny because it was just small stuff but it was enough to make me feel like, ok, well now I know. After that one visit I understand how it's going to work now. I'd had a chance to ask a few questions as necessary (Michelle/Mark, interview 2).

The four schools offered parents between one and six visits of about one and a half hours duration, with a parent staying with the child for most of each visit. Three schools arranged visits so that parents and children could meet other families who would be starting school soon. The fourth school scheduled visits so only one child was visiting the class at a time.

Four parents commented on the warm relationships they observed between the teacher or principal and children at school. This gave them confidence about the kind of environment their child would experience and that their child would be taken care of if he became upset.

Neisel and Griebel (2007) suggest that a child can only become a 'school child' by having the chance to experience school life. Pre-entry visits are an attempt to provide a bridge between prior-to-school settings and school by 'making the strange familiar' in small doses before the child is required to attend all day. This reflects a sociocultural view that learning drives development so long as the learner has adequate support from a more experienced other (Dockett \& Perry, 2007; Vygotsky, 1978), in this case the presence of their parent. They are an example of what LoCassle-Crouch et al. (2008) refer to as 'high-intensity' transition activities, which reach 
both children and parents prior to the physical move into the new classroom, and which can involve a series of opportunities to become familiar with the setting and acquire information.

Once the children had started school there were regular formal and informal opportunities for parents to get information. All four schools sent home a weekly newsletter and regular notices on a variety of topics from the class teacher, school office or parent committee. One school had a notebook system for daily two-way communication between the teacher and parents. Another school held a parent information evening to discuss how writing was taught in the school, which also provided an opportunity for parents to ask questions about school unrelated to writing.

It's funny that there are simple things that you only learn by going day after day, by the experience of being there. Cause you can't think to ask them in advance (Michelle, focus group).

Most parents also had the opportunity to talk to the teacher at least sometimes before and after school, although there was also the sense of not wanting to add to a busy teacher's workload (see Section 7.3.2). Brooker (2002) comments that an 'open door' policy can mean no formal opportunities are created for parents to talk to the teacher, so access comes to depend on personal skills. For most parents, just being in and out of the school each day provided opportunities to receive and clarify information.

\subsubsection{Worries about school}

During the interviews most parents expressed some worries or concerns about how the school experience would affect their child, and about their own early interactions with that school. For example, two families wondered how their children would cope with a more sedentary learning environment than they had experienced in early childhood. Parents were still learning about how the schools ran, and in some cases these worries were alleviated by receiving more information and by observing how the teacher managed the class in practice. Parents sometimes, but not always, raised their concerns with the schools. Their attempts to do so are discussed further in

\section{Section 7.2.3.}

Five families reported worrying about how the school would ensure the safety of children during the school day, although they were pleased to find that most schools had a process to release children to the correct caregivers after school. Parents noted that, compared with the centre, schools were open to the street enabling children to leave the premises unobserved, and that the playtime and lunch times were minimally supervised. Children would suddenly be expected to manage social interactions independently. 
At crèche he's had a very safe environment ... And you know they're locked in. They can't escape (Rebecca/Richard, interview 1).

While noting they had seldom heard through the media of children wandering from the school grounds, these parents wanted to know more before school entry about how the school planned to ensure children's safety. One family was also concerned that the larger group sizes at school could lead to a less emotionally supportive environment than the centre had been. Bulkeley and Fabian (2006) note that where there was concern by parents about negative effects on their child's emotional well-being brought on by aspects of school routines, these issues might have been resolved more quickly through discussion between the school and parents to raise awareness and find solutions.

\subsubsection{Barriers to obtaining information about school}

Some parents in this study reported difficulties with getting the information they wanted before their child started school. This included not knowing beforehand what information they needed, limited access to school staff, and haphazard or incomplete induction processes.

\section{Delayed pre-entry visits}

At the first interview, four weeks before school entry, three families had not had any school visits and one of these families had also not received any written information from the school. These three families expressed the least satisfaction with their knowledge about school at that time, and each reported anxiety about the transition to school.

I just sort of feel like I'm still [so unaware]. Because I haven't got set dates for visits, or because I don't know who his teacher is. It's probably more my issue than it is Ryan's (Rebecca/Richard, interview 1).

I hated that month beforehand. I hated the transition. And the not knowing, and, you know, just the anticipation. Yeah, I was really stressed (Sarah/Scott, interview 2).

In one school a new new entrants' class was being formed, and the school elected to postpone pre-entry visits until after the new teacher started rather than hold familiarisation visits with another class. This meant that Michelle and Matthew had their sole pre-entry visit the day after Matthew's fifth birthday.

We only had one visit. And it was a completely new class being put together. So, the visit was not a normal classroom lesson. So we had no idea what was going to happen on the next day (Michelle, focus group). 


\section{Discontinuity in visits}

The two new entrant teachers interviewed each reported that they used a series of pre-entry visits to slowly induct children and their parents into the class routines and answer parent questions. Sarah arranged three pre-entry visits in the weeks prior to school entry. However, each visit happened to involve a different teacher, and no teacher was available to talk with her before school or at a break until the third visit.

We had different teachers on every single visit. They've only got one new entrants class but [the teacher is] deputy principal, so she has relievers in quite a bit (Sarah/Scott, interview 2).

Sarah and Scott had received very little written information from this school, and reported being given incomplete and conflicting verbal information about requirements when they spoke with different school staff. The discontinuity in visits made forming a relationship with the teacher difficult, which affected Sarah's ability to gather information about the transition to school. The aspect of forming relationships at school will be discussed further in Section 6.2.3.

\section{Use of jargon}

The schools' use of educational jargon in written information created a barrier for some families. And a lot of it I wasn't aware of. And then you go back to other parents there, and you say 'so what exactly is the story with this? Well how does it exactly work?' (Nicole, interview 2).

While jargon is a useful shorthand for those aware of its meaning, it emphasised to several parents their ignorance of apparently obvious school practices. Parents found out what these words meant in a sometimes haphazard way by asking teachers or other parents after their child started school.

\section{Incomplete induction processes}

Two families commented on their schools' general approach to the induction process and parents' need for information prior to starting school. Mark had gathered from talking to friends and neighbours that working with limited information was a fairly normal experience for parents prior to school entry.

Most of that information I've got from our friends who've got children twelve to eighteen months older. And their experience has sort of universally been they just have to go along and play it by ear. ... And I think the issue isn't so much for you, we're grown-ups, we can handle it. We're used to having things a lot more vague than that in our lives. But, it's nice to be able to prepare your children for [starting school]. Cause inevitably you're going to get some questions, what's going to happen. Are you going to be allowed to stay. And you have to fill in all these gaps. And you cross 
your fingers and hope you get it right (Michelle/Mark, interview 1).

It's all a bit mysterious because [the school] are continually coming into contact with new parents, new children, who won't know [anything]. So how is the knowledge imparted? There must be a simpler process to do it than just trial and error (Sarah/Scott, interview 2).

For parents, having an oldest child start school is often a new endeavour with new roles and expectations to learn, and relationships to form (Brooker, 2002; Dockett \& Perry, 2007; Niesel \& Griebel, 2007). However, inducting new families is a routine practice for the school, and these parents were surprised that difficulties with the process had not been resolved. Parents wanted to be able to prepare their child for school by talking with him about the people and activities there (see Section 6.3.1). Lack of information, as well as adding to their own uncertainty about the transition, limited their ability to support their child's transition. Some parents made an effort to give feedback to their centre or school about what information or practices would have helped them with the transition of their child. This is discussed in Section 7.2.3.

\subsection{Parents' understanding of the transition to school}

In the period leading up to their child starting school the parents in my study combined their experience and understanding of transitions with the information obtained in order to construct knowledge of the transition to school. In doing this they reflected on their own memories of starting school, their observations of their child in different settings, and their theories about human development and education. They drew on this thinking to develop strategies to support their child's transition. Specific parent strategies to support their child's transition will be discussed further in Section 6.3.1.

\subsubsection{Memories of school}

One of the ways that parents understand school is by reflecting on their own experience of the school system (Barnett \& Taylor, 2009; Dockett \& Perry, 1999). Of the eleven parents interviewed, nine described at least one strong lingering impression of their own first days at primary school. These memories arose in conversation about how they assessed aspects of the schools they were considering for their child, or thought about how to help their child settle at school.

Four parents expressed generally positive memories of the school environment and activities.

I went to a rural school when I first started and we used to have, it was called calf club day. You could bring your pet calves or your sheep, as well as having little competitions and stuff like that. I remember making a replica of this Humpty Dumpty toy that I had, out of vegetables, and I got a 
highly commended for it (Julie/James, interview 1).

I do remember though having to do these, the early writing and having to do these spiral circles and that sort of has stuck in my mind. Rows and rows and rows of spirals (Nicole, interview 1).

Rebecca remembered clearly the three friends she had at school entry, but also remembered feeling completely overwhelmed by the experience of being introduced to school.

That was my first experience going to the school, looking around the school, and then being introduced, this is my teacher, and this is my classroom, and it was all totally overwhelming (Rebecca/Richard, interview 1).

Three mothers' strongest memory of starting school was the impression of teacher unkindness or injustice either to themselves or their classmates. Sarah recalled puzzling for years over the different treatment received by boys and girls at her school. She remembered that she and her girl friend were not punished for arriving late to school, but that the boys were.

They got punished for it. And we were kind of like, 'why are we never punished?' I remember thinking, isn't that strange. And noticing even early on, that boys were treated different to girls (Sarah/Scott, interview 1).

It was notable that these parents often recalled the strong feelings associated with a childhood school event. Memories seemed to have a bearing on what parents sought in a school in cases where they had a choice, or what information they tried to obtain. For example, the way James interpreted his first impressions from the school fairs of the two schools they were considering was influenced by his positive memories of the tone of his own school experience (see Section 5.2.2). Sarah's anxiety prior to Sean starting school may have been exacerbated by her difficulty obtaining information coupled with her memory of how boys were treated at her own school.

Dockett and Perry (1999) comment that if memories of school are negative, a parent may find engaging with school institutions as an adult more challenging. Barnett and Taylor (2009) found there was also a connection between parents' memories of schooling and their experience as parents of a new entrant. Parents with more memories of their own parents' positive involvement with school engaged in more transition activities with their child.

\subsubsection{Parent theories of development and transition}

While talking about the transition to school each of the families in my study mentioned some beliefs they held about how children develop and about learning. These comments arose as the parents considered what they had been looking for in choosing a school for their child and how they helped their child adapt to school. 


\section{'Getting their feet muddy'}

Three families commented on physical activity and the advantages of a 'natural' physical environment for children, with access to trees and fields. They perceived being physically active and 'getting their feet muddy' as an important part of childhood.

Julie: $\quad$ The environment's important for us. That, rural environment,

James: Yeah,

Julie: $\quad$ just a lot of grass, and, close to nature.

James: Where kids can be kids.

Julie: $\quad$ And kids can run and play, yeah, and get their feet muddy (Julie/James, interview 1).

Each of the centres allowed children reasonable choice about their level of physical activity and access to outdoor spaces. Parents expected that school culture would involve more sedentary activities, and several parents wondered whether their children might find this challenging to adapt to. These beliefs about what children need and awareness of their child's preferred activity level influenced which schools parents preferred and had implications for the strategies parents used to help their child settle at school (see Section 6.3.1).

\section{'A milestone'}

Most parents in my study commented that starting school was a significant milestone for their child, their family, and within the community. New Zealand has a strong culture of starting school on or soon after a child's fifth birthday, although school enrolment is not compulsory until age six. Children see their older peers leaving the centre to 'go to school' and know this will happen when they turn five.

I think that kind of 'passage' stuff happens when the people they know move on. So every time we have a poroporoaki or something at playcentre that there were farewells for children leaving and then your child became the big kid....they knew that this was happening (Amanda, focus group).

In the focus group the parents agreed that relatives and neighbours constantly reinforced the expectation, to both parents and children, that starting school at age five is 'normal'. Children also became aware during their fifth year that they would take on a new position as a school child and engaged in pretend play of school life. Sarah described her son rehearsing the new roles he and his sister would have in the family:

He was saying before he went to school, 'Dad will go off to work, and I'll be going to school. Sophia, you'll have to stay here. You'll be staying here with Mum' (Sarah, focus group).

Two families commented that this social expectation amounted to a 'cultural imperative' which 
partially constrained their decision about when their child should start school. They had considered delaying school entry for several months, but decided against this as they felt it might disadvantage their child socially in some way.

\section{'A big change'}

Five of the families noted that moving from the centre to school was a dramatic change, which involved discontinuities in a number of different areas:

- A different physical setting with new rules and routines;

- Extra daily transitions between school and after school care arrangements;

- Large numbers of children at school and reduced adult supervision levels, implying increased social independence;

- Curriculum and programme activities in sharp contrast to those at the ECE centre;

- A possible reduction in parent involvement during much of the day.

So it's such a big step now, that's what it is. It's wow. Little to big (Rebecca/Richard, interview 1).

Where the transition to school coincided with other family events, such as moving house or travelling, this was viewed as an extra stress for the child to adjust to.

Several parents referred to the importance of predictability for their children and having enough information to talk to their child beforehand about what to expect.

Cause I think, you know it is a massive step into the unknown for him, even more so than for us, and I don't want it, I don't want to make it any more nerve wracking for him than it needs to be (Michelle/Mark, interview 1).

Parents expected their child to adjust over a period of time and monitored this adjustment after school entry, watching for signs of tiredness. They theorised that he would adjust more easily if some changes could be staggered, such as delaying the start of group after-school care.

\section{'Ready for school'}

The discourse of 'readiness' arose in each family's talk, both in looking back at the ECE centre experience and looking forward to what they expected school to provide. Three fathers believed that their children had outgrown the centre and were in need of a more stimulating learning environment, which they anticipated would occur at school.

And [the centre's] not extending him any more. Hasn't been for a while (Sarah/Scott, interview 1).

I just think he's ready for it. He's done all he can do at [the centre]. He's ready to move on and he's ready for some new challenges (Julie/James, interview 1). 
The most frequent use of the concept of 'readiness' by parents was in commenting that their child was ready for new academic challenges. Parents described their children's increased interest in writing letters or names at home and in exploring numbers and addition. Several parents commented that their child was 'desperate' to learn to read. The parents expressed excitement and pleasure in their children's eagerness for this new learning.

He's really getting into numbers and writing. He's writing letters all over the place, trying to write his friends names, and he recognises letters and spells them (Rebecca/Richard, interview 1).

Nicole particularly emphasised her son's awareness of the social side of starting school and his pride in becoming five and starting school. He was very aware of his place among his peers moving to school.

You know like, the emotional side of it, it's the whole, 'oh no but I'm going to school before so-andso because I'm five before them' (Nicole, interview 1).

'Readiness' appears as a common theme in literature about the transition to school (Fosnot \& Perry, 2004; Hair et al., 2006), although the usefulness of this theoretical construct has been challenged by some authors as being too restrictive (Doucet \& Tudge, 2007; Rimm-Kaufman \& Pianta, 2000; Scott-Little et al., 2006; Snow, 2007). In the literature, readiness is linked with maturation and commonly refers to the ways that adults assess a child to gauge their chance of success in the school environment. It is often a combination of the child showing certain skills such as independence in personal care, social ability, and cognitive and language knowledge and ability (Blair et al., 2007; Dockett \& Perry, 2007; Hair et al., 2006; Scott-Little et al., 2006). The development of the child at a point in time can theoretically be measured against some ideal, and children may be coached in the skills they are deemed to need.

The meaning that parents in my study had for the concept 'ready for school' appeared quite different from the meanings in the literature. My impression from the parents' talk was that they saw starting school as a doorway into a wider world which would provide their children with both opportunities and challenges. They had observed their child's development and noted with some pride that he was showing an interest in the new challenges ahead. Parent theories of readiness, developed from watching their child respond to routine and new situations in the past, gave them confidence their child would also meet the new challenges of starting school.

\subsection{Chapter summary}

In this chapter I have reported how the parents in my study learned about school and reflected on this information in order to support their child's transition. Parents gained information through 
formal and informal means, in settings prior to contact with the school, and from the school itself.

'Seeing for yourself', through meetings with school staff, and especially visits to the classroom prior to school entry, was particularly important in helping parents anticipate their child's transition and in obtaining initial or follow-up information. Parents also learned about school by reflecting on their own memories of school and by filtering information through the theories of development and transition they held. These theories assisted parents in deciding what was important for them in a school, and suggested things to be aware of during their child's transition to school.

In Chapter Six I will report on the experience of these parents in forming relationships within the school community, helping their child to settle in to school, and of adapting their home life and personal routines to accommodate the requirements of being a school parent. The relationships which parents had in the school community also impacted on their ability to access information and ask supplementary questions. 


\section{Becoming a school parent - settling in to school}

\subsection{Introduction}

This chapter presents findings focusing on the second research sub-question: what affects the relationships between parents and other people at school? This is part of the overarching question: what is it like for parents during the transition of their oldest child from early childhood settings to school.

The chapter is divided into three sections: the school as a community, settling your child into school, and the adaptations parents make to accommodate school routines. When asking parents about forming relationships with people at school their answers indicated they viewed school as a community of people they wished their child, and themselves, to come to belong to. Establishing this sense of belonging included becoming familiar with the routines of school, and seeing their child become comfortable with school people and settle into routines. These adaptations for parents and children occurred over a period of some weeks before and after school entry, and were interconnected.

\subsection{The school as a community}

While education, in common discourse, is sometimes thought of as an individual's acquisition of knowledge and skills (Gordon, 1982; Tolley, 2011), other writers view it as dependent on social structures and relationships and cultural knowledge (Claxton, 2008; Neyland, 2010; Noddings, 1992; Postman, 1996). The parents in my study expressed strong connections between school and participating in a community. They saw education as firmly embedded in a wider network of relationships, friendships and potential rivalries or enmity, within a set of shared social practices. Building relationships required that parents and children come to feel a sense of the school community and their place in it. This section looks at these parents' developing sense of community and some of the factors that enabled and constrained this.

\subsubsection{Feeling a sense of belonging}

The parents in my study wanted to feel that they and their families belonged in the school community, rather than just being 'users' of an education service. Building relationships and feeling like you belong takes time and intention. Some parents anticipated spending time during the school day helping, or after school interacting with other children and parents, in order to be known at school and create this sense of belonging. 
I think I'll be down there making the burgers on Fridays. You know, doing those things. ... And those things I think make you become a presence in the school and people know who you are, and other kids. And I want to know that stuff (Amanda/Angela, interview 2).

Julie anticipated that she would want to collect her son after school, so had arranged her work hours to accommodate this. She saw her community connections as revolving around her son and his friends, and "making sure his friends are welcome around here" (Julie/James, interview 1).

Michelle reported being taken by surprise by her desire to feel connected with the school and participate in the social activities which occurred around the edges of the school day.

I work four days a week. I didn't expect to feel like I was missing out by not being there for drop offs and pick ups. But I do. I feel like I want to be part of his school day much more than I ever felt like I wanted to be part of his crèche day (Michelle, focus group).

She speculated that this sense of wanting to be involved in school life related to her deep belief in the importance of school education. Her son's teacher welcomed parent help in the classroom and Michelle found helping with the writing programme one part-morning per week gave her the sense of connection that she wanted.

Te Whāriki (Ministry of Education, 1996) characterises belonging as "a secure and safe place where each member is entitled to respect and to the best of care. The feeling of belonging ... contributes to inner well-being, security and identity" (p. 54). A feeling of personal well-being and belonging, which has both social-emotional and academic aspects, is one indication of a child's successful transition to school (Brostrom, 2002; Bulkeley \& Fabian, 2006). These parents seemed to agree with this indication, and also applied it to themselves. They mentioned being known, respected and included, and feeling that they were connected with other adults and children at school as indicating their own developing sense of belonging.

\subsubsection{A local school}

All the families in my study stressed in some way the desirability of attending a school in their local neighbourhood, and some families only considered schools which were close to their homes. 'Localness' was seen as offering several advantages. If a school was close to home parents expected that their children would one day be able to walk to school or to friends' houses by themselves. James remembered having this independence and wanted it for his own son.

I preferred a school where when Jacob feels old enough and confident enough he can walk to school himself if he wants to. ... Cause I used to walk to school when I was a kid with my sister (Julie/James, interview 1). 
Attending a local school also offered the opportunity to develop relationships with children from a variety of backgrounds. This social mixing was given a high priority by two families who were prepared to balance a school's academic reputation with this factor.

We did look at the ERO report. Which wasn't so great. [But] we ignored that because having him in school in our local community was of more value than what seemed to be slightly, ah, iffy academic interest (Sarah/Scott, interview 1).

Two families identified their 'community' primarily as the community of families at the playcentre and tried first to enrol their child at the school where most children from that centre went. However, both families were out of zone for that school. In the end Nicole decided to form new relationships at a school near her home, and Amanda and Angela moved house to be in zone for the desired school because of the importance they placed on keeping continuity of relationships.

That was another thing that was really important to me, and I didn't realise that was really important until Alex and I were at the swimming pool one day. And the [school] kids were there on their school visit to the pool. And one of the siblings of Alex's friend came over, and she said 'oh Alex, come on, I'll look after you.' And I just felt another level of relief and of tiers of people knowing somebody (Amanda/Angela, interview 1).

Amanda noted how important being part of a wider established network was for her, and contrasted this with her own experience of moving school frequently as a child, an experience which she did not want for her son.

Parents saw the advantage to developing relationships of attending school near their home. Maintaining existing relationships was sometimes a competing value, which necessitated tradeoffs. Section 7.2.1 discusses further these parents' decision making process in choosing a school, and Table 7.1 (page 80) summarises the process for each family.

\subsubsection{Factors which support forming relationships}

Parents described, and appreciated, ways in which school practices or staff encouraged relationships among children or parents at school. They also noted how other children and the community of parents supported a developing sense of belonging. Forming friendships helped their child settle into the school environment, and forming relationships helped them to learn about school practices, feel comfortable in the school community and help their child to settle.

Three of the four schools had a practice of organising pre-entry visits with new families attending on the same days. Pre-entry visits were discussed in Section 5.2.2. This practice 
allowed new children and parents to meet each other prior to school entry. The five families who transitioned to these schools all spoke positively about having the opportunity to get to know another family who would be starting school at about the same time as their child.

The day that Jacob had his first visit there was another boy visiting, and we met both of his mothers, and they just live down the road, we found out. So, that's quite handy. We exchanged phone numbers (Julie/James, interview 1).

Several parents commented on a teacher or principal who made a particular effort to create connections between people at school, for example by linking a new entrant with older child buddies, or by helping parents make connections with other families their child seemed friendly with. These interactions were important because not all parents were able to collect their child from school due to other commitments.

Those parents who were able to attend junior or whole-school assemblies reported that these events helped them feel their family was joining a larger community.

Always on a Friday is assembly. And whānau are all welcome. ... It was fabulous. It's a place where you actually get to have conversations with parents as well. So I arrived early and I sat with a group of parents that I didn't know. It was really nice actually. And they were all cheering on other people's kids (Amanda/Angela, interview 2).

Other children at school, including those several years older than the new entrants, could also help the new family feel a sense of belonging. Several parents commented on the friendly relationships evident in the interactions between children in the playground, including helping the new children, talking to new parents after school about what their child had been doing, and calling out in the playground to invite the new entrants to join in play.

In the morning we'll often stop off to play at the playground or they're playing tag, and they're like 'oh Noah come join us, come play tag'. And again, I think they're from one of the older classes. But immediately it was like this whole camaraderie, 'oh come, we're playing tag, come play' (Nicole, interview 2).

Interactions like these gave parents the sense that the community of children at school was 'opening up' to include their child, and that their child was settling into school.

Several parents noted the other parents at school who created a supportive community which offered them practical and emotional help. Rebecca knew there were other parents she could count on if needed, for example if she was delayed after school, and thought this support was especially important for a 'working mum'. 
And I know that I've got good supportive friends that I can call upon and say hey can you pick up Ryan. That's been the big thing for me (Rebecca/Richard, interview 1).

Parents also mentioned some expectation that once their own child was settled they would be able to help new parents that started afterwards.

Rimm-Kaufmann and Pianta (2005) comment on the importance of individual teacher actions and school practices in supporting positive family-school relationships. They note that effective and frequent communication enables a positive family-school relationship to form, and that actions of individual teachers are important in enabling this communication. The actions reported which teachers or schools took to support the development of relationships included: arranging pre-entry visits where new families attended on the same days; linking a new child with a buddy; inviting parents to attend assemblies; and teachers who made connections between families. In addition, other children and parents at school who were friendly and communicative helped parents form relationships.

Some schools promote a 'buddy system' where older experienced students are paired with new entrants to help them adjust to school. Dockett and Perry (2005) report on a project which involved training the older buddies and evaluating the buddy programme during the school year. They found that the programme helped to establish positive relationships across the school and the new entrants to feel safe in the school and playground.

\subsubsection{Barriers to forming relationships at school}

All the parents in my study wished to develop a sense of belonging in the school community and relationships with people there, and had ideas about how they might do this. Sometimes circumstances made this difficult. Sarah had hoped to meet the parent of the other boy she knew was soon starting at her son's school, and organise a 'play date' before school entry.

I also thought I'd quite like to find out who that other person is who's starting and see if we can get a play date going or something beforehand. Just so there's one familiar face (Sarah/Scott, interview 1).

However this school discouraged families from attending pre-entry visits at the same time, which limited opportunities to meet and form relationships prior to school entry.

Parents in this study generally believed that having their child at an ECE centre with other children who will attend the same school was an advantage, and Sarah reflected in the focus group that moving her child to a different centre in the months before school entry may have helped with his transition. Writers in New Zealand are mixed in their view of this belief. With 
New Zealand's policy of continuous entry to primary school, Ledger, Smith and Rich (2000) note that children with friends in kindergarten transitioning to the same school do not make an easier transition, because a gap of several weeks is long enough to disrupt existing friendships. Instead, it is the parents that are key to children maintaining friendships and in allowing new friendships to flourish by providing opportunities for children to spend time together.

Parent beliefs about the respective role of teachers and parents, and the way they perceived interactions with school staff, could be a barrier to forming relationships. Four parents mentioned feeling inhibited or shy in approaching the teacher or asking questions. This was either because they had observed the teacher to be very busy and hesitated to add to her workload, or because they had been given the impression on previous approaches that their questions were a nuisance. This tendency was also noted by centre staff members (see Section 5.2.1), and is discussed further in Section 7.3.1.

Parents in this study mentioned relationships with people within the microsystems of home, centre and school as impacting on their or their child's transition to school. Overlaps in membership between these three microsystems helped parents and children to develop relationships in the new setting. Figure 6.1 summarises the people mentioned by parents and the microsystems they belonged to.

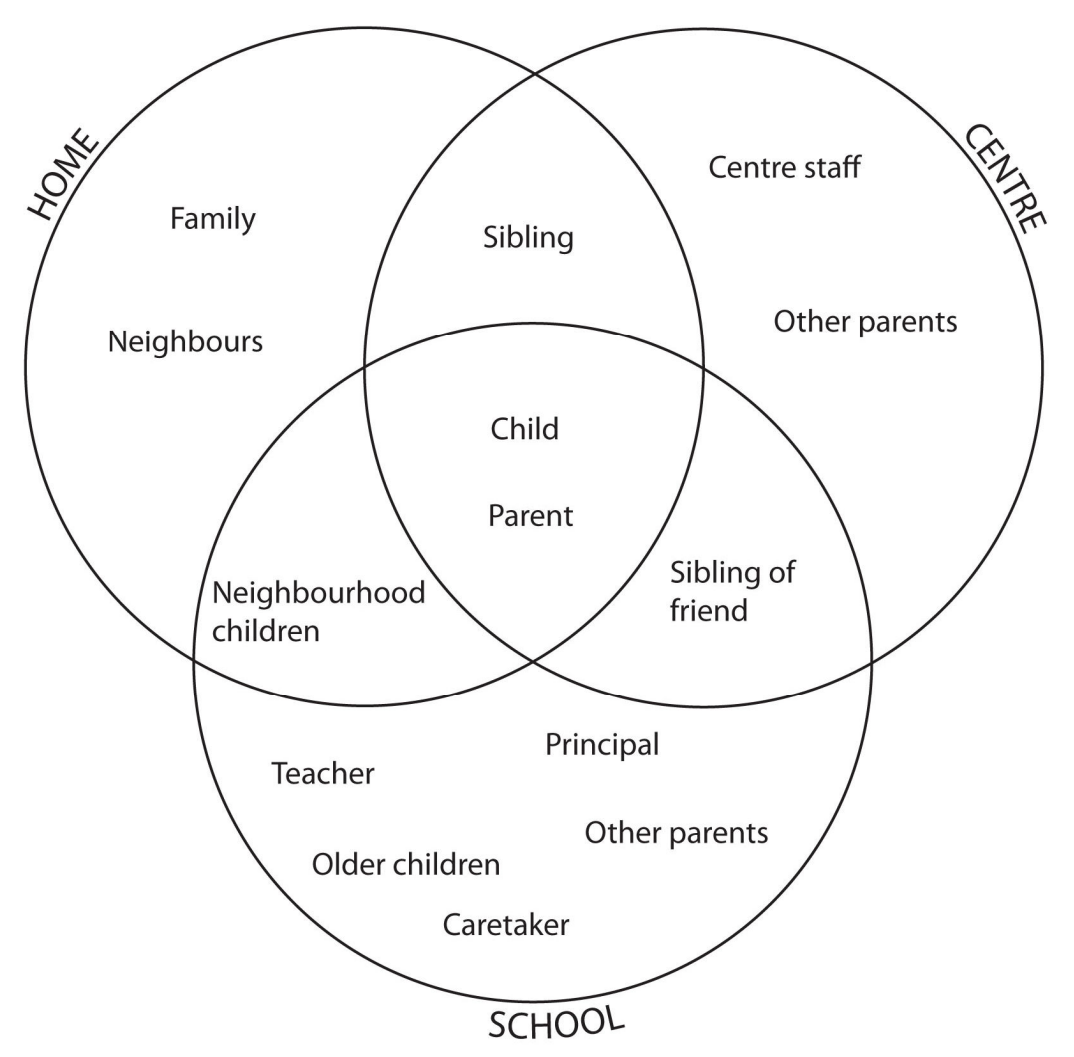

Figure 6.1 Summary of relationships which impacted on transition to school 


\subsection{The settling in process}

Four of the six families in my study considered more than one school before making a final decision. This choice process is discussed further in Section 7.2.1. Once the parents had decided on a school their focus turned to helping their child settle in at that school. To do this they drew on their knowledge of their child and of the school, and their theories of transitions and child development. The following sections discuss the strategies that parents in my study employed to help their child settle, and how they recognised that their child was settling into school.

\subsubsection{Parent strategies to help their child settle}

In the weeks and months leading up to school entry parents developed and implemented a variety of strategies to help their child with the transition to school. No school was considered perfect and each choice involved some compromise which parents sought to mitigate for their child.

\section{Becoming familiar with the school environment}

The parents in this study assumed that children would cope better with a new situation they were familiar with. To support this, each of the families attended between one and five pre-entry school visits in the classroom prior to school entry. As well as this four parents commented on other ways they helped their child become familiar with the school environment, such as visiting the school office or playground, or visits by the ECE centre.

Mark: We take him up every now and then, for a play.

Michelle: And he's been to the dental clinic there (Michelle/Mark, interview 1).

Julie and James particularly discussed their son's personality, noting that he needed time to observe and get used to a new situation before becoming involved.

And just the more time he does, the better he is ... And that's pretty much him. He'll just sit back and suss everything out and then, when he's ready, off he goes (Julie/James, interview 1).

They were pleased that the school encouraged a series of visits which enabled Jacob to become familiar at his own pace. They also provided other opportunities outside school visits for this to occur. Developing familiarity with the school environment is mentioned frequently in literature as a way to support children and parents with the transition to school (Brostrom, 2007; Dockett \& Perry, 2007; Hartley et al., 2010; Ledger, 2000; Peters, 2004).

\section{'Easing him in'}

Several parents theorised that starting school would be 'a big change' for their child (see Section 
5.3.2) and if there was any way they could make the transition more gradual, he would find it easier. One child attended school for shortened days for the first three weeks. Julie and Nicole rearranged their work hours so they could collect their sons each day, and to provide a relaxed after-school environment. Families with paid work commitments outside of school hours talked about not wanting to enrol their child in group after-school care for at least the first few months.

I'm thinking, how can you continue working but not put your child in after school care and holiday programmes right throughout the year because I don't want to do that right now. I want him to get really settled into school and feel really familiar about that before introducing other new things really (Rebecca/Richard, interview 1).

Rebecca and Michelle shared care between both parents and with neighbours or relatives. The families planned to review these arrangements as their children got older, taking into account how their children were handling the new demands of school.

\section{Talking with their child about school}

Parents discussed talking with their child about who his teacher would be, the other children who would be at school, and the expected routines and activities. Sometimes neighbours and wider family members were included in these discussions.

We were [at school] at three o'clock one day when all the kids came out, and Ethan, who's our neighbour, came out of his classroom. And I said, you know, that's Ethan's classroom, and so we had a bit of a conversation about that (Michelle/Mark, interview 1).

Griebel and Niesel (2002) describe co-construction of the transition to school and explain that parents and children do this through talking about their expectations, hopes and fears. However, three families commented that they lacked current knowledge or experience with this school to confidently talk with their child and answer his questions. Families who had had many contact points with the school, such as several visits over a period of weeks, a meeting with the principal and an information pack, reported being more likely to feel they had sufficient information to prepare their child in this way. Figure 4.1 summarised the contact points each family had with the school they chose prior to school entry.

\section{Providing the school with information about their child}

None of the four schools asked the parents for any information about the children prior to school entry apart from contact and health information. Nor did they ask for, or receive, any information from the ECE centres. Four weeks prior to her son starting school Sarah had not yet met the 
teacher, but planned the information she wanted to share which she thought would help support his transition to school.

I will say that it would be nice if he had a buddy or something, or someone's kind of looking out for him at the beginning. And I'll also say that he is the kind of kid who will want to know what the rules are. So that he won't break them. Because he gets really worried if he thinks he's breaking a rule (Sarah/Scott, interview 1).

Once their children were at school all the parents in my study said they had more opportunity to share information with the teachers, using formal communication methods initiated by the school, such as a post-entry interview, and informal methods, such as after-school chats.

\section{Providing food for school}

The parents in my study knew that their child would need adequate food and drink to successfully manage the school day. All families provided a packed lunch, and many noticed in the first weeks that their children ate little during the school day, and arrived home tired and hungry. They reasoned this was because their children were distracted by talk or play at lunchtime, and tried out different plans to help their child eat enough during the day.

They're busy talking and the moment the bell goes, immediately, slam goes the lunchbox. And run and put it inside and off you go (Nicole, focus group).

Each school seemed to have a practice of seating the children for the first ten minutes of lunch time before they were allowed to play. Richard mentioned his concern to his son's teacher in the hope that she would monitor the situation.

He's not eating at all. And we know why. He just wants to go and play. So, I picked him up last Friday and I mentioned it to the teacher about it. She was going to monitor it (Rebecca/Richard, interview 2).

During the second interviews and focus group these parents talked about the practical strategies around food which they had learned from other parents or from experience, or which they would recommend to new parents. Strategies included making sure children had a large breakfast, asking other parents for successful lunch box ideas, and telling children specifically what to eat at morning tea and at lunch time.

Providing food seemed to be a powerful symbol for these families of caring for their child, and achieving workable strategies around food took some trial and error. Most parents noted they were pleased their children had access to their water bottle at any time during the day. 


\section{Protect from parent's own stress}

The parents in my study believed that the way they talked about school, both positive and negative, set the tone for how their child would approach the transition. They reported feeling both enjoyment and anxiety about different aspects of their child starting school, but made a point of being cheerful about school whatever their own feelings. Michelle described how she had talked with her son very enthusiastically about school some months before school entry, but had then consciously moderated her approach.

A couple of months ago we were talking about it a lot and I deliberately eased back on that stuff because I didn't want to build it up to be this huge, fearful thing. For Matthew (Michelle/Mark, interview 1).

Where parents felt particularly stressed about the transition, they actively tried to shield their child from their stress. Four parents reported being anxious and even tearful in private but doing their best to keep this from their child.

But that stress, and not being able to show the stress. Every time I had to go "oh it's going to be so great" and I'm thinking 'oh god, what are you going to do to him? They're going to mess him up. Oh it's going to be awful (Sarah, focus group).

Some writers have noted parent concern that their own anxiety might affect their children's transition (Peters, 1998; Sanagavarapu, 2010). Some of the ways that parents in my study protected their child from their stress included arranging an initial meeting with the principal without their child present, only discussing their concerns out of sight and hearing of their child, and ensuring they always spoke cheerfully about school. By being self-reflective of their own feelings, these parents attempted to meet their own needs and manage their child's feelings around the transition to school. Parent feelings are discussed further in Section 7.3.1.

\subsubsection{Recognising your child is settling at school}

The parents in this study seemed to intuitively understand 'settling in' as a process during which their child was learning about the school and becoming a comfortable participant in school life. They took it as a positive sign that their child was settling successfully when he was keen to go to school, engaged confidently with school activities and practices, and seemed comfortable with other children.

Parents talked about the social side of their children settling into the school community and routines. School playgrounds are relatively unsupervised compared to ECE centre playgrounds, and include a much greater number of children. Several parents wondered before school entry 
whether their child would cope in those conditions and wanted to know how the school would ensure their child's safety (see Section 5.2.3). During the weeks before and after school entry parents observed their child in the playground, and noticed as his level of comfort there grew.

Probably [for] about the first week it was I'd run around with him until the teacher turned up. Then for the second week it was until the bell rang. Now it's pretty much he's comfortable doing his own thing. And sending me off on my way (Sarah/Scott, interview 2).

One of the ways that I was gauging how he was settling in was when the couple of days that I dropped him at school and he'd see someone that he knew and he'd call out their name and wave to them. And I hadn't necessarily met that kid before or seen them in the class. And I thought that was really cool. That he was obviously feeling really confident (Julie/James, interview 2).

If their child appeared to feel comfortable in the playground and talked about playing with several different children, parents understood this as indicating he was settling into the social environment. Some writers have suggested the transition process may be considered complete and a child 'settled' when he experiences a sense of well-being in the new environment (Dunlop, 2007; Everiss, 2010; Fthenakis, 1998; Mirkhil, 2010b). Parents used their observations of their child to make a judgement on whether their, or the teacher's, strategies were resulting in the child being happy at school. They watched their child and adjusted strategies, for example, by allowing more time in the morning to arrive at school early.

\subsubsection{Difficulties with settling}

Five of the six families reported their children having some difficulties settling into school in their first few weeks. Of these three families reported minor issues with tiredness, encountering meanness of other children or not wishing to join in with group after school childcare. On balance these minor issues seemed to be greatly outweighed by the child's interest and engagement with school during those weeks.

For two families the difficulties their children experienced were more pervasive and coloured the transition period for both parents and child. Ryan was particularly upset each day on being left at school. By week four, and following some changes to settling strategies (see Section 6.4.1), he was much happier about attending school. As previously mentioned, in week three, Amanda discovered that her son had been subject to two weeks of playground bullying. Staff had been unaware of it, but dealt with the situation swiftly once it was discovered.

During that time he would say 'please come and get me at morning tea time'. And initially I didn't, I just thought that was a time in his head. But that must have been when things sort of started to go wrong. At morning tea (Amanda/Angela, interview 2). 
Amanda was distressed at her inability to correctly interpret Alex's pleas to stay home or be collected at lunchtime.

\section{Unusual tiredness or aggression}

It is a common expectation among parents that children are likely to be unusually tired while they adapt to school routines (Dockett \& Perry, 2007; Renwick, 1997) and most parents in my study referred to this. Parents planned strategies to counter tiredness, including trying to make after school and the weekends particularly relaxing times and being prepared to give their child a day at home if they appeared to need this.

I'm not going to be working afternoons. It means I'll pick him up from school and then I will actually have time for him when he comes home from school. You speak to other parents and hear how exhausted kids are often when they start school (Nicole, interview 1).

As it turned out, unusual tiredness affected two children in my study in the period up to the focus group. However, three families also commented that they were pleasantly surprised that this was not an issue for their child.

In contrast, unusually aggressive behaviour, such as kicking and throwing chairs, was not expected by these parents and was reported with surprise by three families in the weeks following school entry. Bulkeley and Fabian (2006) note that the reduced emotional well-being experienced by some children during transitions can cause stress, which can lead to aggression or withdrawal. These mothers attempted to use the behaviour management technique of putting their child in his room for 'time out', but commented on being confronted by their children's increased strength.

A maturational view of transition can suggest that if a child is slow to settle into school it is the child at fault (Kienig, 2002); possibly the child was not sufficiently 'ready' for school. However, Dockett and Perry (2007b) are concerned that this assumption of the 'child readiness' view implies that the person who has the least life experience should be the one who is expected to change the most during any transition. An alternative view is that the transition to school is coconstructed by many people working together, including school staff, parents, centre staff, child, and wider family and community members (Fabian, 2007; Hartly et al., 2010; Johansson, 2007). It is unlikely that every child will have a similar transition, and the goal for all parties is to ensure each child receives the support for beginning school that will most help them.

\section{'Toughen up'}

After the parents had done their best to make arrangements which they thought would suit their 
child, and perhaps modify standard arrangements where possible, there were still some adjustments to school which the child was unhappy with. In the end, parents had a sense of wry acceptance that not everything in life could be perfect. This was a pragmatic acceptance that, having started school, the parents were not able to control all aspects of their child's experience there. They realised that some things he had to learn to deal with even if he did not want to.

Towards the end of the term he was like 'I don't want to go'. His dad was like, 'well, you know, it's one day a week, so suck it up. You've just going to have to have one day a week that you don't like after school (Michelle, focus group).

This might be an uncomfortable experience for the child. It was also an uncomfortable experience for the parent, watching their child unhappy and sometimes upset.

During the focus group several parents reflected that learning to handle things you do not like was a necessary part of growing up, and were delighted when their child ultimately extended his ability to cope in the new situation. Julie commented on what she initially thought was a callous attitude by the teacher in expecting Jacob to be involved in the school production after only a few weeks at school. She realised afterwards that her son was robust and could rise to the challenge presented.

That's what the teacher said to me about the school production. There are just some times you've got to say to them, you've just got to do it. And I was quite affronted about the teacher saying that to me. ... And then, I'm really glad she did. Because it was a huge milestone for Jacob to do that (Julie, focus group).

These parents did what they could to help their child adapt to a new role as a school child, and were also having to accept a new role as a school parent; someone who does not have as much control of their child's daily situation as they may have in the past. During the focus group, parents agreed that children are resilient, and that small set-backs need not have long-term negative effects.

\subsection{Parent adaptations to school life}

As well as learning about school and helping their child settle in and be ready to participate, having a child start school requires parents to make changes to their home and work schedules and adjust personally to accommodate the requirements of each setting. This section discusses how the parents in this study adapted their family routines to fit in with the requirements of school, changes in the way they experienced the flow of time across the day and week, and the influence of the wider context on their experience of the transition. This section relates strongly 
to the third sub-question, the factors which affect parents' development of their identity as a school parent, and could have been included in Chapter Seven. It is included in this chapter because the relationships parents developed were important in the ways they adapted their family routines, and because of the interrelated effects of parents' and children's transitions.

\subsubsection{Developing new family routines}

Parents anticipated that having a child start school would require changes in their home life and care of children outside school hours, and that these changes would affect everyone in the family. They discussed their expectations in the first interview, and reviewed the changes they had made in the second interview and focus group.

\section{Morning organisation}

Three families anticipated they would need to be more organised in the morning, and two families talked about organising each parent's time differently with more specific roles in order to get everyone ready for their day. Rebecca experimented with the morning routine and found that by leaving home earlier she could help her son get settled for the day and still get to work on time.

Week three, again he found that quite hard. So we made an effort to get to school earlier. Have a look at his books. Talk. Do his routine of putting his bottle away, then maybe reading a story. And then I can leave, so I can get to work in time. And he's settled. So it's not such a [rush] (Rebecca/Richard, interview 2).

Each of the families with two children had previously taken both children to the same centre in the morning. They now needed to plan for an extra drop off at a different place each day, and with a more prescribed start time. One way that families managed was by taking turns leaving early for work while the other parent organised the children to school and centre. This had the unexpected benefit for Julie that she had extra relaxed time to spend with her children on those mornings.

Whereas on the day that I get to drop them off I lie in bed, and we read books, and it's great. I spend time with them in the morning which I'm not used to doing (Julie/James, interview 2).

\section{After school pick ups}

Working out the logistics of after school pick ups required careful planning for several families. Four of the six families in my study arranged their schedules so a parent could collect their child from school every day. The other two families talked about the complicated schedule for drop offs and after school collections which they had organised. Compared to the convenience of the 
centre, with its full day hours, scheduling after school care was a significant stress for them.

Michelle: Although it is going to be quite a logistical,

Mark: It's actually been the most stressful thing about the whole,

Michelle: It's quite convenient you know that crèche is eight till five. We've sort of organised our lives around that three days a week (Michelle/Mark, interview 1).

While avoiding group after school care was valued, it was not simple to arrange. Parents talked about the need to buy another car seat if they were sharing after school care with another family and remembering to advise the teacher each morning on who was collecting the child after school.

\section{School holiday care}

At the time of the focus group arranging care for the children during school holidays, especially the long summer holidays, was an unresolved issue for four families.

Michelle: And then you've also got holidays. Which are crazy. I'm in denial about the summer holidays.

Julie: I know, it's like, what am I going to do? I guess that's as a working parent, with both of us working. But summer holidays, it's this huge chunk. Work for a government department you get four weeks of holidays a year (Julie and Michelle, focus group).

Parents wanted to avoid enrolling their children in a formal holiday programmes for the full holiday period, but were constrained by the reality of their workplace leave entitlements. They were considering a combination of using annual leave, holiday programmes and extended family care, and knew they had to plan ahead to secure a place in a holiday programme.

Parents were grateful when their employers gave them some flexibility in their work hours. This affected four parents, who generally described themselves as 'lucky'. Legislation giving parents with care responsibilities the right to request a variation in hours or days at work was passed in 2008 (Department of Labour, 2011). These parents acknowledged this flexibility as a privilege rather than a right.

I will be able to do some work from home, and I will be able to, yeah, just juggle my hours around really. So I'm quite lucky to have an employer like that really (Rebecca/Richard, interview 1).

Three families mentioned the possibility of working in with relatives for some after school and holiday care. But there was also the sense of being careful to avoid 'using up' the good-will of relatives in case you should need to call on them for an emergency. Parents' ability to make plans for new routines depended to some extent on maintaining good relationships with friends, family members and neighbours. 


\subsubsection{Experience of time}

Families reorganised their daily routines in response to the requirements of attending school. This had a number of effects on how time was perceived by parents. Southerton (2006) notes that family schedules are generally organised around fixed obligations and arrangements with a high degree of coordination with others, with discretionary activities fitted in to available moments. Depending on parental decisions about work and care arrangements, this resulted in parents reporting an impression of 'having more time', or 'greater time pressure', and often some aspects of both of these. These impressions are summarised in Table 6.1 (page 76).

\section{'Having more time'}

Five families commented that some aspects of the change in routine gave them the impression of having more discretionary time. Two mothers changed their work hours so that they had every afternoon from three o'clock with their children. While wanting to take primary responsibility for their children's after school care, they also commented they enjoyed the freedom of this regular time with their children. Nicole also planned to allow for more discretionary time by reducing her own study commitments. While she was planning to return to a greater study and work load in the future she commented on how pleasant it was to have a 'sane' routine for a change.

In one way it will mean, at least for the rest of this year it will actually be quite nice being able to have that bit of breather time. We'll have afternoons, or late afternoons, home (Nicole, interview 1).

Michelle reported that a pleasant side effect of her older child starting school was the opportunity for extra one-on-one time with her toddler.

And I on my one day [off] now get four hours or three hours with the younger one by myself which he's never had in his whole life (Michelle, focus group).

Several fathers noted that the daily schedule fell into a different pattern now that children needed to be at school later than they had to the centre, or organisational responsibilities were shared differently between the two parents. Scott commented that he was getting to work earlier, and James was surprised to find that he had 'too much time' on his hands on the mornings he dropped the children at school and centre.

\section{'Greater time pressure'}

Aspects of the new routines and children's school responsibilities also resulted in the impression for five families of greater time pressure. For some there was extra rushing at each end of the 
day. Several parents also noted that their children had too much they wanted or needed to do in the afternoons: read the book from school; have some 'alone time'; play with their sibling; and have time with parents. Several parents commented that it was now difficult to also fit in time to play with friends who had gone to different schools, and for the child to follow other interests such as crafts or construction at home.

For some families weekdays were now so busy that family time together was restricted to the weekend. Even having the weekend dynamic that you wished could be a challenge.

I miss time with my boy. And because we've got two kids we end up splitting our weekends. So we very rarely the four of us spend time together (Julie, focus group).

There appeared to be two broad reasons why starting school created more time pressure: extra obligations, and the need for children to unwind. Several families mentioned that school was a more intense experience for their child than the centre had been, and required an 'unwinding' period each afternoon. Some of the families in my study experienced both these effects in the first month of school.

\section{Attitude makes a difference}

In reflecting on the changed routines, two parents commented that their attitude affected how they felt. Each school gave a specific time before which parents may not leave their child at school. Julie reflected on the value of accepting these constraints rather than succumb to a 'gotta get to work' feeling and be constantly rushing. Mark also resigned himself to being late on the mornings he dropped his son at school.

I actually find it quite luxurious knowing that I've got to be [at school] till quarter to nine. It's no longer a rush. You know you're going to be late. The traffic's a bit lighter. Just enjoy the fact that you're not pressured for once (Michelle/Mark, interview 1).

Sarup (1996) notes that in the narratives people use to describe and give meaning to their lives "to some extent we construct our story, and hence our identity" (p. 16). One way people do this is by choosing what they notice and what they subordinate. In constructing the story that made sense of time and how it affected them, Julie and Mark's attitudes enabled them to be relaxed about obligations which might otherwise be experienced as a stress (Meissner, 2008). 
Table 6.1 summarises how each family noted changes in their experience of time over the transition to school.

\begin{tabular}{|c|c|c|}
\hline & Having more time & Greater time pressure \\
\hline Amanda \& Angela & $\begin{array}{l}\text { Less hands-on childcare during day. } \\
\text { Commenced part-time work during } \\
\text { school hours. }\end{array}$ & $\begin{array}{l}\text { Less opportunity to spend time with child's } \\
\text { friends. }\end{array}$ \\
\hline Julie \& James & $\begin{array}{l}\text { Changed work hours to within school } \\
\text { hours. } \\
\text { Parents take turns with morning } \\
\text { routine: Julie has relaxed time with } \\
\text { children; James notes extra time on his } \\
\text { hands. }\end{array}$ & $\begin{array}{l}\text { No free weekday. } \\
\text { Weekends more rushed. } \\
\text { Worry about arranging holiday care. }\end{array}$ \\
\hline Michelle \& Mark & $\begin{array}{l}\text { One-on-one time with toddler on free } \\
\text { weekday. } \\
\text { Parents alternating drop-offs makes } \\
\text { more efficient use of time. } \\
\text { Acknowledging lateness in morning is } \\
\text { unavoidable means less sense of rush. }\end{array}$ & $\begin{array}{l}\text { Complex after school schedule. } \\
\text { Rushed at start and end of day. } \\
\text { Worry about arranging holiday care. }\end{array}$ \\
\hline Nicole & $\begin{array}{l}\text { Changed work hours to within school } \\
\text { hours. } \\
\text { Reduced study commitments for first } 6 \\
\text { months - a 'sane' routine. }\end{array}$ & Worry about arranging holiday care. \\
\hline Rebecca \& Richard & & $\begin{array}{l}\text { Careful scheduling in morning required. } \\
\text { Complex after school schedule. } \\
\text { Worry about arranging holiday care. }\end{array}$ \\
\hline Sarah \& Scott & $\begin{array}{l}\text { Parents more organised in morning - } \\
\text { getting to work earlier. }\end{array}$ & $\begin{array}{l}\text { Busier morning routine - an earlier start } \\
\text { required. } \\
\text { Less opportunity to spend time with child's } \\
\text { friends. }\end{array}$ \\
\hline
\end{tabular}

Table 6.1 Changes in subjective experience of time 


\subsubsection{Wider context}

The way parents experienced the transition to school and could help their child was affected by what else was happening in their lives at the time. Bronfenbrenner (1979) uses the term exosystem to describe how events which occur in one setting can affect other settings. For example, work conditions, such as the option for some flexibility in hours, can enable a parent to implement some measures they believe will support their child's transition, such as being able to collect their child after school for the first few weeks.

Four families identified elements of their wider life context in the period around starting school which affected their, and their child's, experience of the transition. Two examples were the relocation of a mother's work or being unusually busy at work, which led to increased stress for the parent concerned. Those parents speculated this could have affected how responsive or available they were to their child.

Other examples involved the child more closely and were described by the parent concerned as having a strong effect on the family. One family moved house in the weeks prior to starting school. Another family experienced the death of a grandparent close to this time which required travel to another city.

For me, personally, my mum died just a couple of weeks before Jacob went to start school. That had a huge impact on this whole thing. ... I think it's probably environment, what else is going on and just how that impacts on their transition as well (Julie, focus group).

Major life events are sometimes planned, such as moving house or starting school, or can be unpredictable. Multiple stresses place a greater demand on the parent's personal and social resources and make communication and flexibility more important. Where possible, planning for fewer commitments in the weeks following the transition to school can allow for this flexibility.

After four weeks at school most parents had adapted to the new family routines. For each of the families this coincided with their child also seeming more settled in school, creating a sense that, while there might be future adjustments, they had successfully negotiated the transition for now.

\subsection{Chapter summary}

In this chapter I have reported on how parents and children formed relationships and experienced becoming part of the school community. Feeling a sense of belonging in the school community was important, and parents thought this would be assisted by joining a school near their home, or one where they already had strong connections. Pre-entry visits over an extended period of time and school staff who actively facilitated relationships were important enablers of the parents and 
children feeling a sense of belonging.

Helping their child settle into the school environment was a key task for parents over the transition period. Parents used a range of strategies to help their child settle into school, and observed their child to determine whether they needed to adapt those strategies. They saw settling into school as involving the child becoming comfortable with both class and playground settings, and with managing the demands of a more intense learning environment.

The parents' own adaptations to school routines were influenced by the wider context of their lives and by their child's experiences with school. Changes to family routines took considerable planning, and included changes to parents' subjective experience of time.

In Chapter Seven I will report on the experience of these parents in their sense of personal agency and engaging with issues of identity as a school parent. Parents' sense of agency and the roles they took on also affected the ways they could help their child settle into the school community. 


\section{Becoming a school parent - agency and identity}

\subsection{Introduction}

This chapter presents findings focusing on the third research sub-question: what affects how parents develop their identity as a school parent? This is part of the overarching question: what is it like for parents during the transition of their oldest child from early childhood setting to school.

The chapter is divided into two sections: the ways in which these parents experienced agency during the transition period; and factors relating to their personal identity in their new role. The parents' ability to support their child during the transition was affected by their sense of personal and shared agency and the relationships they made with school staff. This is reported in the first section. Parents' sense of effectiveness also impacted how they viewed themselves as a school parent, along with their feelings, the discourses they operated within, and their expectation of their own role in relation to school. This is discussed in the second section.

\subsection{Agency}

When the parents in my study talked about some aspects of their experiences over the transition to school, their sense of personal agency - the influence they were able to exert in relation to their child's transition (Gunn, 2009) - was a regular theme. Questions of personal agency related to their desired involvement in decision making about starting school, and the way they responded to circumstances they might wish to question or change. In this section I will look at families' decision process when choosing a school and their attempts to negotiate aspects of the transition for their children.

\subsubsection{Choosing a school}

There were three interrelated factors which parents in my study seemed to consider when choosing a school for their child:

- ' 'localness' - a school in close proximity to home, which is discussed in Section 6.2.2,

- 'connections' - existing relationships the family had to a school, and

- 'suitability' - the school having some particular quality the parents were looking for for this child. 
values. Parents' decision processes are described in Chapter Four and the factors are summarised in Table 7.1 .

\begin{tabular}{|c|c|c|c|}
\hline & $\begin{array}{l}\text { Parents value the 'local' } \\
\text { school }\end{array}$ & $\begin{array}{l}\text { Family has 'connections' } \\
\text { with the school }\end{array}$ & $\begin{array}{l}\text { School is 'suitable' - has good } \\
\text { reputation or matches parents' } \\
\text { values }\end{array}$ \\
\hline Amanda \& Angela & $\begin{array}{l}\text { Out of zone for preferred } \\
\text { school, so moved house. }\end{array}$ & $\begin{array}{l}\text { Strong connections with one } \\
\text { school. }\end{array}$ & $\begin{array}{l}\text { Schools closest to original } \\
\text { home deemed a poor match to } \\
\text { parent values. }\end{array}$ \\
\hline Julie \& James & $\begin{array}{l}\text { Strongly value a local } \\
\text { school, within walking } \\
\text { distance of home. }\end{array}$ & $\begin{array}{l}\text { Some connections with } \\
\text { school prior to starting. }\end{array}$ & $\begin{array}{l}\text { Had heard from neighbours } \\
\text { and friends that local school } \\
\text { had a good reputation, and } \\
\text { valued rural appearance of } \\
\text { school. }\end{array}$ \\
\hline Michelle \& Mark & $\begin{array}{l}\text { Strongly } \text { value a local } \\
\text { school, with mixed } \\
\text { social group. }\end{array}$ & $\begin{array}{l}\text { Minimal connections with } \\
\text { school staff or families } \\
\text { before first day. }\end{array}$ & $\begin{array}{l}\text { Had heard local school had a } \\
\text { good reputation. }\end{array}$ \\
\hline Nicole & $\begin{array}{l}\text { Acknowledged } \\
\text { convenience of closest } \\
\text { school, but prioritised } \\
\text { other factors. }\end{array}$ & $\begin{array}{l}\text { Worked to establish } \\
\text { connections with chosen } \\
\text { school. }\end{array}$ & $\begin{array}{l}\text { Looked for a school that } \\
\text { would meet child's learning } \\
\text { needs. }\end{array}$ \\
\hline Rebecca \& Richard & $\begin{array}{l}\text { Had choice of two local } \\
\text { schools. }\end{array}$ & $\begin{array}{l}\text { Weak connections with } \\
\text { school prior to starting. }\end{array}$ & $\begin{array}{l}\text { Visited both schools and } \\
\text { chose the best fit for child. }\end{array}$ \\
\hline Sarah \& Scott & $\begin{array}{l}\text { Strongly value a local } \\
\text { school, and considered } \\
\text { no others. }\end{array}$ & $\begin{array}{l}\text { Minimal connections with } \\
\text { school staff or families } \\
\text { before first day. }\end{array}$ & $\begin{array}{l}\text { School has mixed reputation } \\
\text { and matched some parent } \\
\text { values. }\end{array}$ \\
\hline
\end{tabular}

\section{Table 7.1 Summary of factors in choosing a school}

School choice was sometimes constrained by school zoning policies. Five families mentioned an awareness of school zones and that enrolment zones were strictly enforced. School enrolment zones create a home zone around a school. Children living within that zone having the right to attend (Ministry of Education, 2010b). The school may have additional places which are offered to children living outside the zone based on criteria or by ballot.

Four families in my study actively considered more than one school for their child. Along with 'localness' and 'connections', factors which were mentioned as making a school seem 'suitable' 
included the school's apparent responsiveness to a child's special learning need, knowing that the school community included other lesbian headed families, and the apparent energy and engagement of children and teachers at the school.

I was looking for warmth, the feeling, the energy in a school. The engagement of the children when you're walking around the school (Rebecca/Richard, interview 2)

The playcentre had an established relationship with its neighbouring school and most playcentre families reportedly transitioned to that school. However, each of the three playcentre families in my study happened to live outside the school zone. Each of these families thought it would be easier to move to a school where their child already knew many children and they knew many parents. Amanda and Angela decided to move house in order to attend this school. Sarah and Scott prioritised attending their local school and concentrated on helping their son settle there.

Nicole considered her local school in her decision making process but then opted for a third school which seemed more responsive to her son's special learning need.

I'd gone up [to the school] and had a visit, and I mentioned [Noah's speech delay], and her response was just more open, like, 'what can we do. Is there anything we can do to help' (Nicole, interview 1).

Two families in this study decided to look no further than their closest school. Sarah reasoned that settling into any school would require work, so they should avoid the inconvenience of travelling further from home. Michelle and Mark elected, on principle, to attend the state school in their local area, so their son could make friends from their local community.

I made an active decision not to make a choice other than the local school. I'm not suggesting this is right, but I didn't want to be part of any white flight (Michelle, focus group).

Parents in New Zealand have the right to choose which school their child will attend and are encouraged to be active in their choice of a school (Education Review Office, 2009). However, there appears to be little written about parental choice of school (Everiss, 2010). In a consumer society, deciding which choices to actively engage in, based on values or circumstances, is a way of managing the myriad available options (Schwartz, 2004). These two families identified the key value which made their local school desirable, and then planned to make it work for their child.

\subsubsection{Negotiating the transition to school}

In recent years some authors have talked about the concept of a 'child-ready school' which adapts to be welcoming of the particular families joining the class (Brostrom, 2007; Doucet \& Tudge, 
2007; LoCassale-Crouch et al., 2008). In such an environment the teachers proactively alter practices so they benefit an individual child and family.

The experience of families in my study was largely that their child was expected to adapt to fit in with an established class. Each of the families in my study implemented strategies to help their child settle into school. As described in section 6.3.1, these often involved changes in family routines outside school hours which did not involve co-ordination with the teacher.

Some parents in the study also reported 'negotiating' with school staff to adjust some aspect of the expected transition process to better suit their child's apparent needs using proxy or collective agency (Bandura, 2002). In order to negotiate, parents seemed to require information about what might happen at school and possible alternatives, and the opportunity to engage with the teacher in dialogue. For example, Sarah explained that the teacher had initially offered pre-entry visits only in the week that her son would start school. She rang the teacher and explained that she thought Sean would benefit from several visits spaced over several weeks. As a result, a series of visits was arranged.

They wanted us to have school visits the two days before he started. And I was like, I need it before then. We need it before that for him because I think he needs time to reflect and ask questions. (Sarah/Scott, interview 1).

When school staff provided options for aspects of the transition and made time to talk and listen to parents, these parents felt more able to raise any questions they had and support their child. Amanda commented that she was very impressed that her son's teacher was very open about discussing how Alex was settling, and it seemed that she and the teacher were equal partners in settling her son. In some instances the negotiation process involved a suggestion by the parent and a counter-suggestion by the teacher. Amanda described a conversation with her son's teacher in which she talked about managing Alex's tiredness in the first weeks.

I said I think I might pick him up at lunch time because he's just shattered. [The teacher] said, please don't pick him up at lunchtime. That time over lunchtime is so important for their friendships. And if they don't have that she said that school can be a really difficult place. And so she's really aware of that and it totally made sense (Amanda/Angela, interview 2).

Amanda was grateful that the teacher could accommodate variations in routine, and she also appreciated receiving an explanation of the advantages of a different action.

Where normalising language was used by school staff this tended to inhibit parent questions and limit conversations around negotiation. 
ask questions I felt like we got this kind of thing of, 'oh what? Has Sean got some problem? Has he had a traumatic experience in the past that you want to know all this information?' (Sarah, focus group).

While parents were still finding out about school and had not yet formed a trusting relationship with the teacher, this response could give the sense that requesting alternatives to 'standard' transition practices implied their child had some abnormality. Parents wanted to help their child fit in, not be set apart.

\section{Improving systems to support future parents}

As well as try to resolve issues for their own child, several parents talked about what they personally had done, or could do, which might improve systems for future parents. Rebecca commented that she had talked to her friends who had also attended the same ECE centre and discovered they also felt they lacked information about the transition to school. Towards the end of her time at the centre, Rebecca offered the head teacher feedback on what support she thought would have helped her during the transition.

[The other parents at crèche] sort of all had the same concerns really in terms of [the lack of information about] transition to school. At the centre at the time we didn't really have anything. But I spoke to the head teacher before Ryan left, and they sort of realised as well that it was something they need to work on (Rebecca/Richard, interview 2).

Sarah and Scott also reflected that a lot of their stress over the transition period could have been avoided if there had been better information and communication with school staff before school entry. At the second interview they discussed what information would have helped them, and Sarah suggested wryly that she was likely to offer to help rewrite the school's parent information pack if asked.

All the parents were keen to ensure their child was happy at school. Being able to discuss and sometimes alter what might happen gave parents a sense of some control of the transition process, and being listened to helped them to feel valued as a partner by the teacher. Bandura (2006) notes that planning to change things for the future requires people to see their own experience embedded in a longer history of families coming through the centre and school system. In attempting to effect a change in practice, Rebecca relied on proxy agency (Bandura, 2002). She gave feedback, but counted on others to take appropriate action. Sarah was suggesting she could work together with school staff to prepare better induction information - a process of collective agency which also relied on school staff to distribute this information. 
These parents wanted to think that they and the teacher would work in partnership to successfully settle the child.

\subsubsection{Powerlessness}

Some parents reported the feeling of loss of control and powerlessness in the new educational setting, in contrast to the ECE setting. During their child's transition parents were slowly learning what was expected of them and their child and establishing relationships. Being able to be actively involved in supporting their child was important to these parents. Their identity as parents required them to nurture and protect their children (Bronson \& Merryman, 2009), and situations where they found they could not were deeply painful. Sarah ached watching her child upset on a pre-entry visit and being unable to help him. She did not have the information he needed, and was also already committed to helping another group of children.

Sean ended up on the third visit he was just absolutely in tears because he didn't know what to do and he was sobbing. Just saying 'I don't know what I'm supposed to do.' And I couldn't really help him, not only because I didn't know what he was supposed to do but, because they were down a teacher, I'd been roped into looking after the trampoline. And so I couldn't even help him (Sarah, focus group).

Lack of knowledge and opportunity to talk with school staff created a tension between parents' need to be active agents on behalf of their child and understanding and adhering to school practices. This tension was identified as an 'information-power imbalance' during discussion in the focus group: the gap between parents wanting to engage with the school for the good of their child but not yet having the information resources or relationships to adequately do so. This tension was exacerbated by a tendency to defer to a professional and to avoid being a 'problem parent', which is discussed in Section 7.3.2.

Several writers have also noted a tension between parents' attempts to support their child's transition and the realities of interacting with school staff (Brooker, 2002; Gallagher, 2006; Peters, 2004). Dockett and Perry (2007) note that this tension is reduced where there are "relatively few differences between the cultures of home and school" (p. 78). Feeling able to support their child helped parents see themselves as effective in their role of school parents. The level of agency felt also affected how parents approached any concerns: whether they chose to resolve them with the school or to try and mitigate at home.

\subsection{Identity}

During a child's transition to school their parents also undergo a transition as they take on the 
roles and expectations which come with having a child at school (Bronfenbrenner, 1979; 2005). Prevalent discourses, and the opportunities and expectations of involvement at school, appeared to affect the way these parents saw themselves in their new role as school parents. In two cases these trajectories changed noticeably over the nine to twelve week period around school entry. In the following sections I will discuss the feelings which parents in my study had around the transition to school, look at some of the discourses which appeared to shape and constrain identity development for them, and the ways in which they anticipated they might participate in their chosen school.

\subsubsection{Parent feelings}

In this study parents reported a range of feelings, including excitement, anxiety, pride in their child and a sense of loss, and experienced contrasting feelings held at the same time. On the whole there was a difference in the feelings expressed by the mothers and the fathers. Fathers were generally excited and felt positive about their sons starting school. Mothers reported more mixed feelings - excited but nervous, proud of their son's capability but worried about how he would cope at school.

Yeah I'm excited. I'm apprehensive though. I've got that strong maternal [feeling]. It's that initial phase that I'm a wee bit apprehensive about (Julie/James, interview 1).

Parent feelings about the transition may have been influenced by their memory of starting school as a child (discussed in Section 5.3.1.). Most mothers in my study had negative to neutral memories of starting school. Memories included feeling fearful, a teacher who called the child 'names', a teacher who was unkind, and teachers treating boys more harshly than girls. The fathers in my study all had neutral to positive memories of starting school. Their memories included doing interesting activities relating to the school fair, walking to school with extended family members, and a sense of independence associated with school. These positive memories may have given the fathers greater confidence about their own sons' transition to school.

All the parents said that watching their child learn to read was a very satisfying experience, and their children were 'loving learning to read' or write and other academic work. It was a pleasure to see their child so proud of their ability to share books with their families at home.

But certainly reading and maths he's coming home excited about the things he's [learning]. Because he's desperate to read (Amanda/Angela, interview 2).

The book isn't really like homework. It's like a treat, 'cause he rushes in and Sophia goes "read story Sean". He reads the story to her and to me. And to Scott when he gets in (Sarah, focus group). 
Writers on transition to school have noted that parents experienced a range of feelings similar to those noted above (Dockett \& Perry, 1999; Giallo et al., 2010; Griebel \& Niesel, 2002; Renwick, 1997). Some writers also link feelings parents have with their sense of personal agency. Giallo et al. (2008) found that when parents had the sense that they could be active in helping their children with the transition to school they tended to feel less anxious and have fewer worries about how the school experience would be.

\section{Child independence - sense of loss}

The parents in this study reported the sense that the transition to school, which marked a significant social and educational step for their child (see Section 6.3.2), also heralded the end of a stage in their child's life where he relied mainly on his parents for his identity and sense of place in the world. Reflecting on their changing roles as parents created a sense of loss.

On the one hand, as well as noting practical ways their child seemed to be becoming independent, most families commented that their children were starting to assert knowledge they had learned at school, sometimes in competition with what was said at home. Children corrected parents' pronunciation and letter formation, quoted the teacher, and asserted parents did not know things which could be learned at school. The parents were mostly quite amused by this, and thought it was a sign that their children were adapting to the new setting and paying attention to their teacher.

But you know for Sean, it's like being part of this secret club. He's enjoyed learning about this thing that I don't know anything about (Sarah, focus group).

During the focus group these parents speculated that the assertion of precise knowledge at home might be the children's response to a new and confusing situation. If so much about school is new, perhaps some children find it a comfort to command facts they can be confident of.

On the other hand, the parents also expected their child would begin to rely on them less. They noted a sense that 'growing up' also meant their child was starting to 'grow away' from his parents.

You know, it is the end of an era. ...from speaking to other parents you know once your kid starts school, the parents stop being the focus. You know suddenly peers become more important, and peer opinion (Nicole, interview 1).

This sense of 'loss of child' may have been sharpened when there had not yet been time to develop a relationship with the teacher. Dockett and Perry (2007) note that ''Handing over' children to someone who is known and trusted may be a challenge; handing children over to the 
care of someone who is unknown and with whom there is no established sense of trust places a great emotional strain on families and communities” (pp. 93-4). As they supported their child in the transition to school, parents were also negotiating a transition in what their own role as 'parent' meant.

\subsubsection{Discourses}

The transition period for parents in my study was affected by discourses about parents and teachers which they held or encountered. The term discourse refers to the categories people use to make sense of, and engage with, our social world. Dahlberg, Moss and Pence (2007) note that "the importance of discourse comes from the decisive role of language in constructing the world rather than being simply a means of representing or copying reality" (p. 31). Two discourses, which I have called the 'problem parent' and 'deference to a professional', were identified as affecting the actions of some of these parents.

\section{The 'problem parent'}

Several parents in the study appeared to invoke the discourse of a 'problem parent': one who takes up too much of the teacher's time or makes unreasonable demands. Mark suggested that such parents exist and that they were likely to be a problem for schools.

I guess the conversation started off with a bit of a sense where she was a little bit wary, as I imagine she's right to be, of parents who expect gold plated service for their first born (Michelle/Mark, interview 1).

Parents who invoked this discourse suggested that being seen as a problem parent was something to be avoided, because it could affect your relationship with the teacher and ability to access information for your child's sake. Parents acknowledged that teachers were very busy, and they could see the fairness in avoiding taking up more than their share of teacher time when all the other parents also wanted to communicate.

[Catching the teacher] is quite hard because it's such a rush at the end of the day. Everyone's very anxious and wants to know how their child's doing and what they're doing and who's writing what. And obviously some people are more vocal about it than others. So I don't want to sort of tie her up (Rebecca/Richard, interview 2).

This discourse was troubling because avoiding being 'a problem' could act as a barrier to good communication between parents and teachers and meant that misunderstandings which might have been resolved quickly were allowed to continue. Teachers could also not get accurate feedback on which issues were concerning parents. 
Related to this was the discourse of the 'needy parent': the belief that a parent's wish to spend time helping or observing in the classroom was more about the parent's 'need' than what would help the child.

But I think [this teacher] would see [parents wanting to help in the class] more as perhaps the parent's need, than the child's need (Amanda/Angela, interview 2).

Around the time of their child's transition to school parents were re-visiting their own role with their child, and the role of others involved in care and education. The discourse of 'problem parent' affected what roles or choices were considered available or acceptable. Some of the things that parents in this study reported doing to try and avoid being a problem parent were: defend school practices which they heard someone criticise; help their child adapt to homework practices which they disagreed with; accept decisions by the school but question them in private later; and avoid confrontation with the school but find ways to offset a practice in out-of-school hours.

\section{'Deference to a professional'}

During the focus group, the parents discussed the information they had wanted, and why they had not raised questions about some of the decisions made by the teacher or school, or had only questioned them at home later rather than in a way that might lead to change. They identified in themselves a tendency to defer to the teacher's professionalism, and compared this to the traditional doctor-patient relationship of accepting without question the judgement of specialised knowledge.

Michelle: You know you kind of get into this thing. It's a bit like with doctors, where when they tell you, the school tells you something, you kind of go 'uh huh. Mm hm.' There's an authority thing, which is kind of, odd.

Julie: It's that professional and the authority, and the, yeah, you don't tend to question people who are professionals (Julie and Michelle, focus group).

The focus group participants discussed three possible reasons for this reaction. They may have been conditioned by their own experience of being school students in a hierarchical system and automatically assumed the subordinate role. Enz et al. (2008) note that questioning school authority is regarded as disrespectful in many cultures. A second suggestion was that the imbalance between teacher and parent knowledge of what happens at school prevented parents from suggesting viable alternatives to issues concerning them.

The third reason for unquestioning deference to teacher professionalism rested on a tension between two goals held by the parents: negotiating details of the transition to best suit their child, 
and ensuring their child felt safe at school. Any questioning of the teacher's judgement contained the risk of de-stabilising the child's secure relationship with their teacher. The parents expressed that they were careful to not undermine the teacher in the eyes of their child.

It's a fine line you're treading in a way because you know that it's important for your kid when they're at school that they're listening to the teacher and they are respecting the teacher. So you don't want to undermine that. But you want to keep your own sort of power in the situation as well (Sarah, focus group).

This meant being very tactful in what was said, especially in front of the child, and choosing which issues to avoid.

Some writers have commented that parents and teachers may misinterpret each others' actions or comments. A parent who does not conform to school culture or prepare their child 'correctly', for example by providing the right food for school, may be judged by the teacher (Brooker, 2002). Or a comment by the teacher intended as informative may be interpreted as criticism by the parent (Peters, 2004). Good communication, talking and listening for understanding, takes time (Burke, 2011), which may be in short supply in busy classrooms and families. Repeat opportunities for communication between parents and teachers helps to build the relationship and avoid misunderstandings.

\subsubsection{Parent involvement at school}

The parents in this study generally recognised the value of parents being involved with the operation of their child's school, and prior to school entry had an expectation of some level of involvement with the school.

I think that is the key to a healthy school, is having parents involved (Amanda/Angela, interview 1).

I would be quite keen to get involved in running things on sort of, either at a governance role or maybe at a more organisational role. ... I think it is pretty important for [parents] to be involved with the school (Michelle/Mark, interview 1).

\section{Inviting parent involvement}

Each of the four schools welcomed parent help with some aspects of school life. The schools invited help through information packs and through communication between the teacher and parents. Several parents also learned about helping at school from speaking to friends and colleagues with children either at their own or another school. Schools, and especially the classroom, were seen by these parents as the domain of the teacher which parents could only enter with permission, so having an explicit invitation to do so was important. 
Communication was important for enabling a positive parent help experience. Michelle had explained to the teacher that she could only help in the classroom if she could bring her toddler with her. They discussed the practicalities of doing so before the day. The teacher at Nicole's school established early through discussion which parents were free on some days to help with class events so she could invite particular parents to help with particular events.

Then this morning [the teacher] just asked me. She was 'oh, you're free Thursdays aren't you?' And I was like yes. 'Oh would you like to come with us [on a trip]? Because the junior school are coming and we need to have some parents come with us as well (Nicole, interview 2).

Amanda noted a lost opportunity for the younger siblings to make connections with the school.

[The school said] 'We require four parents from each of the two classrooms. And no preschoolers.' And I just thought, oh that's so sad. Why don't you just let as many parents come who want to come. Because you're probably not going to get much more than five, maybe. And just let the preschoolers come because they're missing their siblings (Amanda/Angela, interview 2).

In some cases, more communication between the teacher and parents might have created a better shared understanding of the benefits and challenges of having pre-schoolers attend school trips.

\section{'Help out if needed'}

In response to a question in the first interview about how they thought they might be involved at school the parents in my study tended to think they would either 'help out if needed', or 'be fully involved'. The expectation of involvement that parents had before their child started school seemed to be similar to the level of involvement they had had in their ECE centre.

Each of the three families recruited through a childcare centre expressed their primary role within the school environment as supporting their child, and also helping the school occasionally if needed, perhaps on a monthly or termly basis. Some level of involvement with the running of the school was seen as a way of building relationships with the teacher and knowing enough about school work to help their child at home. Parents also wanted to have some involvement with the wider school community.

If they have school trips and things I'd like to be involved with that. And school fairs [and] supporting fundraising type involvement (Rebecca/Richard, interview 1).

Where both parents were in paid work the time they had available and their other obligations were factors they considered when thinking about potential school involvement.

\section{'Be fully involved'}

Each of the three families recruited through the playcentre anticipated being regularly involved 
at school, perhaps on a weekly basis. The experience of volunteering during their child's ECE years appeared to have acclimatised them to the expectation of volunteering at school.

[Parent help] is something that I am thinking of doing. But ... just the fact that when we were at playcentre, I did the courses. And again it was being in a place where parents could be involved. And wanting to be involved (Nicole, interview 1).

Playcentre parents seemed to see themselves as 'someone who gets involved'. They could also be seen by others as a likely candidate to approach - 'someone who should get involved'.

And in Scott's case [helping with the fair] was from a playcentre connection. Because this woman came out who knew [someone we know from playcentre] and said'ooh. I heard about you. Can you come and help me with...' (Sarah/Scott, interview 2).

While social connections can help parents to form relationships in the new setting, if a parent happened to not want to volunteer at school they might find this social approach awkward to resist unless they had a particular reason, such as starting or increasing paid work commitments.

There are many ways that parents can be involved in the day to day running of a school. Epstein (1995) presents a model of six levels of parental involvement with school, including providing a supportive home learning environment, helping with elective options and trips, fundraising, and assisting with the governance of the school. There appear to be a variety of opinions, among both teachers and parents, on what involvement by parents in the operation of the school is useful and desirable (Brooker, 2002; Peters, 2004; Renwick, 1997; Sauvao et al., 2000), although research indicates that parent involvement at school is positively linked to child academic outcomes (Giallo et al., 2010). Good communication between the teacher and parent is essential to establish a partnership in relation to the child's education, and should take into account the wishes of all parties (Epstein, 1995). Amanda wanted to be involved in the classroom programme, but this was not encouraged by her son's teacher. She became involved in the ways which were available, outside the classroom, but her non-participation was experienced as marginalisation (Wenger, 1998) because it was not by her choice and the possible reasons remained undiscussed.

Each of the six families found it interesting and exciting to observe their own child's engagement in and progress with learning at school. The parents who had spent some time in the classroom all commented that having the chance to observe the range of learning happening among the wider group of children was fascinating, and gave them a great respect for the work of new entrant teachers. 


\subsubsection{Trajectories of identity}

The parents in this study had a prior expectation of their role within the school, and the opportunity that their other commitments allowed them, creating an expected trajectory of what their role as a school parent might be. Of the five two-parent families, two seemed to expect both parents to have a similar level of involvement with school, although possibly in different ways. Three families expected one parent to have a greater opportunity to interact with the school. Once their child had started school the interactions which two mothers had with school staff, and their experience of being a school parent, resulted in a change in their projected trajectory. Michelle had imagined she would wish to help out occasionally, and experienced a pull towards being involved in the class on a more frequent basis.

I do two drop offs and one pick up a week. And it's not quite enough for me. ... So I go in and do parent help for my one day off in the morning just because I wanted to feel more connected. And I was really surprised by that. I didn't expect to feel like I wanted to be part of it. And sort of jealous of parents who were picking their kids up, and able to walk home more days a week than one (Michelle, focus group).

On the other hand, Sarah assumed that she would help at school each week as she had done at playcentre. While the school said they welcomed parent involvement, her experience in the first four weeks was that there was not the culture of parent involvement than she had expected from her conversations with the principal. She was wary of taking on too much responsibility if others were not also sharing the load.

I feel like parents should be involved and we both went and helped with the [fair]. [But] seeing that it seems like not that many people do volunteer we're reluctant to become the only people who do anything considering there's also playcentre and we do lots with that (Sarah/Scott, interview 2).

From the parents' talk it appeared that if their hopes of learning about school, forming relationships, or participation at school was what occurred, then they found the transition a more satisfying experience. If, on the other hand, a parent's expectations were not met, and there seemed to be no simple way to resolve or understand the issue, this could create a problem for their experience of their child starting school. Wenger (1998) notes that both participation and non-participation - what you choose, and also what is denied you - affect how a person's identity within the group develops. As noted above, any frustration may have been avoided with better communication and more developed relationships. 


\subsection{Chapter summary}

In this chapter I have reported on some of the factors that affected how the parents in my study formed their identity as school parents. These families had a choice of school, and weighed up the factors of 'localness', connections and suitability in making the choice of which school to enrol their child at. They then used their personal agency to negotiate details of the process to support their child's transition.

Parents generally experienced multiple feelings over the course of the transition of their child to school, including anxiety and excitement, and pride in their child's new learning. The experience of having a child start school was one of relative powerlessness in the face of normative institutional expectations about the role of parents and school. Parents were also affected by dominant discourses within their social group about the role of parents and teachers. Parents approached school entry with an expectation of how they might be involved in the life of the school. For two mothers, their actual experience of school life changed their vision about their role in the school.

In Chapter Eight I will reflect on the implications of this study for parents in negotiating the transition to school for their child and themselves, and for staff in early childhood centres and schools in supporting both children and parents with this transition. I will also comment on some limitations of the study, and suggest possible lines for further research. 


\section{The parents' experience - negotiating the transition}

\subsection{Introduction}

This study investigated parents' experience of the transition of their oldest child from ECE centre to school. These parents had not previously experienced the schooling sector as parents, and as their child transitioned to become a pupil, they experienced a transition to becoming a 'school parent.' The study explored this transition through three sub-questions: how do parents learn about school and the transition to school; what affected the relationships they formed as school parents; and what affected how they developed their identity as school parents?

This chapter firstly summarises the findings of the study in relation to the three sub-questions, and then discusses some implications of these findings for supporting children's transition to school for ECE and school teachers, and for parents. It then discusses limitations of the research, and finally suggests some possible areas for future research.

\subsection{Summary of findings}

The main data collection method in this study was semi-structured interviews with the parents of six families. These occurred at three points: four weeks before their oldest child was due to start school; four weeks after he actually started school; and a focus group several weeks after the second interviews. In preparing the schedule of interview questions (see Appendices I and J) the three sub-question areas of information, relationships, and identity were used as a guide.

When participants' responses were analysed, it became clear that their experiences could only partially be sorted within the categories of information, relationships and identity. The experiences parents had learning about school, forming relationships with people at school, and developing their identity as a school parent were interdependent. Chapters Five, Six and Seven identify places where this was particularly the case.

This section summarises the main themes found in this research also under the categories of information, relationships and identity, and again, there is overlap where a parent's experience in one area is contingent on their experience in other areas. The main themes found in analysis of the research data are summarised in Figure 8.1. 


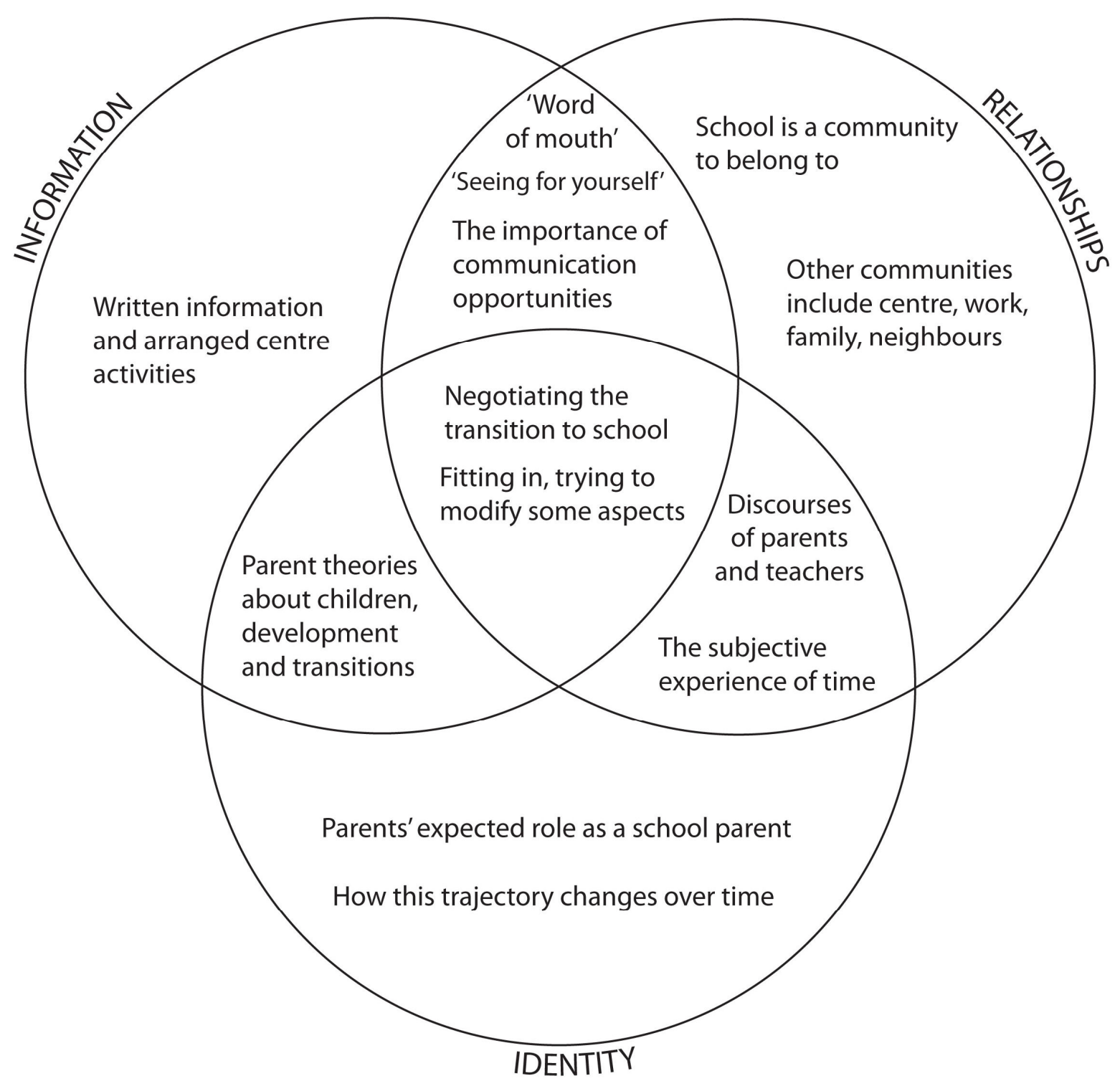

Figure 8.1 Summary of main themes in research

\section{Information}

Learning about schools and the transition to school was an important task for parents prior to enrolling their child in a school and each of the parents in the study used a number of different methods to find information, and thought about the transition to a greater or lesser extent over many months.

The most significant methods of learning about school were by 'word of mouth,' through talking with friends, family members and neighbours, and by 'seeing for yourself,' via visits to the school. These strategies relied on having existing relationships with informants, or developing relationships with school staff. Reading material prepared by the school or available on websites 
was a useful supplementary way for parents to learn about school and was less contingent on developing new relationships. Formal transition activities planned by the ECE centre were an important source of information for those parents who had access to them. Parents already had warm and trusting relationships with the staff at their child's centre, so seemed more able to ask them follow up questions.

Both before and after their child started school, opportunities for good communication were highly important to parents. This included time to talk and ask questions and development of a consistent relationship with a knowledgeable other. Where good communication opportunities were available they allowed parents to ask questions raised by the written material and also about things they had thought of since the last contact.

\section{Relationships}

The parents in this study saw the school as a community which they and their child would come to belong in and contribute to. This expectation was much wider than seeing schooling as a transaction to obtain education for their child. They viewed school as a place for their child to be involved with a variety of people and have opportunity for a wide range of development. Other communities which the families were part of included the ECE centre, the parents' workplace, extended family and neighbours, and these were important sources of information about what school might be like.

Changes in the way that relationships within the family and external to it could be managed resulted in parents' subjective experience of time across the week changing noticeably, both in a positive and negative direction. This experience was in response to the new obligations which parents had on behalf of their child. By the later interviews parents were adjusting to their new routines.

Less tangibly, the relationships which parents developed with people at school were affected by some of the discourses about parents and teachers which they held. This created assumptions about what teacher actions or comments meant, and about how parent approaches to school staff might be received. Some of these assumptions appeared to influence the possible roles that parents saw as available to them as a school parent.

\section{Identity}

Parents' identity was bound up with being able to protect and nurture their child, and they brought this expectation to their experience of the transition to school. These parents had existing theories about children, transitions and education which guided how they planned to help their 
child settle into school. They actively researched, with neighbours, friends, the school, and through written material, and planned strategies to help their child settle into school. Which strategies they were able to implement depended on maintaining a balance with their other family commitments, and also on their sense of personal agency.

The transition to school was noted as a time when children were becoming more independent, and parents expected their child would begin to need them less. They appeared to find it difficult to find themselves in a situation where their ability to directly protect and nurture their child was reduced.

Parents in this study had some expectation of what being a school parent would involve, and also sought information from the school about what was expected of them as parents. Two themes, of 'helping out if needed', and 'being fully involved' were evident in parent expectations of involvement with school. For most parents their expected role was confirmed by their experience of the transition and school, but for two parents it changed in response to the interactions they had with school staff and the feelings they detected in themselves over the transition.

\section{The 'essence' of parents' experience-negotiating the transition}

The main experience of the six families in my study was of 'negotiating' the transition to school with their child. This comprised two aspects: a process of 'finding out and fitting in' to an already established class, and discussion with the teacher to modify details of the transition experience to best suit their child.

New Zealand's practice of continuous entry to primary school means that most children join a class which is already established. Parents in this study sought to learn about school and its practices and support their child to become comfortable as a member of the class and school community. Both child and parent had the task of learning the rules or expectations of being a school pupil or school parent (Brooker, 2002; Dockett \& Perry, 2007; Griebel \& Neisel, 2002; Peters, 2004). This perception was supported by comments from each of the two new entrant teachers interviewed that they used a series of pre-entry visits to slowly induct the child into the class routines and explain school processes to the parent.

Alongside this expectation of 'fitting in', was the experience of attempting to modify some of the conditions around the school experience to best meet their child's personality and needs. Each of the families in this study used their judgement and agency to plan and enact strategies to support their child's transition to school. Some of these strategies required give-and-take with the school staff to achieve a shared understanding and plan, and others were changes the parent could make outside the bounds of school. The experience of negotiating aspects of their child's transition 
with the teacher - of feeling their point of view had been heard and also understanding the teacher's point of view - helped these parents to feel effective and valued in their role as school parents.

Feeling heard seemed to help the parents build a partnership with their child's teacher. The necessary conditions for this partnership were good communication opportunities between the school and parent, having some knowledge about alternative ways the transition to school could be managed, and having sufficient time to form a trusting relationship with key school staff.

\subsection{Implications}

The findings of this study imply recommendations for centre staff, for school staff and for parents in improving the transition to school experience. These recommendations cannot be generalised to a larger sample, however the following implications are supported by the study findings and may be useful for the following groups to consider. This section also discusses a recommendation evident in literature that ECE and school staff further develop their working relationships.

\subsubsection{Early childhood staff}

The ECE centre is the education setting that parents visit frequently prior to their child starting school, and where they have many opportunities to talk to staff. From this study, the following implications for practice for ECE staff and centres can be identified.

\section{Provide parents with information}

ECE centre staff should endeavour to maintain general knowledge about the transition to school and up to date information on local schools to be shared with parents. In particular, researching some of the different transition and orientation practices of local schools means centre staff could offer parents insights into what might happen at their chosen school and encourage them to visit the school. One approach would be to develop a process that systematically provided information to parents, for example six months before the child is expected to leave for school, and included maintaining discussion with parents throughout the remaining period at the centre.

\section{Capitalise on existing warm relationships}

All the parents in this study reported their centre was a friendly place and they felt comfortable interacting with staff. ECE staff could capitalise on this relationship to help parents learn about schools and transitions, for example, by inviting school staff to meet parents at the centre. Small group visits of staff and children to a school seem to be useful for familiarisation. Where it is 
possible to include parents in these visits they provide an opportunity for joint conversations and shared understandings between child, parent, ECE staff and school teacher.

\subsubsection{School teachers}

Schools induct new families often, but for each new family starting school with their oldest child it is the first time they are likely to have interacted with a school as a parent. From this study, these are some implications for practice for schools and school staff.

\section{Provide clear information for parents}

A written information pack and up to date website provide a useful means of informing parents about school. Although written information cannot include everything that every parent may want to know, it will give a place to start discussions. The study parents found the written information most useful when they could talk with the teacher several times during pre-entry visits or informal meetings to clarify questions.

\section{Provide a series of pre-entry visits over several weeks}

Pre-entry classroom visits in this study seemed to be most useful where they occurred over several weeks and when other new families attended at the same time. In particular, the three families who had had no pre-entry visits four weeks before their child was due to start school showed the most uncertainty and anxiety about supporting their child through the transition. It appears to be very helpful to have the same teacher speak with parents each visit as this allows a relationship to develop. In the transition process, parents could be offered some alternatives for their child which teachers have seen work well for the transition to school. Parents also appreciated being listened to and having explanations of reasons for particular practices.

\section{Good communication with parents is key}

Both before and after their child started school parents were appreciative of teachers who were open to, and made time for, parent questions. Good communication takes time, but there were episodes where it would have made the transition go more smoothly. Informal talks with teachers at the start and end of the school day were useful, but not every parent was available then. Providing other opportunities for scheduled meetings with parents is recommended.

\section{Encourage relationships between the family and other children and parents}

Forming friendships with other children is crucial to children settling into school. Forming relationships with other parents was also important in helping these new parents become comfortable in the school community. Facilitation of connections between families, by inviting 
parents to assemblies and other school events, and introducing them to each other, could be useful.

Each of these parents had some interest in involvement with school in tasks that were meaningful for them, although they had differing availability. Clear communication with parents about how they can support their child's learning at home were very welcome, and these parents also welcomed suggested options about how they could support the life of the school.

\subsubsection{Parents}

Parents are the adults who move with the child between the settings of home, ECE centre and school. From this study, the following suggestions may be useful for parents with a child starting school.

\section{Use networks for information}

Word of mouth is an important way to find out about schools and the transition to school, supplemented by written information. It is recommended that parents talk to their friends, family and neighbours about their experiences with having a child start school, and what things they should be aware of. Hearing about a range of transition experiences gives parents ideas for what might help them settle their own child.

\section{Get to know the school and environment}

When parents are choosing between several schools, it is recommended that they contact schools several months before their child's expected start date to obtain an information pack and meet staff, ask questions, and narrow their choice.

Most schools suggest parent and child visits to the classroom before school entry, and this is a good way to find out what will happen at school, familiarise the child with the teacher, other children and programme, and to ask any questions that arise. It is recommended that classroom visits start at least one month before school entry, as children are likely to become more comfortable with repeat visits. Parents are also recommended to make use of informal opportunities such as school fairs or visiting the playground at weekends to help their child get used to the school environment.

\section{Good communication is key}

Parents in this study found it is easier to communicate with people once they knew them. It is suggested parents look for ways to get to know school staff and other parents and children, and take up the chance to attend school events such as assemblies if possible. Chatting with the 
teacher sometimes before or after school is a useful way of developing rapport and understanding. Parents should observe their child both in the weeks before and weeks after the start of school and share the good things they notice with the teacher, as well as any concerns. All children are not the same. It is recommended that parents be prepared to talk about any aspects of school practices or the transition to school they think could work better for their child, and also listen to the teacher's point of view.

\section{Care for self during the transition months}

The transition to school can have elements of uncertainty and potential stress about it. Children are resilient and most settle happily into school. If at all possible, it is suggested parents reduce their commitments for a few months around school entry to enable some flexibility in helping their child adjust. It is recommended that parents look for ways to get their own questions answered and feelings acknowledged. If there are stresses involved with the transition to school, parents can also look for the benefits for their child and themselves.

\subsubsection{Liaison between ECE and school staff}

One recommendation that arose strongly within the literature on transition to school, but less from the actual findings in this study, was the importance of ECE and school staff working together to support each child's transition. In their study of ECE and school teacher attitudes to the transition to school, Timperley et al. (2003) noted that teachers in each sector did not have a shared understanding of what each should do to support children's transition. Teachers in the two education sectors are important parts of the network which co-constructs the transition (Fabian, 2007; Hartley et al., 2010; Johansson, 2007; Niesel \& Griebel, 2007), and when staff from both sectors learn about each others' practice and value the learning and programme of the other sector, a streamlined transition to school is possible. The literature recommends that ECE and school staff build relationships with each other and learn about how each contributes to children's on-going learning. One method suggested by Hartley et al. (2010) involved collaborating on resources for children soon to start school and their parents.

\subsection{Limitations}

This study interviewed six families as their oldest or only child approached and started primary school. The data collection included bringing the families together in a focus group so they could discuss their own experience in the light of the others' experiences. The themes from a study with such a small sample size cannot be generalised to other parents, however, readers of the study may relate the findings to their own context. 
The process of site and participant selection directed me to parents who had been prompted to think about the transition to school for at least two months before their child was due to turn five. While it seems likely that most parents plan their child's school entry for at least this long, it is possible that some parents may not. By contacting the centre first, involvement in the study may have prompted centre staff to initiate conversations with parents about the transition to school that they possibly may otherwise not have.

Child gender was not a criteria for participant selection for this study, and it so happened that all six families had boys due to start school. This removed the need to consider any differences with how boys and girls may be socialised. It is possible that girls have a different experience of starting school, or that parents of girls may have different concerns which they bring to the experience.

The design of the research provided for three families to be recruited from a full-day childcare centre and three families from a parent-run playcentre. This design was chosen to provide some variation in parent workforce and centre participation, and because state kindergartens, which have traditionally offered half-day teacher-led programmes, have been the site for many transition to school studies in New Zealand.

\subsection{Further research}

This study first interviewed parents one month before their oldest child was due to start school, with second interviews and the focus group completed within two months of the first child starting school. Each family had had some contact with their chosen school by the first interview, and at the focus group each family was reporting continued changes in their child's and their own adaptation to school routines. The experience of these parents suggest that the transition period extends for longer than three months around the child's school start date, and longitudinal research that starts earlier and follows families longer could be of value and interest.

This study particularly chose parents whose oldest or only child was starting school to learn about their first contact with a school as a parent. An extension of the study would be to follow families with subsequent children to learn in what ways the experiences of parents are different.

It so happened that the children in this study were all boys, and the families all lived in a medium-sized mixed socio-economic urban area. Participant families were recruited through ECE centres. It would be useful to repeat the study with a wider range of participant families, including with girl children, a range of cultural or socio-economic backgrounds, and families who have chosen to not use formal out-of-home ECE for their children. 


\subsection{Concluding comments}

A successful transition to school is the result of the interaction of many factors, including the people involved, the practices of home, centre and school, the effects of the wider context on all participants, and the communication and relationships between settings and participants. People involved include child, parents, ECE staff and families, other community members, and school staff. This study has contributed to an understanding of transition to school in Aotearoa New Zealand by focusing on the viewpoint of parents with an oldest or only child beginning school.

The essence of these parents' experience of their child's transition to school was of negotiating the transition, with their child, and with the school teacher. This involved 'finding out and fitting in' to the school environment, and discussing with the teacher ways to enhance the transition experience for this child. This experience is illustrated by Figure 8.2, which pictures two gardeners working in partnership to transplant a young sapling. The sapling is already a tree in its own right, and parents and teachers each bring skills to settle the sapling into its new environment so it will flourish. Supports are put in place, the sapling is watered and nurtured, and both parent and teacher watch over it, confident that it will take root and grow strong.

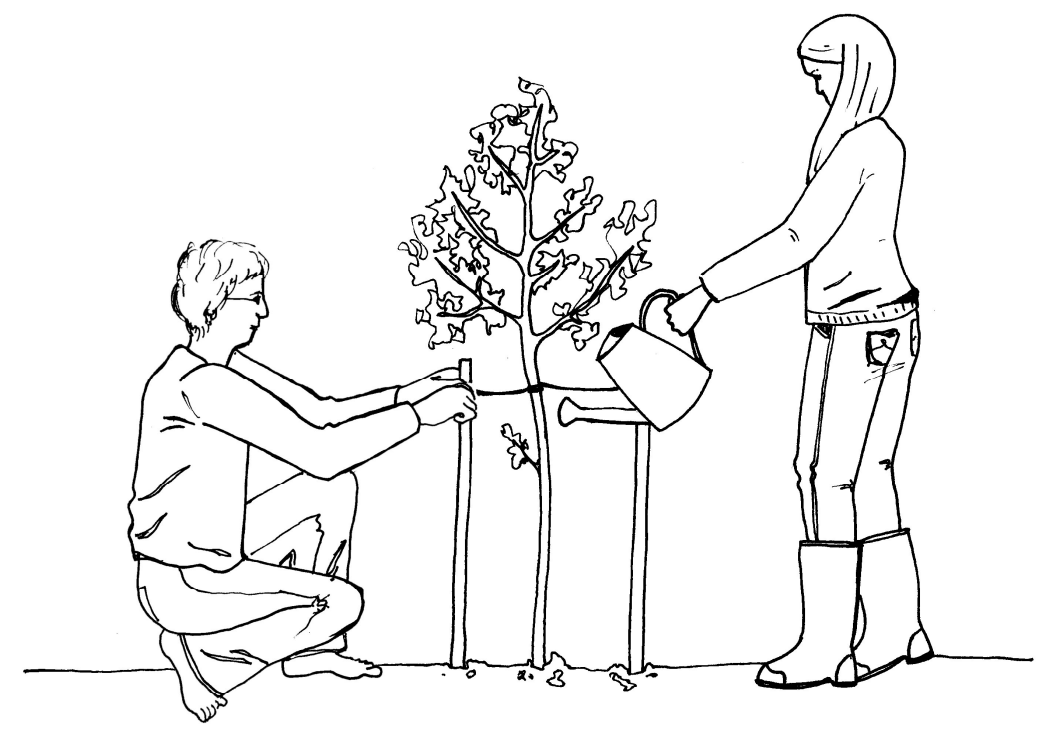

Figure 8.2 Two gardeners working in partnership 


\section{References}

Anderson, G. (1998). Fundamentals of educational research. London, England: RoutledgeFalmer.

Auerbach, C. F., \& Silverstein, L. B. (2003). Qualitative data: An introduction to coding and analysis. New York, NY: New York University Press.

Bandura, A. (2002). Social cognitive theory in cultural context. Applied Psychology: An International Review, 51(2), 269-290.

Bandura, A. (2006). Toward a psychology of human agency. Association for Psychological Science, 1(2), 164-180.

Barbour, R. (2007). Doing focus groups. London, England: Sage Publications Ltd.

Barnett, M. A., \& Taylor, L. C. (2009). Parental recollections of school experiences and current kindergarten transition practices. Journal of Applied Developmental Psychology, 30(2), 140-148.

Biddulph, S., \& Biddulph, S. (2000). Love, laughter and parenting: In the precious years from birth to age six. London, England: Dorling Kindersley.

Blair, C., Knipe, H., Cummings, E., Baker, D. P., Gamson, D., Eslinger, P., \& Thorn, S. L. (2007). A developmental neuroscience approach to the study of school readiness. In Robert C. Pianta, Martha J. Cox, \& Kyle L. Snow (Eds.), School readiness \& the transition to kindergarten in the era of accountability (pp. 149-174). Baltimore, MD: Paul H. Brookes Publishing Co.

Bronfenbrenner, U. (1979). The ecology of human development: Experiments by nature and design. Cambridge, MA: Harvard University Press.

Bronfenbrenner, U. (2005). The future of childhood. In U. Bronfenbrenner (Ed.), Making human beings human: Bioecological perspectives on human development. Thousand Oaks, CA: Sage Publishing Inc.

Bronson, P., \& Merryman, A. (2009). Nurtureshock: New thinking about children. New York, NY: Hachette Book Group.

Brooker, L. (2002). Starting school: Young children learning cultures. Buckingham, England: Open University Press.

Brostrom, S. (2002). Communication and continuity in the transition from kindergarten to school. In H. Fabian \& A.-W. Dunlop (Eds.), Transitions in the early years: Debating continuity and progression for young children in early education (pp. 52-63). London, England: Routledge.

Brostrom, S. (2007). Transitions in children's thinking. In A.-W. Dunlop \& H. Fabian (Eds.), Informing transitions in the early years: Research, policy and practice (pp. 61-73). England: Open University Press.

Bruner, J. (1978). The role of dialogue in language acquisition. In A. Sinclair, R. J. Jarvella, \& W. J. M. Levelt (Eds.), The child's conception of language (pp. 241-256). New York, NY: Springer-Verlag.

Bulkeley, J., \& Fabian, H. (2006). Well-being and belonging during early educational transitions. International Journal of Transitions in Childhood, 2, 18-30. 
Burke, R. (2011). Making consensus work: Decisions that all can live with. Auckland, New Zealand: Playcentre Publications.

Burr, V. (2003). Social constructionism. London, England: Routledge.

Campbell, K. K. (2005). Agency: Promiscuous and protean. Communication and Critical/Cultural Studies, 2(1), 1-19.

Claxton, G. (2008). What's the point of school?: Rediscovering the heart of education. Oxford, England: One World Publications.

Clarke, C. (2007). Parent involvement in the transition to school. In A.-W. Dunlop \& H. Fabian (Eds.), Informing transitions in the early years: Research, policy and practice (120-136). England: Open University Press.

Cosaro, W., \& Molinari, L. (2000). Priming events and Italian children's transition from preschool to elementary school: representations and actions. Social Psychology Quarterly, 63(1), 16-33.

Creswell, J. W. (1998). Qualitative inquiry and research design: Choosing among five traditions. Thousand Oaks, CA: Sage Publishing.

Crotty, M. (1998). The foundations of social research: Meaning and perspective in the research process. Crows Nest, Australia: Allen \& Unwin.

Dahlberg, G., Moss, P., \& Pence, A. (2007). Beyond quality in early childhood education and care: Languages of evaluation. ( $2^{\text {nd }}$ ed.). Oxon, England: Routledge.

Dalli, C. (2002). From home to childcare centre: Challenges for mothers, teachers and children. In H. Fabian \& A.-W. Dunlop (Eds.), Transitions in the early years: Debating continuity and progression for young children in early education (pp. 38-51). London, England: Routledge.

Davis, P. W. (1999). Corporal punishment cessation: Social contexts and parents' experiences. Journal of interpersonal violence, 14, May. 492-510.

Denscombe, M. (2007). The good research guide for small-scale social research projects $\left(3^{\text {rd }}\right.$ ed.). Berkshire, England: Open University Press.

Denzin, N. K., \& Lincoln, Y. S. (1995). Introduction: Entering the field of qualitative research. In N. K. Denzin \& Y. S. Lincoln (Eds.), The handbook of qualitative research (pp. 1-17). London, England: Sage Publications.

Denzin, N. K., \& Lincoln, Y. S. (2008). Introduction: The discipline and practice of qualitative research. In N. K. Denzin \& Y. S. Lincoln (Eds.) The Landscape of Qualitative Research (pp. 1-43). Thousand Oaks: Sage Publications Ltd.

Department of Labour. (2011). Work-life balance in New Zealand. Retrieved from www.dol.govt.nz.

Dickie, J. (2005). Transition from kindergarten to school: Sharing children's understandings about literacy. Wellington, New Zealand: Victoria University of Wellington College of Education.

Dockett, S., \& Perry, B. (1999). Starting school: What matters for children, parents, and educators? Canberra, Australia: Goanna Print

Dockett, S., \& Perry, B. (2005). "A buddy doesn't let kids get hurt in the playground": Starting school with buddies. International Journal of Transitions in Childhood, 1, 22-34. 
Dockett, S., \& Perry, B. (2007). Transitions to school: Perceptions, expectations, experiences. Sydney, Australia: University of New South Wales Press Ltd.

Dockett, S., \& Perry, B. (2007b). Children's transition to school: Changing expectations. In A.W. Dunlop \& H. Fabian (Eds.), Informing transitions in the early years: Research, policy and practice (pp. 92-106). England: Open University Press.

Dockett, S., \& Perry, B. (2009). Readiness for school: A relational construct. Australasian Journal of Early Childhood, 34(1), 20-26.

Doucet, F., \& Tudge, J. (2007). Co-constructing the transition to school: Reframing the novice verses expert roles of children, parents and teachers from a cultural perspective. In Robert C. Pianta, Martha J Cox \& Kyle L. Snow (Eds.), School readiness \& the transition to kindergarten in the era of accountability (pp. 307-328). Baltimore, MD: Paul H. Brookes Publishing Co.

Duncan, J., Bowden, C., \& Smith, A. B. (2006). A gossip or a good yack? Reconceptualizing parent support in New Zealand early childhood centre based programmes. International Journal of Early Years Education, 14(1), 1-13.

Dunlop, A.-W. (2007). Bridging research, policy and practice. In A.-W. Dunlop \& H. Fabian (Eds.), Informing transitions in the early years: Research, policy and practice (pp. 151168). England: Open University Press.

Education Act 1989, (1989) S.N.Z. No. 80. Retrieved from www.legislation.govt.nz

Education (Early Childhood Education) Regulations 2008, (2008). S.R. (2008/204). Retrieved from www.legislation.govt.nz

Education Review Office. (2009). Choosing a school for a five year old. Wellington, New Zealand: Education Review Office.

Einarsdottir, J., Dockett, S., \& Perry, B. (2009). Making meaning: Children's perspectives expressed through drawings. Early Childhood Development and Care, 179(2), 217-232.

Enz, B., Rhodes, M., \& LaCount, M. (2008). Easing the transition: Family support programs and early school success. In M. M. Cornish (Ed.), Promising practices for partnering with families in the early years (pp. 59-78). Charlotte, NC: Information Age Publishing Inc.

Epstein, J. L. (1995). School/family/community partnerships: Caring for the children we share. Phi Delta Kappan, 76(9), 701-712.

Everiss, L. (2010). Transitions and home-based care: A literature review. In Anne Meade (Ed.), Dispersing waves: Innovation in early childhood education. Wellington, New Zealand: NZCER Press.

Fabian, H., \& Dunlop, A.-W. (2005). The importance of play in the transition to school. In J. Moyles (Ed.), The excellence of play ( $2^{\text {nd }}$ ed.) (pp. 229-243). Berkshire, CA: Open University Press.

Fabian, H. (2007). Informing transitions. In A.-W. Dunlop \& H. Fabian (Eds.), Informing transitions in the early years: Research, policy and practice (pp. 3-17). England: Open University Press.

Feltham, S. (2004). Smoothing the road to school. Education Gazette, 83(16). Retrieved from www.edgazette.govt.nz.

Firlik, R. (2003). Preschool-kindergarten collaboration makes a difference. Young Children, 
$58(1), 73-79$.

Fischer, C. T., \& Wertz, F. J. (2002). Empirical phenomenological analyses of being criminally victimized. In A. M. Huberman \& M. B. Miles (Eds.), The qualitative researcher's companion (pp. 275-348). Thousand Oaks, CA: Sage Publications Ltd.

Fontana, A., \& J. H. Frey. (2008). The interview: From neutral stance to political involvement. In N. K. Denzin \& Y. S. Lincoln (Eds.), Collecting and interpreting qualitative materials (pp. 115-160). Thousand Oaks: Sage Publications.

Fosnot, C. T., \& Perry, R. S. (2004). Constructivism: A psychological theory of learning. In C. T. Fosnot (Ed.), Constructivism: Theory, perspectives, and practice $\left(2^{\text {nd }}\right.$ ed.) (pp. 8-38). New York, NY: Teachers College Press.

Freeman, M., \& Mathison, S. (2009). Researching children's experiences. New York, NY: The Guilford Press.

Fthenakis, W. E. (1998). Family transitions and quality in early childhood education. European Early childhood Education Research Journal, 6(1), 5-17.

Gallagher, G. (2006). Contact or communication breakdown: The impact of parent-teacher relationships in the transition to school for gifted children. Tall Poppies, 32(2). 10-15.

Gergan, K. (2003). Meaning in relationship. In Kenneth J. Gergen and Mary Gergen (Eds.), Social construction: A reader (pp. 148-155). London, England: Sage.

Giallo, R., Kienhuis, M., Treyvaud, K., \& Matthews, J. (2008). A Psychometric Evaluation of the Parent Self-efficacy in Managing the Transition to School Scale. Australian Journal of Educational and Developmental Psychology, 8, 36-48.

Giallo, R., Treyvaud, K., Matthews, J., \& Kienhuis, M. (2010). Making the transition to primary school: An evaluation of a transition programme for parents. Australian Journal of Educational \& Developmental Psychology, 10, 1-17.

Graue, M. E. (1992). Social interpretations of readiness for kindergarten. Early Childhood Research Quarterly, 7, 225-243.

Griebel, W., \& Niesel, R. (2002). Co-constructing transition into kindergarten and school by children, parents and teachers. In H. Fabian \& A.-W. Dunlop (Eds.), Transitions in the early years: Debating continuity and progression for young children in early education (pp. 64-75). London, England: Routledge.

Gordon, I. A. (1982). The new collins concise dictionary of the English language: New Zealand edition. Auckland, New Zealand: Collins.

Guba, E. G., \& Lincoln, Y. S. (2008). Paradigmatic controversies, contradictions and emerging confluences. In N. K. Denzin \& Y. S. Lincoln (Eds.), The Landscape of Qualitative Research (pp. 255-286). Thousand Oaks: Sage Publications Ltd.

Guenther, K. M. (2009). The politics of names: rethinking the methodological and ethical significance of naming people, organisations and places. Qualitative Research, 9, 411-421.

Gunn, J. (2009). Agency. Encyclopaedia of Communication Theory. SAGE Publications. Retrieved from www.sage-ereference.com/communicationtheory/Article n 11

Hair, E., Halle, T., Terry-Humen, E., Lavelle, B., \& Calkins, J. (2006). Children's school readiness $\mathrm{n}$ the ECLS-K: Predictions to academic, health, and social outcomes in first grade. Early Childhood Research Quarterly, 21, 431-454 
Hannigan, I. (1998). Off to school: A parent's eye view of the kindergarten year. Washington: NAEYC.

Hartley, C., Rogers, P., Smith, J., Peters, S., \& Carr, M. (2010). Building relationships between early childhood and school: Mutually interesting projects. In Anne Meade (Ed.), Dispersing waves: Innovation in early childhood education (pp. 19-26). Wellington, New Zealand: NZCER Press.

Iyengar, S. (2010). The art of choosing. New York, NY: Twelve Hatchett Book Group.

Jenks, C. (2004). Constructing childhood sociologically. In M. J. Kehily (Ed.), An introduction to childhood studies. New York, NY: Open University Press.

Johansson, I. (2007). Horizontal transitions: what can it mean for children in the early school years? In A.-W. Dunlop \& H. Fabian (Eds.), Informing transitions in the early years: Research, policy and practice (pp. 33-44). England: Open University Press.

Jordan, B. (2004). Scaffolding learning and co-constructing understandings. In A. Anning, J. Cullen \& M. Fleer (Eds.), Early childhood education: society and culture (pp. 31-42). London, England: Sage.

Kienig, A. (2002). The importance of social adjustment for future success. In H. Fabian \& A.-W. Dunlop (Eds.), Transitions in the early years: Debating continuity and progression for young children in early education (pp. 23-37). London, England: Routledge.

Lam, M. S., \& Pollard, A. (2006). A conceptual framework for understanding children as agents in the transition from home to kindergarten. Early Years, 26(2), 123-141.

Lara-Cinisomo, S., Fuligni, A. S., Ritchie, S., Howes, C., \& Karoly, L. (2008). Getting ready for school: An examination of early childhood educators' belief systems. Early Childhood Education Journal, 35(4), 343-349.

Ledger, E. (2000). Children's perspectives of their everyday lives with a focus on the transition from early childhood centre to school. Unpublished doctoral thesis. Dunedin, New Zealand: University of Otago.

Ledger, E., Smith, A. B., \& Rich, P. (2000). Friendships over the transition from early childhood centre to school. International Journal of Early Years Education, 8(1), 57-69.

LoCasale-Crouch, J., Mashburn, A. J., Downer, J. T., \& Pianta, R. C. (2008). Pre-kindergarten teachers' use of transition practices and children's adjustment to kindergarten. Early Childhood Research Quarterly, 23, 124-139.

MacDonald, A. (2009). Drawing stories: The power of children's drawings to communicate the lived experience of starting school. Australasian Journal of Early Childhood, 34(3), 40-49.

Margetts, K. (2007). Understanding and supporting children: Shaping transition practices. In A.W. Dunlop \& H. Fabian (Eds.), Informing transitions in the early years: Research, policy and practice (pp. 107-119). England: Open University Press.

Meissner, W. W. (2008). Self and time. Journal of the American Academy of Psychoanalysis and Dynamic Psychiatry, Winter, 36(4), 707-736.

Ministry of Education. (1996). Te Whariki he whariki matauranga mo nga mokopuna o Aotearoa: Early childhood curriculum. Wellington, New Zealand: Learning Media.

Ministry of Education. (2002). Pathways to the future Ngā huarahi arataki: A 10 year strategic plan for early childhood education. Wellington, New Zealand: Learning Media. 
Ministry of Education. (2007). The New Zealand Curriculum: For English-medium teaching and learning in years 1-13. Wellington, New Zealand: Ministry of Education.

Ministry of Education. (2008). Ka Hikitia - managing for success: The Māori education strategy 2008 - 2012. Retrieved from www.educationcounts.govt.nz

Ministry of Education (2010). Annual ECE Summary Report 2010. Retrieved from www.educationcounts.govt.nz

Ministry of Education. (2010b). School enrolment zones: Your guide to how they work and where they are. Retrieved from http://www.schoolzones.co.nz/enrolmentzones/FAQ.aspx

Ministry of Education (2011). The school curriculum design and review. Retrieved from www.nzcurriculum.tiki.org.nz

Mirkhil, M. (2010). 'I want to play when I go to school': Children's views on the transition to school from kindergarten. Australasian Journal of Early Childhood, 35(3), 134-139.

Mirkhil, M. (2010b). Important ingredients for a successful transition to school. International Research in Early Childhood Education, 1(1), 60-70.

Mitchell, L., Wylie, C., \& Carr, M. (2008). Outcomes of early childhood education: Report to the Ministry of Education. Wellington, New Zealand: Ministry of Education.

Munford, R. \& Sanders, J. (1999). Supporting Families. Palmerston North, New Zealand: Dunmore Press Ltd.

Mutch, C. (2005). Doing educational research: A practitioner's guide to getting started. Wellington, New Zealand: NZCER Press.

Neuman, M. J. (2002). The wider context: An international overview of transition issues. In H. Fabian \& A. W. A. Dunlop (Eds.), Transitions in the early years: Debating continuity and progression for young children in early education (pp. 8-22). London, England: Routledge.

Neyland, J. (2010). Rediscovering the spirit of education after scientific management. Rotterdam, Netherlands: Sense Publishers.

Niesel, R., \& Griebel, W. (2005). Transition competence and resiliency in educational institutions. International Journal of Transitions in Childhood, 1, 4-11.

Niesel, R., \& Griebel, W. (2007). Enhancing the competence of transition systems through coconstruction. In A.-W. Dunlop \& H. Fabian (Eds.), Informing transitions in the early years: Research, policy and practice (pp. 21-32). England: Open University Press.

Noddings, N. (1992). The challenge to care in schools: An alternative approach to education. New York, NY: Teachers College Press.

Norris, J. (2000). Crossing the threshold: Masculinities and the transition to school. Unpublished masters thesis. Wellington, New Zealand: Victoria University.

Peters, S. (1998). Assessment and reporting within the context of the transition to school. Wellington, New Zealand: Institute for early childhood studies.

Peters, S. (2003). Theoretical approaches to transition. Set: Research information for teachers, 3. $15-20$.

Peters, S. (2004). "Crossing the border": An interpretive study of children making the transition to school. Unpublished doctoral thesis. Hamilton, New Zealand: University of Waikato.

Peters, S. (2010). Literature review: Transition from early childhood education to school. Report 
to the Ministry of Education. Wellington, New Zealand: Ministry of Education.

Pianta, R., \& Kraft-Sayre, M. (2003). Successful kindergarten transitions: Your guide to connecting children, families and schools. Baltimore: Paul H. Brookes Publishing Co.

Postman, N. (1996). The end of education: Redefining the value of school. New York, NY: Vintage Books.

Punch, K. F. (2005). Introduction to social research: Quantitative and qualitative approaches. London, England: Sage Publications.

Rapley, T. (2007). Doing conversation, discourse and document analysis. Los Angelos, CA: Sage Publications.

Reid, R., \& Stover, S. (2005). Am I in the right place? A reflective model of individual agency. The First Years, Ngā Tau Tuitahi: New Zealand Journal of Infant and Toddler Education, $7(2) 36-40$.

Renwick, M. (1997). Starting school: A guide for parents and caregivers. Wellington, New Zealand: NZCER.

Rimm-Kaufman, S. E., \& Pianta, R. C. (2000). An ecological perspective on the transition to kindergarten: A theoretical framework to guide empirical research. Journal of Applied Developmental Psychology, 21(5), 491-511.

Rimm-Kaufman, S. E., \& Pianta, R. C. (2005). Family-school communication in preschool and kindergarten in the context of a relationship-enhancing intervention. Early Education \& Development, 16(3), 287-316.

Robertson, J., Gunn, T. R., Lanumata, T., \& Pryor, J. (2007). Parental decision making in relation to the use of early childhood education services: Report to the Ministry of Education. Wellington, New Zealand: Roy McKenzie Centre for the Study of Families.

Rogoff, B. (1990). Apprenticeship in thinking: Cognitive development in social context. Oxford, England: Oxford University Press.

Rogoff, B. (2003). The cultural nature of human development. Oxford, England: Oxford University Press.

Rosewarne, S,. White, E. J., \& Wright, L. (2010). Exploring transition through collective biographical work. Australasian Journal of Early Childhood, 35(3), 24-32.

Ross, M., \& Buehler, R. (2004). Identity through time: Constructing personal pasts and futures. In M. B. Brewer \& M. Hewstone (Eds.), Self and social identity (pp. 25-51). Malden, MA: Blackwell Publishing Ltd.

Salter, J., \& Redman, J. (2006). Transition to school: A pilot project. Kairaranga, 7(1), 8-12.

Sanagavarapu, P. (2010). Children's transition to school: Voices of Bangladeshi parents in Sydney, Australia. Australasian Journal of Early Childhood, 35(4), 21-29.

Sarup, M. (1996). Identity, culture and the postmodern world. Edinburgh, Scotland: Edinburgh University Press Ltd.

Sauvao, L., Mapa, L., \& Podmore, V. (2000). Transition to school from Pacific Islands early childhood services. Wellington, New Zealand: New Zealand Council for Educational Research.

Schull, C. P., \& Anderson, E. A. (2008). The effect of home visiting and home safety on 
children's school readiness. European Early Childhood Education Research Journal, 16(3), 313-324.

Schwartz, B. (2004). The paradox of choice: Why more is less. New York, NY: Harper Perennial.

Scott-Little, C., Kagan, S. L., \& Frelow, V. S. (2006). Conceptualization of readiness and the content of early learning standards: The intersection of policy and research? Early Childhood Quarterly, 21. 153-173.

Seidman, I. (1998). Interviewing as qualitative research. New York, NY: Teachers College Columbia University.

Shulruf, B. (2005). Parent support and education programmes: A systematic review. New Zealand research in early childhood education, 8. 81-102.

Silverman, D. (2006). Interpreting qualitative data ( $3^{\text {rd }}$ ed.). London, England: Sage Publications.

Smith, A. B. (2002). Interpreting and supporting participation rights: Contributions from sociocultural theory. The International Journal of Children's Rights, 10, 73-88.

Snook, I. (1999). The ethics and politics of social research. In C. Davidson and M. Tolich (Eds.), Social science research in New Zealand: Many paths to understanding (pp. 69-81). Auckland, New Zealand: Pearson Education.

Snow, K. L. (2007). Integrative views of the domains of child function. In R. C. Pianta, M. J. Cox \& K. L. Snow (Eds.), School readiness \& the transition to kindergarten in the era of accountability (pp. 197-216). Baltimore, MD: Paul H. Brookes Publishing Co.

Southerton, D. (2006). Analysing the temporal organization of daily life: Social constraints, practices and their allocation. Sociology 40(3), 435-454.

Steele, C. M., \& Aronson, J. (1995). Stereotype threat and the intellectual text performance of African Americans. Journal of Personality and Social Psychology, 69(5), 797-811.

Straus, A. L. (1987). Qualitative analysis for social scientists. Cambridge, England: Cambridge University Press.

Taylor, L. C., Clayton, J. D., \& Rowley, S. J. (2004). Academic socialization: Understanding parental influences on children's school-related development in the early years. Review of General Psychology, 8(3), 163-178.

Te One, S. (2003). The context for Te Whāriki: Contemporary issues of influence. In J. Nuttall (Ed.), Weaving Te Whāriki: Aotearoa New Zealand's early childhood curriculum document in theory and practice (pp. 17-49). Wellington, New Zealand: NZCER.

Thesing, A. (2008). Parent Education and Support through Early Childhood Centre Networks. New Zealand research in early childhood education, 11, 65-76.

Timperley, H., McNaughton, S., Howie, L., \& Robinson, V. (2003). Transitioning children from early childhood education to school: Teacher beliefs and transition practices. Australian Journal of Early Education, 28(2), 32-38.

Tolley, A. (2011). Speech to NZEI annual conference. Retrieved from www.beehive.govt.nz.

Toma, J. D. (2006). Approaching rigor in applied qualitative research. In C. F. Conrad \& R. C. Serlin (Eds.), The sage handbook for research in education (pp. 405-423). London, England: Sage Publications. 
Turoa, L., Wolfgramm, E., Tanielu, L., \& McNaughton, S. (2002). Pathways over the transition to school: Studies in family literacy practices and effective classroom contexts for Maori and Pasifica children. Wellington, New Zealand: Ministry of Education.

Victoria University of Wellington.(n.d.) Research Ethics. Retrieved from www.victoria.ac.nz/fgr/current-phd/ethics

Vygotsky, L. (1978). Mind in society. Cambridge, Massachusetts: Harvard University Press.

Waldegrave, C. (1999). Focus groups: Participation in poverty research. In C. Davidson \& M. Tolich (Eds.), Social science research in New Zeeland: Many paths to understanding (pp. 231-242). Auckland, New Zealand: Pearson Education New Zealand.

Walliman, N. (2005). Your research project ( $2^{\text {nd }}$ ed.). London, England: Sage Publications Limited.

Wenger, E. (1998). Communities of practice: Learning, meaning, and identity. Cambridge, England: Cambridge University Press.

White, G., \& Sharp, C. (2007). 'It is different ... because you are getting older and growing up.' How children make sense of the transition to year 1. European Early Childhood Research Journal, 15(1). 87-102.

Willig, C. (2003). Introducing qualitative research in psychology. Buckingham, England: Open University Press.

Woodhams, B., \& Woodhams, M. (2008). Supporting Playcentre in the $21^{\text {st }}$ Century. New Zealand Playcentre Federation. 


\section{Appendices}
A: Information Sheet - Childcare centre
B: Information Sheet - Playcentre.
C: $\quad$ Consent Form - Early childhood education centre
D: Information Sheet - Parent participant
E: Consent Form - Parent participant
F: Information Sheet - School Principal
G: Information Sheet - School Teacher
H: Consent Form - School key informant
I: $\quad$ Open-ended Interview Schedule - Parent participant, first interview
$\mathrm{J}$ : Open-ended Interview Schedule - Parent participant, second interview
K: Open-ended Interview Schedule - Early childhood education centre
L: $\quad$ Open-ended Interview Schedule - School key informant
M: Transcriber Confidentiality Agreement
$\mathrm{N}$ : $\quad$ Focus group Interview Notetaker Agreement 
Faculty of Education

Appendix A

1 June 2009

\section{Information sheet \\ Becoming a school parent: Parents' experience of the transition to school of their oldest child}

My name is Maureen Woodhams, and I am a student at Victoria University working on a thesis towards a Master's degree in education.

My project focuses on what it is like to be the parent of a child who is starting school. To study this I am conducting interviews with a number of parents whose oldest or only child is starting school in the next few months. I would also like to collect documents and information from the early childhood centre the child attends about how the centre helps with the process of transition for the family.

I would like to invite you to participate in this research. This would involve you identifying parents who have their oldest child due to start school between May and July this year and giving them an information sheet inviting them to be involved in the study. Parents would be fully informed about the project and would be able to choose whether to participate or not.

I would also like you to provide me with any documentation the centre may have on transition to school, such as handouts for parents or transition policies.

Finally, I would like to be able to talk to one teacher from the centre about practices the centre has around the transition to school. This meeting is likely to take approximately 20 minutes. The interview will be transcribed, and the transcriber has signed a confidentiality agreement. Transcripts would be stored securely in a locked filing cabinet and in password-protected computer files for up to five years. In the event of follow up study being done, further consent would be sought.

Any participants, whether the parent participants or the teacher, who feel they want to withdraw from the project may do so without question at any time before the data is analysed. Just let me know at the time.

Responses collected will form the basis of my research project and will be put into a written report. All material collected will be kept confidential, and individuals and centres will not be identified in the report or any other manner. The thesis will be submitted for marking to the School of Education and deposited in the Victoria University Library. It is intended that one or more articles will be submitted for publication in scholarly journals.

If at any time you have questions or concerns about the conduct of the research, please feel free to contact my supervisor, Sarah Te One, at (04) 463 5716, e-mail sarah.teone@vuw.ac.nz.

Thank you for your consideration. I look forward to your prompt response.

Yours faithfully,

Maureen Woodhams.

Phone: (04) 9345244

e-mail: maureen@paradise.net.nz

This project has been reviewed and has ethics approval from the Victoria University of Wellington College of Education Ethics Committee. 
Faculty of Education

Appendix B

1 June 2009

\section{Information sheet \\ Becoming a school parent: Parents' experience of the transition to school of their oldest child}

My name is Maureen Woodhams, and I am a student at Victoria University working on a thesis towards a Master's degree in education.

My project focuses on what it is like to be the parent of a child who is starting school. To study this I am conducting interviews with a number of parents whose oldest or only child is starting school in the next few months. I would also like to collect documents and information from the early childhood centre the child attends about how the centre helps with the process of transition for the family.

I would like to invite you to participate in this research. This would involve you identifying parents who have their oldest child due to start school between May and July this year and giving them an information sheet inviting them to be involved in the study. Parents would be fully informed about the project and would be able to choose whether to participate or not.

I would also like you to provide me with any documentation the centre may have on transition to school, such as handouts for parents or transition policies.

Finally, I would like to be able to talk to one team leader from the centre about practices the centre has around the transition to school. This meeting is likely to take approximately 20 minutes. The interview will be transcribed, and the transcriber has signed a confidentiality agreement. Transcripts would be stored securely in a locked filing cabinet and in password-protected computer files for up to five years. In the event of follow up study being done, further consent would be sought.

Any participants, whether the parent participants or the team leader, who feel they want to withdraw from the project may do so without question at any time before the data is analysed. Just let me know at the time.

Responses collected will form the basis of my research project and will be put into a written report. All material collected will be kept confidential, and individuals and centres will not be identified in the report or any other manner. The thesis will be submitted for marking to the School of Education and deposited in the Victoria University Library. It is intended that one or more articles will be submitted for publication in scholarly journals.

If at any time you have questions or concerns about the conduct of the research, please feel free to contact my supervisor, Sarah Te One, Lecturer, at (04) 463 5716, e-mail sarah.teone@vuw.ac.nz.

Thank you for your consideration. I look forward to your prompt response.

Yours faithfully,

Maureen Woodhams.

Phone: (04) 9345244

e-mail: maureen@paradise.net.nz

This project has been reviewed and has ethics approval from the Victoria University of Wellington College of Education Ethics Committee. 
Faculty of Education

Appendix C

\section{CONSENT TO PARTICIPATION IN RESEARCH}

\section{Becoming a school parent: Parents' experience of the transition to school of their oldest child}

I have been given and have understood an explanation of this research project. I have had an opportunity to ask questions and have them answered to my satisfaction. I understand that I may withdraw myself from this project at any time up to the end of data collection, without having to give reasons.

I understand that the information I provide will be kept confidential.

I understand that the published results will not use my name or that of the centre.

I understand that the tape recording of the interview will be electronically wiped at the end of the project unless I indicate that I would like them returned to me.

I would like the tape recording of my interview returned to me at the conclusion of the project.

I would like to receive a summary of the results of this research when it is completed.

I agree to take part in this research.

Signed:

Position:

Date: 
Faculty of Education

Appendix D

8 June 2009

\section{Information sheet}

Becoming a school parent: Parents' experience of the transition to school of their oldest child

My name is Maureen Woodhams, and I would like to invite you to be part of my research project looking at parents' experience of the transition to school of their oldest child. Please read this letter carefully to make sure you fully understand the project and your rights if you choose to be involved.

I am doing the research as part of my Masters of Education degree through Victoria University. Please feel free to contact me or my research supervisor is you have any questions or concerns regarding the research.

\section{Researcher}

Maureen Woodhams

Phone: (04) 9345244

e-mail: maureen@paradise.net.nz

\author{
Supervisor \\ Sarah Te One, Lecturer \\ Phone: (04) 4635716 \\ e-mail: sarah.teone@vuw.ac.nz
}

My project focuses on what it is like to be the parent of a child who is starting school. To study this I am conducting individual interviews with a number of parents whose oldest child is starting school shortly, and a group interview with all the parents after all the children have started school.

If you oldest or only child is starting school in the next few months I would love to include you in this research. This would involve you attending an interview with me on two occasions, firstly a few weeks before your child starts school, and secondly a few weeks after they start school. Each interview will take about 40 minutes, and the time and place for the interviews will be at a negotiated to be convenient to you.

After all the participant children have started school I would also like to invite you to participate in a group interview for about 1 hour with other parents of children who have been involved in the study. The interviews will be tape recorded if you agree, and this recording will be transcribed. The transcriber will sign a confidentiality agreement. Transcripts would be stored securely in a locked filing cabinet and in password-protected computer files for up to five years. In the event of follow up study being done, further consent would be sought.

You will also have the opportunity to record your thoughts about events in between these times in a diary which I will provide. I hope this will become an interesting keepsake of your child's transition to school.

Should you feel you want to withdraw from the project, you may do so without question at any time up to the end of interviewing. Just let me know at the time.

Responses collected will form the basis of my research project and will be put into a written report. All material collected will be kept confidential, and individuals will not be identified in the report or any other manner, nor will the name of the centre or school the child attended. The thesis will be submitted for marking to the School of Education and deposited in the Victoria University Library. It is intended that one or more articles will be submitted for publication in scholarly journals.

If you agree to participate please let your centre know and I will contact you to arrange a time and place for the first interview.

Thank you for your consideration. I look forward to your prompt response.

Yours faithfully,

Maureen Woodhams.

This project has been reviewed and has ethics approval from the Victoria University of Wellington College of Education Ethics Committee. 


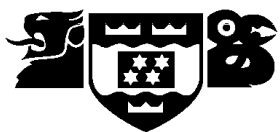

Faculty of Education

Appendix E

\section{CONSENT TO PARTICIPATION IN RESEARCH}

\section{Becoming a school parent: Parents' experience of the transition to school of their oldest child}

I have been given and have understood an explanation of this research project. I have had an opportunity to ask questions and have them answered to my satisfaction. I understand that I may withdraw myself from this project at any time up to the end of data collection, without having to give reasons.

I understand that the information I provide will be kept confidential.

I understand that the published results will not use my name or that of my child's centre.

I understand that the tape recording of interviews will be electronically wiped at the end of the project unless I indicate that I would like them returned to me.

I would like the tape recordings of my interviews returned to me at the end of the project.

I would like to receive a summary of the results of this research when it is completed.

I agree to take part in this research.

I agree to take part in a group interview of parents

Signed:

Name:

Date: 
Faculty of Education

Appendix F

1 October 2009

\section{Information sheet \\ Becoming a school parent: Parents' experience of the transition to school of their oldest child}

My name is Maureen Woodhams, and I am a student at Victoria University working on a thesis towards a Master's degree in education.

My project focuses on what it is like to be the parent of a child who is starting school. To study this I am conducting interviews with a number of parents whose oldest child is starting school shortly. I would also like to collect documents and information from the school the child will attend about how the school helps with the process of transition for the family.

One of the families in the study has enrolled their child in your school.

I would like to invite you to participate in this research. This would involve you providing me with any documentation the school may have on transition to school, such as handouts for parents or transition policies.

I would also like to be able to interview one teacher, such as the new entrant teacher, about practices the school has around the transition to school. This meeting is likely to take approximately 20 minutes. This interview would be audio recorded if the teacher agrees, and transcribed. The transcriber has signed a confidentiality agreement. Transcripts would be stored securely in a locked filing cabinet and in passwordprotected computer files for up to five years. In the event of follow up study being done, further consent would be sought.

The school is under no obligation to participate in this study. The school, or the key informant teacher, may withdraw from the project without question at any time up to the end of data collection. Just let me know at the time.

Responses collected will form the basis of my research project and will be put into a written report. All material collected will be kept confidential, and individuals and schools will not be identified in the report or any other manner. The thesis will be submitted for marking to the School of Education and deposited in the Victoria University Library. It is intended that one or more articles will be submitted for publication in scholarly journals.

If at any time you have questions or concerns about the conduct of the research, please feel free to contact my supervisor, Sarah Te One, Lecturer, at (04) 463 5716, e-mail sarah.teone@vuw.ac.nz.

Thank you for your consideration. I look forward to your prompt response.

Yours faithfully,

Maureen Woodhams.

Phone: (04) 9345244

e-mail: maureen@paradise.net.nz

This project has been reviewed and has ethics approval from the Victoria University of Wellington College of Education Ethics Committee. 
Faculty of Education

Appendix G

1 October 2009

\section{Information sheet \\ Becoming a school parent: Parents' experience of the transition to school of their oldest child}

My name is Maureen Woodhams, and I am a student at Victoria University working on a thesis towards a Master's degree in education.

My project focuses on what it is like to be the parent of a child who is starting school. To study this I am conducting interviews with a number of parents whose oldest child is starting school. I would also like to collect documents and information from the school the child will attend about how the school helps with the process of transition for the family.

One of the families in the study has enrolled their child in your school.

I would like to invite you to participate in this research. This would involve you in an interview with me to talk about the practices the school has around transition to school. This inteview is likely to take approximately 20 minutes. I have also asked the school to provide me with any documentation the school may have on transition to school, such as handouts for parents or transition policies.

If you agree, I would like to audio record the interview. This would then be transcribed .The transcriber has signed a confidentiality agreement. Transcripts would be stored securely in a locked filing cabinet and in password-protected computer files for up to five years. In the event of follow up study being done, further consent would be sought.

The school is under no obligation to participate in this study. The school, or the key informant teacher, may withdraw from the project without question at any time up to the end of data collection. Just let me know at the time.

Responses collected will form the basis of my research project and will be put into a written report. All material collected will be kept confidential, and individuals and schools will not be identified in the report or any other manner. The thesis will be submitted for marking to the School of Education and deposited in the Victoria University Library. It is intended that one or more articles will be submitted for publication in scholarly journals.

If at any time you have questions or concerns about the conduct of the research, please feel free to contact my supervisor, Sarah Te One, Lecturer, at (04) 463 5716, e-mail sarah.teone@vuw.ac.nz.

Thank you for your consideration. I look forward to your prompt response.

Yours faithfully,

Maureen Woodhams.

Phone: (04) 9345244

e-mail: maureen@paradise.net.nz

This project has been reviewed and has ethics approval from the Victoria University of Wellington College of Education Ethics Committee. 


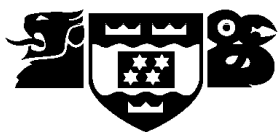

Faculty of Education

Appendix H

\section{CONSENT TO PARTICIPATION IN RESEARCH}

\section{Becoming a school parent: Parents' experience of the transition to school of their oldest child}

I have been given and have understood an explanation of this research project. I have had an opportunity to ask questions and have them answered to my satisfaction. I understand that I may withdraw myself from this project at any time up to the end of data collection, without having to give reasons.

I understand that the information I provide will be kept confidential.

I understand that the published results will not use my name or that of the school.

I understand that the tape recording of the interview will be electronically wiped at the end of the project unless I indicate that I would like it returned to me.

I would like the tape recording of my interview returned to me at the conclusion of the project.

I would like to receive a summary of the results of this research when it is completed.

I agree to take part in this research.

Signed:

Position:

Date: 


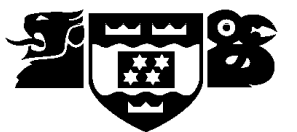

Faculty of Education

Appendix I

What do you remember about starting school from when you were a child?

(First establish whether parent has chosen the school)

Have you chosen a school for your child? -> (if 'no' - how will you..., where will you...)

How did you come to choose this school?

schools?

(Prompt: Where did you get information from? Friends/other people? The ece centre? The

What were you looking for?

What did you like about the schools you considered? )

Do you already know anyone associated with this school?

(Prompt: children/parent/teachers/other staff?

How do you come to know them?)

How do you feel about your child going to school?

(Prompt: for your child?

For yourself?)

How do you think you might be involved at school?

(Prompt: how involved do you want to be?

How do you see that you could help?

Do you know some ways parents are involved in this school?) 


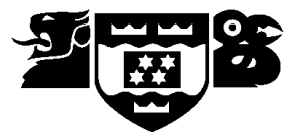

Faculty of Education

Appendix J

How did you child's first day/week go?

(Prompt: how do you think they have settled in overall?

What's been good?

What's been a challenge for them?)

What information have you had from the school about your child starting school?

(Prompt: meetings, chats, newsletter/notes?

Have you had any trouble finding out information?)

How have you been getting on with /getting to know the people at school?

(Prompt: the teacher? Other staff? Other parents? Other children?

What opportunities have you found to get to know people at school?)

What has it been like for you having a child at school?

(Prompt: what has changed for you?

\section{Good things?}

Challenges?)

How have you been involved with the school since your child started?

(Prompt: how do you plan to be involved?

Anything you would like to do?)

Anything else about your experience around starting school?

(Prompt: for self? For child?) 
Faculty of Education

Appendix K

How do you help parents think about the transition to school?

(Prompt: provide information? Written? Verbal? What information?

Have meetings? Informal chats?

Provide reassurance? )

What relationship does your centre have with the schools which children go to?

(Prompt: are there mutual visits? Meetings?

Is information provided by the school for you to give parents?

Do you have any other comments on parents' experience of the transition to school? 


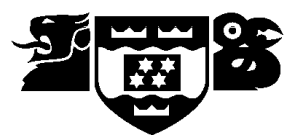

Faculty of Education

Appendix L

What do you do to help parents whose child is starting at this school?

(Prompt: information packs?

Meetings?

Visits to early childhood centres?

Chatting at the time of preschool visits?)

What are the ways that parents can get to know other people at school?

(Prompt: the child's teacher?

Other staff?

Other parents?

Other children?)

How do parents get involved at school?

(Prompt: What involvement would you like from parents?

How do they seem to want to get involved?

What affects this?)

Do you have any other comments about parents and the process of starting school? 


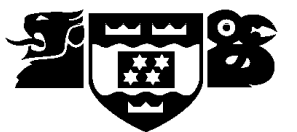

Faculty of Education

Appendix M

\section{CONFIDENTIALITY AGREEMENT}

Becoming a school parent: Parents' experience of the transition to school of their oldest child

$\mathrm{I}$, tapes I transcribe for the above project.

I will not reveal any information, including the names of participants or anything that they reveal in the course of the interview project to any person other than the researcher.

The material will be stored securely during the transcription process.

After forwarding the transcripts to the researcher I shall delete any materials relating to the project from my computer system.

Signed:

Date: 


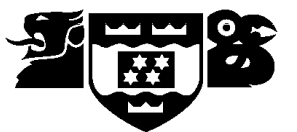

Faculty of Education

Appendix N

\section{CONFIDENTIALITY AGREEMENT}

Becoming a school parent: Parents' experience of the transition to school of their oldest child

$\mathrm{I}$, , agree to maintain full confidentiality of all information I have access to while note taking during focus group interviews for the above project.

I will not reveal any information, including the names of participants or anything that they reveal in the course of the interview project to any person other than the researcher.

After forwarding the notes to the researcher I shall delete any materials relating to the project from my computer system.

Signed:

Date: 